Acta Botanica Mexicana 69: 1-82 (2004)

\title{
LISTA CON ANOTACIONES DE LOS PTERIDÓFITOS DEL ESTADO DE MÉXICO, MÉXICO
}

\author{
J. Daniel Tejero-Díez ${ }^{1}$ y Ma. de la Luz Arreguín-SáncheZ² \\ ${ }^{1}$ Universidad Nacional Autónoma de México, Facultad de Estudios Superiores \\ Iztacala, Carrera de Biología, Apdo. postal 314 \\ 54090 Tlalnepantla, Estado de México \\ ${ }_{2}^{2}$ Instituto Politécnico Nacional, Escuela Nacional de Ciencias Biológicas, \\ Laboratorio de Botánica Fanerogámica, Plan de Ayala y Carpio, Sto. Tomás, \\ 11314 México, D.F.
}

\section{RESUMEN}

Se listan 248 especies y taxa subespecíficos de pteridófitos encontrados en el estado de México, de los cuales 60 se consideran citados por primera vez y dos son especies nuevas. Cada taxon específico o infraespecífico es acompañado por datos de distribución en el mundo, México y el estado de México, así como su forma biológica, hábitat, tipo de vegetación e intervalo de altitud en que se encuentran dentro del área de estudio.

Palabras clave: flora, helechos, México, pteridófitos.

\begin{abstract}
248 pteridophyte species and subspecific taxa are recorded for the state of Mexico, including 60 new state records and two new species. Specific and infraspecific taxa are accompanied by information regarding distribution world-wide and within Mexico and the state of Mexico, as well as life form, habitat, vegetation type, and altitudinal range within the study area.
\end{abstract}

Key words: ferns, flora, Mexico, pteridophytes.

\section{INTRODUCCIÓN}

El estado de México ha sido una región visitada por numerosos botánicos, quienes han producido buena cantidad de trabajos florísticos y dejado vastas colecciones en herbarios extranjeros y nacionales. En muchos casos, tanto en las 
colectas como en los trabajos, se incluyen o citan a los pteridófitos indirectamente (véase Jones, 1966; Rzedowski y Calderón, 1979 y Riba y Butanda, 1987). Matuda (1956a y 1956b) publicó "Los helechos del estado de México" y "Los helechos del valle de México y sus alrededores" donde citó 93 y 76 especies y taxa subespecíficos respectivamente para el área de estudio. De especial importancia son las contribuciones que Smith (1981), Mickel y Beitel (1988) y Mickel (1992) llevaron a cabo para Chiapas, Oaxaca y Nueva Galicia, pues al señalar la distribución de las especies, indican cuáles se hallan también en el estado de México (en total se citan en estas obras 129, 170 y 148 especies respectivamente que se comparten).

Entre los numerosos botánicos que han recolectado pteridófitos en el área de estudio descuellan: J. G. Schaffner, quien estuvo activo en los alrededores de la ciudad de México en 1854, 1855 y en forma esporádica en años subsecuentes (Rzedowski, 1959); C. G. Pringle, quien visitó el área de estudio entre 1890 y 1901 y concentró sus visitas en Plan de Salazar, Toluca y alrededores, Tultenango, El Oro, Flor de María, Almoloya del Río y alrededores de la ciudad de México (Davis, 1936); G. B. Hinton, que entre 1931 y 1935 recolectó al menos sus primeros 9000 ejemplares en el suroeste del área de estudio (J. Hinton, com. pers.), de los que cerca de 257 fueron pteridófitos (Hinton y Rzedowski, 1975); el hermano Ernest Lyonnet, de la congregación La Salle, acopió ejemplares entre 1932 y 1938 principalmente en Salazar, Lagunas de Zempoala y Mexicapa (entre los municipios de Ocuilan y Cuernavaca) y en los alrededores de la ciudad de México. En las últimas décadas sobresale el trabajo de campo de J. Rzedowski, G. Calderón y equipo de colaboradores, quienes concentraron su actividad en la cuenca de México (donde están incluidos los municipios orientales del estado de México) con el objetivo de inventariar la flora de la misma; proyecto en conexión con el cual la segunda autora del presente escrito ha desarrollado estudios (Arreguín-Sánchez 1983, 1985a, 1985b, 1986, 1991) encaminados a definir la parte correspondiente a los pteridófitos.

A partir de la revisión de herbarios y de la literatura, así como de recolectas de campo llevadas a cabo desde 1984, el primer autor estimó (Tejero-Díez, 1987) que la riqueza de pteridófitos en el estado de México era muy superior a la conocida. Por tal motivo, se inició un estudio formal encaminado a conocer de manera integral la diversidad de helechos y plantas afines en el área. Dentro de esta línea de trabajo se encuentran los estudios taxonómicos de Abundiz-Bonilla y Tejero-Díez (1990), Cruz Palacios (1992), Gallegos (1997), Tejero-Díez et al. (1998) y Tejero-Díez (1998).

\section{ÁREA DE ESTUDIO}

El estado de México se encuentra entre los $18^{\circ} 23^{\prime}$ y $20^{\circ} 17^{\prime}$ latitud norte y $98^{\circ} 37^{\prime}$ y $100^{\circ} 38^{\prime}$ longitud oeste. La entidad está dividida en dos cuerpos: el occidental 
o principal y el oriental, de menor proporción, parcialmente dividido por el territorio del Distrito Federal, separado de sus límites antiguos a fines del siglo XIX. Además de este último, políticamente colinda con el estado de Hidalgo al norte y con Querétaro al noroeste, al este con Tlaxcala y al oeste con Michoacán, al sur con Morelos y Guerrero. Abarca una superficie de 23,244.220 km², dividida en 121 municipios de acuerdo con lo presentado por la Secretaría de Programación y Presupuesto (Anónimo, 1981a).

Desde el punto de vista fisiográfico, las tres cuartas partes boreales del territorio (aproximadamente a partir de la latitud de los $19^{\circ}$ ) pertenecen a la provincia del Eje Volcánico Transversal, mientras que el suroeste del estado se encuentra en la porción media septentrional de la cuenca del río Balsas. En la provincia del Eje Volcánico Transversal destacan sierras que contienen algunos de los picos más altos de la República, como la sierra Nevada (al oriente), sierras del Ajusco, Zempoala, de las Cruces y Monte Alto (al centro) y Nevado de Toluca (al centro-occidente). A partir de estas serranías y sus elevaciones adyacentes, el área de estudio se puede dividir en subprovincias y cuencas hidrológicas, tales como los llanos y planicies del noroeste ligadas a la cuenca del alto Pánuco, la cuenca de México (artificialmente abierta al alto Pánuco), los valles y la semicuenca de Toluca, donde nace el río Lerma, y los declives al río Balsas en el suroeste del estado, participando estos últimos de las subcuencas de los ríos Amacuzac, Zirándaro y Atoyac (Anónimo, 1981a).

Jáuregui Oslo y Vidal Bello (1981), indican que, de acuerdo con el sistema de Köppen (1948), en el estado de México se distinguen los siguientes tipos de climas: 80\% del territorio (el comprendido en el Eje Volcánico Transversal) presenta el templado subhúmedo; una fracción del noreste del estado lo tiene de tipo seco estepario, mientras que en la porción correspondiente a la cuenca del río Balsas se presenta el tropical lluvioso estacional y una franja de transición (tropical/templado) entre las altitudes de 1300 y 1900 m s.n.m.

Bajo el anterior escenario, la vegetación que presenta el área de estudio, de acuerdo con Miranda (1947), Rzedowski (1978), Rzedowski y Calderón (1979) y Tejero-Díez (1998), está constituida de la siguiente manera:

a) Al norte del área de estudio (de Polotitlán a Otumba), en llanos y lomeríos, se desarrollan pastizales y pastizales con matorral xerófilo, la mayoría de los cuales son secundarios.

b) En la zona de montañas y sierras altas crecen bosques de Quercus y coníferas, que pueden ser de Quercus, Pinus-Quercus o viceversa, Abies, AbiesPinus o viceversa y Pinus ( $P$. hartwegii), para rematar en las partes más altas en pastizal alpino. Los bosques riparios (de galería) en esta región suelen estar conformados por Taxodium, Fraxinus, Alnus y Salix. El bosque mesófilo de montaña prospera en sitios expuestos a la vertiente del Pacífico, en cañadas con ríos entre los (1700) 1900 y 2500 (2700) m s.n.m. 
c) Al suroeste del área de estudio (principalmente en los municipios de Malinalco, Zumpahuacán, Tonatico, Sto. Tomás de los Plátanos, Tejupilco, Sultepec, Amatepec, Tlatlaya) se localiza el bosque tropical caducifolio, generalmente por debajo de los $1700 \mathrm{~m}$ s.n.m. (en ocasiones se pueden observar reliquias del bosque tropical subcaducifolio). Se encuentran bosques riparios tropicales (de galería) en esta región compuestos por Taxodium, Ficus, Salix y algunos otros elementos.

d) En la zona de transición climática, entre la cuenca del río Balsas y la zona de montaña en el suroeste del estado, se hallan bosques mixtos de Quercus, Quercus-Pinus y/o Juniperus mezclados con leguminosas y frecuentemente con Bursera.

\section{MÉTODOS}

Se colectaron intensivamente pteridófitos en el territorio del estado de México y se prepararon los ejemplares de acuerdo con las técnicas propuestas por Lorea y Riba (1990). Los límites territoriales, datos de ubicación relativos a carreteras, poblaciones y municipios asociados a las colectas están dados de acuerdo con la Carta Geográfica en Relieve, estado de México (escala horizontal 1:250 000 y vertical 1:100 000) del Instituto Nacional de Estadística Geografía e Informática (Anónimo, 1981a) y con el Nomenclátor del Estado de México (Anónimo, 1981b). Se determinaron los ejemplares con apoyo de monografías taxonómicas especializadas (de donde se obtuvieron también las referencias de aquellas especies que no se encontraron en el campo y que no se vieron en los herbarios del país), así como de las floras de pteridófitos de Knobloch y Correll (1962), Smith (1981), Mickel y Beitel (1988), Mickel (1992) y Moran y Riba (1995). La distribución en México de cada especie por estado se definió con ayuda de las obras ya citadas y se complementó con observaciones de herbario y las obras de Palacios-Rios (1992), Díaz-Barriga y Palacios-Rios (1992), Aguirre y Arreguín (1988), Riba et al. (1996) y Lorea-Hernández y Velázquez-Montes (1998).

El juego completo de ejemplares colectados en el occidente del estado de México se depositará en el herbario de la Facultad de Estudios Superiores Iztacala, Universidad Nacional Autónoma de México (IZTA) con duplicados para ser distribuidos. Los ejemplares colectados por la segunda autora en el oriente del área de estudio, se encuentran en el herbario de la Escuela Nacional de Ciencias Biológicas, Instituto Politécnico Nacional (ENCB).

Para complementar la información de la pteridoflora de la región se revisaron en 1986 los herbarios del Instituto de Biología de la Universidad Nacional Autónoma de México (MEXU), del Conjunto de Agricultura y Ganadería en Metepec (CODAGEM) y de la Escuela Nacional de Ciencias Biológicas del Instituto 
Politécnico Nacional (ENCB). A lo largo del tiempo se han consultado además diferentes herbarios adicionales con el objeto de dilucidar problemas en taxa particulares; en estos casos los acrónimos que se diponen en cada referencia, están dados de acuerdo con el Index Herbariorum (Holmgren y Holmgren, 2003).

\section{LISTA DE PTERIDÓFITOS CON ANOTACIONES}

El acomodo de las clases se presenta en orden de complejidad, mientras que las familias y especies están arregladas alfabéticamente. Los nombres de los autores de las especies se abreviaron de acuerdo con Brumitt y Powell (1992), colocando entre corchetes el o los sinónimos usados en la literatura referida al área de estudio. La delimitación taxonómica de familias y géneros sigue el criterio expuesto principalmente en la Flora Mesoamericana (Moran y Riba, 1995).

Se marca con un asterisco $\left(^{*}\right)$ aquellos taxa que se mencionan por primera vez para el estado de México y con una cruz $(+)$ las que se consideraron nuevas especies.

La forma biológica está dada de acuerdo con Raunkiaer con modificaciones de Mueller-Dombois y Ellenberg (1974) y adaptada a los helechos, considerando el tipo de tallo/rizoma y la disposición de las hojas (frondes) o ejes superficiales (en el caso de pteridófitos micrófilos). Las afinidades a microhábitat y filiación de clima se incluyeron cuando los registros de colecta fueron suficientes. El significado de los términos correspondientes puede consultarse en Font-Quer (1982); en particular los conceptos mesófilo, termófilo y xerófilo se refieren a los climas templado, cálido y seco de Köppen (1948) respectivamente.

La secuencia de los estados y de los municipios se dispuso latitudinalmente de norte a sur, comenzando a nombrarlos a partir de los ubicados al este. Las referencias al material examinado se encuentran en orden alfabético de colectores. Para dar una idea rápida de la distribución (municipios en que se colectó) y abundancia (cantidad de colectas) de cada especie, los municipios y las referencias se dispusieron en bloques separados.

\section{PSILOTOPSIDA}

\section{Psilotaceae}

\section{Psilotum nudum Sw.}

Hemicriptófito rupícola, rizomatoso de ejes aproximados, ascendente-arqueados, mesófilo, fotófilo; bosque tropical subcaducifolio y mesófilo de montaña, entre 1300 y 2000 m s.n.m.; Sto. Tomás de los Plátanos, Ocuilan, Tejupilco. 
Material de referencia: G. B. Hinton 3923 (ENCB, MEXU). D. Tejero-Díez 2000, 2605 (IZTA).

Distribución: Sureste de E.U.A., México (Chih., Son., Tams., Ver., Jal., Pue., Méx., D.F., Mor., Col., Chis.), Centro a Sudamérica, Antillas, trópicos del Viejo Mundo.

\section{EQUISETOPSIDA}

EQUiSETACEAE

Equisetum xferrissii Clute

Geófito a hidrófito, rizomatoso colonial, ripícola; bosque tropical subcaducifolio, mesófilo de montaña, de Pinus, de Abies, entre 1900 y 3000 m s.n.m.; Villa Allende, Toluca, Ixtapan del Oro, Temascaltepec, Villa Guerrero, Coatepec Harinas, Tejupilco, Ixtapan de la Sal, Zacualpan.

Material de referencia: J. Díaz 188 (ENCB). I. García s. n. 15/nov./1984 (CODAGEM). H. Gómez 124 (ENCB). A. R. López y A. Espejo 815 (UAMIZ). D. Tejero-Diez 2124, 2176, 2746, 3202 (IZTA). E. Vela 4 y D. Tejero-Diez (ENCB).

Distribución: E.U.A., México (B.C., Son., Chih., Coah., N.L., Dgo., Méx.).

Nota: J. T. Mickel (com. pers. en 2001) no está de acuerdo con el reconocimiento de la existencia de este híbrido en la región de estudio, sin embargo Tejero-Díez et al. (1998) ofrecen datos concluyentes respecto a su presencia o en su caso de otro aún no definido.

E. hyemale L. ssp. affine (Engelm.) Calder et R. L. Taylor (=E. robustum A. Braun)

Geófito a hidrófito, rizomatoso, palúdico o ripícola; en hábitats tanto de clima cálido como templado, entre 1700 y 3100 m s.n.m.; Temascalcingo, Tepotzotlán, Villa del Carbón, Tultitlán, Toluca, Donato Guerra, Tlalmanalco, Temascaltepec, Valle de Bravo, Amecameca, Ocuilan, Villa Guerrero, Sultepec.

Material de referencia: S. Aguilar 64 (IZTA). F. Castrejón 8393 (ENCB). R. Cruz 118 (ENCB). M. P. Duarte 85 (ENCB). I. García s. n. 15/nov./1984 (CODAGEM). G. Garduño s. n. (IZTA); J. Rzedowski 28875 (ENCB): D. Tejero-Diez 2150, 2217, 2318, 2548, 2957, 3203, 3363b, 3378 (IZTA).

Distribución: Norteamérica (Alaska a E.U.A.), México (B.C., Son., Chih., Coah., N.L., Sin., Dgo., Ver., Jal., Pue., Méx., Mich., D.F., Chis., Oax., Gro.), Centroamérica, Asia. 
E. myriochaetum Schltdl. et Cham. (=E. ramosissimum var. mulleri Milde)

Geófito rizomatoso, ripícola, esciófilo; bosque mesófilo de montaña, alrededor de los 2100 m s.n.m.; Temascaltepec, Valle de Bravo, Ocuilan, Almoloya de Alquisiras, Zacualpan.

Material de referencia: A. Espejo y A. R. López 4012 (UAMIZ). M. E. Heres s. n. (IZTA). V. Orozco 456 y D. Tejero-Díez (IZTA). D. Tejero-Díez 2038, 3205 (IZTA). R. Fragoso s. n. y D. Tejero-Díez (IZTA).

Distribución: México (N.L., Tams., S.L.P., Ver., Nay., Jal., Hgo., Qro., Pue., Méx., Mich., Chis., Oax., Gro.), Centro a Sudamérica.

E. xhaukeanum Mickel et A. R. Sm.

Geófito a hidrófito rizomatoso, ripícola, fotófilo; bosque mesófilo de montaña, entre 1900 y 2300 m s.n.m.; Ixtapan del Oro, Temascaltepec, Ocuilan, Villa Guerrero, Sultepec, Zacualpan.

Material de referencia: E. Matuda 30295 (MEXU). Moreno 144 (ENCB). D. Tejero-Díez 2152, 2156, 2467, 2671, 3199 (IZTA).

Distribución: México (N.L., Tams., Sin., S.L.P., Ver., Hgo., Méx., Mich., Chis., Oax., Gro.), Guatemala.

\section{LYCOPODIOPSIDA}

\section{LYCOPODIACEAE}

Huperzia cuernavacensis (Underw. et F. E. Lloyd) Holub

Epífito, de tallos cespitosos péndulos en ramas primarias de Quercus o caméfito saxícola, esciófilo; bosque mesófilo de montaña en cañadas, entre 2200 y 2450 m s.n.m.; Tenango de Arista, Ocuilan.

Material de referencia: N. Pozos Banda y alumnos s. $n$. 9/ene./1986 (IZTA). D. Tejero-Díez 2200, 2805 (IZTA).

Distribución: México (Sin., Jal., Méx., Mich., Mor., Chis., Oax., Gro.).

H. pringlei (Underw. et F. E. Lloyd) Holub

Epífito con tallos cespitosos péndulos en troncos y ramas primarias, mesófilo, esciófilo; bosque de Quercus y mesófilo de montaña en cañadas, entre 2200 a 2400 m s.n.m; Temascaltepec, Valle de Bravo, Ocuilan.

Material de referencia: Araujo Silva 20 y M. Fuentes Iniestra (IZTA). A. Gómez Pompa 1955 (MEXU). G. B. Hinton 2347 (CODAGEM). D. Tejero-Diez y M. Castilla Hernández 300 (ENCB). D. Tejero-Díez 2199 (IZTA). 
Distribución: México (Sin., Ver., Jal., Hgo., Méx., Mich., Mor., Chis., Oax., Gro.), Guatemala.

H. reflexa (Lam.) Trevis.

Caméfito de tallo simple (dicotomizado) ascendente en taludes de tierra ruderales; bosque tropical caducifolio y bosque mesófilo de montaña, entre $900 \mathrm{y}$ 2250 m s.n.m.; Ocuilan, Tejupilco.

Material de referencia: G. B. Hinton 3378 (MEXU). D. Tejero-Díez 2732 (IZTA).

Distribución: México (Ver., Jal., Hgo., Pue., Méx., Mor., Chis., Oax., Gro.), Centro a Sudamérica, Antillas.

*H. taxifolia (Sw.) Trevis.

Epífito de tallos cespitosos péndulos en ramas primarias de Quercus, esciófilo; bosque mesófilo de montaña en cañadas, entre 2200 a 2400 m s.n.m.; Ocuilan.

Material de referencia: D. Tejero-Díez y M. Castilla Hernández 298 (ENCB). D. Tejero-Diez 2736, 2987 (IZTA).

Distribución: México (Tams., Sin., S.L.P., Ver., Pue., Méx., D.F., Chis., Oax., Gro.), Centro a Sudamérica (hasta Perú), Antillas.

\section{Lycopodiella cernua (L.) Pic. Serm.}

Caméfito estolonífero, taludes de tierra ruderales; bosque de Quercus-Pinus a 2700 m s.n.m.; Temascaltepec (cumbre Gavia entre Texcaltitlán y Sultepec).

Material de referencia: G. B. Hinton 9017 (NY). (J. T. Mickel, com. pers. en 2001).

Distribución: Sureste de E.U.A., México (Ver., Hgo., Pue., Méx., Mich., Tab., Chis., Oax., Gro.), Centro a Sudamérica, Antillas y regiones tropicales a subtropicales del viejo mundo.

\section{*Lycopodium clavatum L.}

Caméfito estolonífero, ruderal en talud de tierra; bosque de Quercus-Pinus a 2300 m s.n.m.; Temascaltepec, Valle de Bravo.

Material de referencia: D. Tejero-Díez 2930 (IZTA). W. Boege 1811 (MEXU).

Distribución: Norteamérica (Canadá y E.U.A.), México (Ver., Hgo., Qro., Pue., Méx., Mich., Chis., Oax., Gro.), Centro a Sudamérica, Antillas y norte de Europa. 
IsÖETACEAE

Isoëtes montezumae A. A. Eaton

Hidrófito sumergido a palúdico en cuerpos de agua; ambientes con pastizal o bosque de Pinus, entre los 2300 y 2600 m s.n.m.; San Felipe del Progreso, Lagunas Zempoala (entre los municipios de Huitzilac, Mor. y Ocuilan, Méx.).

Material de referencia: J. Bonilla 1516, 1574 (MEXU). G. C. Pringle 3459 (holotipo MO!, isotipos ENCB!, MEXU!).

Distribución: México (Zac., Ags., Nay., Jal., Gto., Méx., Mich., D.F., Mor., Chis.), Guatemala.

\section{Selaginellaceae}

Selaginella delicatissima A. Braun

Caméfito de tallos enraizantes, mesófilo, rupícola o en taludes de tierra ruderales en sitios subexpuestos; bosque tropical subcaducifolio, ripario tropical, mixto de Quercus-Juniperus con leguminosas, mesófilo de montaña, de Pinus, entre 1650 y 2800 m s.n.m.; Jilotepec, Villa del Carbón, Ixtapan del Oro, Tlalmanalco, Temascaltepec, Villa Guerrero, Coatepec Harinas, Malinalco, Sultepec, Zacualpan.

Material de referencia: L. Abundiz-Bonilla 239, 254, 260, 271, 283, 296, 313 (IZTA). M. L. Arreguín 711 (ENCB). C. Galván 13 y S. Romero (IZTA). J. T. Mickel 719 (CODAGEM, ENCB, NY). D. Tejero-Diez 1988, 1997, 2024, 2227 (IZTA). Torres Zúñiga 423 (IZTA).

Distribución: México (N.L., Tams., Sin., S.L.P., Ver., Jal., Hgo., Qro., Gto., Méx., Mich., Mor., Col., Chis., Oax., Gro.), Centroamérica.

\section{S. hoffmannii Hieron.}

Hemicriptófito rizomatoso de tallos erectos, termófilo, esciófilo en taludes riparios o ruderales y rupícola; bosque tropical caducifolio, tropical subcaducifolio, ripario tropical, mixto de Quercus-Juniperus con leguminosas, entre 800 y 1930 m s.n.m.; Sto. Tomás de los Plátanos, Valle de Bravo, Ocuilan, Tejupilco.

Material de referencia: L. Abundiz-Bonilla 234, 290, 301, 311 (IZTA). E. Matuda 27194 (CODAGEM). D. Tejero-Díez 2012 (IZTA), 3191 (IZTA, MEXU).

Distribución: México (Sin., Ver., Jal., Hgo., Qro., Méx., Mich., Col., Chis., Oax., Gro.) a Costa Rica. 


\section{S. landii Greenm. et N. Pfeiff.}

Caméfito rupícola de tallos enraizantes, termófilo, fotófilo en peñas; bosque ripario tropical, a 1300 m s.n.m.; Malinalco.

Material de referencia: D. Tejero-Díez 3066 (IZTA).

Distribución: México (Nay., Jal., Pue., Méx., Mor., Oax.).

\section{S. lepidophylla (Hook. et Grev.) Spring}

Caméfito de tallos arrosetados, termófilo, fotófilo, rupícola en hendiduras o terrestre en taludes; bosque tropical caducifolio, mixto de Quercus-Juniperus con leguminosas y de Quercus, entre 1380 y 1840 m s.n.m.; Tejupilco, Ixtapan de la Sal, Almoloya de Alquisiras, Tonatico, Zacualpan.

Material de referencia: L. Abundiz-Bonilla 259 (IZTA). E. Guizar 180 (MEXU). E. Matuda 7388 (CODAGEM). D. Tejero-Díez 2104, 2174 (IZTA).

Distribución: Sur de E.U.A., México (B.C., Chih., Coah., N.L., Tams., Sin., Dgo., Zac., S.L.P., Ver., Nay., Jal., Hgo., Qro., Gto., Pue., Méx., Mich., Mor., Col., Chis., Oax., Gro.), El Salvador.

\section{S. lineolata Mickel et Beitel}

Terófito de tallo estolonífero, mesófilo, adpreso en hendiduras de rocas y taludes de tierra, higrófilo; huerto de frutales tropicales y bosque tropical caducifolio, mixto de Quercus-Juniperus con leguminosas y mesófilo de montaña, entre 400 y 2290 m s.n.m.; Tejupilco, Zacualpan, Tlatlaya.

Material de referencia: L. Abundiz-Bonilla 302, 305, 308, 310 (IZTA). D. Tejero-Diez 1985 (IZTA).

Distribución: México (Ver., Nay., Jal., Méx., Col., Oax.).

\section{S. pallescens (C. Presl) Spring}

Caméfito de tallos macollados erectos a arrosetados; matorral xerófilo, pastizal y bosque tropical caducifolio, subcaducifolio, ripario tropical y templado, mixto de Quercus-Juniperus con leguminosas, de Quercus-Pinus, mesófilo de montaña y de Pinus-Quercus, entre 440 y 2600 m s.n.m.; Jilotepec, Aculco, Acambay, Temascalcingo, Temascalapa, Tequixquiac, Zumpango, Huehuetoca, Chapa de Mota, Tepotzotlán, Villa del Carbón, Tultitlán, Atizapán, Texcoco, Naucalpan, Donato Guerra, Ixtapan del Oro, Tlalmanalco, Temascaltepec, Valle de Bravo, Sto. Tomás de los Plátanos, Amecameca, Otzoloapan, Ocuilan, Coatepec Harinas, Malinalco, Tejupilco, Ixtapan de la Sal, Sultepec, Zacualpan.

Material de referencia: L. Abundiz-Bonilla 19, 100, 135, 227, 233, 236, $128,240,243,247,248,249,250,252,253,256,262,265,266,267,268$, 
272, 273, 278, 279, 281, 282, 284, 287, 288, 289, 291, 295, 298, 300, 304 (IZTA). M. L. Arreguín 634 (ENCB). W. Boege 1784 (MEXU). R. Cruz 795, 867 (ENCB). I. García 17 (IZTA), 255 (CODAGEM). A. González et al. 7, 8, 25 (IZTA). P. Granillo 7, 10, 13 (CODAGEM). G. B. Hinton 1808, 3974 (CODAGEM). M. E. Huidobro s. n. (IZTA). M. Juárez 24 y S. Romero (IZTA). I. López 667 (ENCB). E. Matuda 26864, 27735 (CODAGEM), 26759 (MEXU). R. Moreno 5, 15, (CODAGEM). A. Moreno 150 y M. L. Arreguín (ENCB). N. Naranjo 202 (ENCB). M. T. Pulido 489 (ENCB). S. Ramírez 20 y D. TejeroDiez (IZTA). S. Romero y C. Rojas 525, 611, 774, 1201, 1379 (IZTA). J. Rzedowski 18727, 22897, 27935 (ENCB), 30911, 32030 (ENCB, MEXU). $H$. Sánchez-Mejorada 556, 809 (MEXU). D. Tejero-Díez 1989, 1999, 2011, 2075, 2078, 2079, 2114, 2134, 2165, 2186, 2276, 2319, 2562, 2579 (IZTA). D. Tejero-Díez y M. Castilla 838, 919 (IZTA). J. Trejo 6 y S. Romero (IZTA). J. Vargas 26 y D. Tejero-Díez (IZTA). Vidal 7 (IZTA).

Distribución: México (B.C., Son., Chih., Coah., N.L., Tams., Sin., Dgo., Zac., S.L.P., Yuc., Ver., Ags., Nay., Jal., Hgo., Qro., Gto., Pue., Méx., Mich., D.F., Mor., Col., Chis., Oax., Gro.), Centro a Sudamérica.

\section{S. peruviana (Milde) Hieron.}

Caméfito de tallos enraizantes, xerófilo, fotófilo, rupícola o comúnmente en substratos cerca de la base de nopales y arbustos; matorral xerófilo y pastizales inducidos, ca. 2300 m s.n.m.; Aculco, Jilotepec, Villa del Carbón.

Material de referencia: L. Abundiz-Bonilla 276, 277, 316 (IZTA). Boyzo 6 y S. Romero (IZTA). Galván 11 y S. Romero (IZTA).

Distribución: Suroeste de E.U.A., México (Chih., Coah., N.L., Dgo., Ver., Jal., Méx., D.F.), Sudamérica.

S. porphyrospora A. Braun (=S. binervis Liebm. ex E. Fourn.)

Terófito de tallos estoloníferos, mesófilo, esciófilo en taludes de tierra ruderales o bajo el dosel; bosque tropical caducifolio, subcaducifolio, ripario tropical y templado, mixto de Quercus-Juniperus con leguminosas, mesófilo de montaña, PinusQuercus, entre 980 y 2600 m s.m.m.; Ixtapan del Oro, Temascaltepec, Valle de Bravo, Ocuilan, Villa Guerrero, Coatepec Harinas, Malinalco, Texcaltitlán, Tejupilco, Sultepec, Zacualpan, Tlatlaya.

Material de referencia: L. Abundiz-Bonilla 228, 232, 237, 244, 245, 246, 255, 257, 258, 261, 270, 274, 280, 285, 307 (IZTA). G. B. Hinton 2491 (CODAGEM), 8212 (ENCB, MEXU). M. Ramírez 12 y D. Tejero-Díez (IZTA). D. Tejero-Díez 2001, 2145, 2233 (TEX) 2278, 2554, 2672, 2685 (IZTA). C. Zeckua 27 y D. Tejero-Díez (IZTA). 
Distribución: México (Son., Ver., Nay., Jal., Hgo., Pue., Méx., Mich., Mor., Chis., Oax., Gro.), Centroamérica.

\section{S. rupincola Underw.}

Caméfito rupícola de tallos suberectos, mesófilo, fotófilo en peñas; matorral xerófilo, pastizales, bosque tropical caducifolio, mixto de Quercus-Juniperus con leguminosas, mesófilo de montaña, de Pinus-Quercus y de Pinus, entre 1550 y 2350

m s.n.m.; Jilotepec, Tepotzotlán, Sto. Tomás de los Plátanos, Malinalco, Coatepec Harinas, Almoloya de Alquisiras, Sultepec, Tonatico.

Material de referencia: L. Abundiz-Bonilla 235, 269, 275, 279 (IZTA). M. L. Arreguín 628 (ENCB). R. Cruz 1696 (ENCB). M. E. Huidobro s. n. (IZTA). D. Tejero-Diez 1998, 2106, 2140b, 2667, 3070 (IZTA).

Distribución: Suroeste de E.U.A., México (Son., Chih., Coah., Tams., Dgo., S.L.P., Ags., Jal., Hgo., Qro., Gto., Pue., Méx., D.F., Mor., Oax.).

S. sartorii Hieron. (=S. hintonii Weath.)

Caméfito de ramas postradas, xerófilo, fotófilo, rupícola; matorral xerófilo y bosque tropical caducifolio, entre 1550 y 2600 m s.n.m.; Atlacomulco, Villa del Carbón, Sto. Tomás de los Plátanos, Malinalco, Tejupilco, Sultepec.

Material de referencia: L. Abundiz-Bonilla 312, 314 (IZTA). P. Granillo 3 (CODAGEM). G. B. Hinton 8423 (ENCB, GH holotipo de S. hintonii; fide Mickel, 1992). H. Sánchez-Mejorada 788 (MEXU). D. Tejero-Díez 2209, 2626, 2668 (IZTA). Vázquez 3 y S. Romero (IZTA).

Distribución: México (Chih., N.L., Tams., Dgo., S.L.P., Ver., Nay., Qro., Méx., Mor., Oax.), Sudamérica.

\section{S. schaffneri Hieron.}

Caméfito de tallos postrados estoloníferos, termófilo, fotófilo, rupícola en peñones; bosque ripario tropical y de Pinus-Quercus, entre 1450 y 1600 m s.n.m.; Tejupilco.

Material de referencia: G. B. Hinton 7391 (MEXU), 8858 (ENCB, MEXU). D. Tejero-Díez 3147 (IZTA).

Distribución: México (S.L.P., Nay., Jal., Gto., Méx., Gro.).

\section{S. schiedeana A. Braun}

Terófito de tallos adpresos, termófilo, en taludes de tierra ruderales húmedos o ripícolas, esciófilo; bosque tropical caducifolio, subcaducifolio y ripario, entre 440 y 1800 m s.n.m.; Zumpahuacán, Tejupilco, Tlatlaya. 
Material de referencia: L. Abundiz-Bonilla 299 (ENCB, IZTA) 303, 309 (IZTA). D. Tejero-Díez 2854, 3147 (IZTA).

Distribución: México (Tams., S.L.P., Ver., Méx., Chis., Oax., Gro.).

\section{S. sellowii Hieron.}

Caméfito de tallos postrados estoloníferos en suelo compactado, xerófilo; pastizales y matorral xerófilo, entre 2200 y 2400 m s.n.m.; Tequixquiac, Villa del Carbón, Otumba.

Material de referencia: L. Abundiz-Bonilla 315, 317 (IZTA). S. Romero y C. Rojas 1781 (IZTA). D. Tejero-Díez y M. Castilla 434, 435 (ENCB, IZTA).

Distribución: México (Tams., Sin., Zac., S.L.P., Ver., Jal., Qro., Pue., Méx., D.F., Oax.), Sudamérica, Antillas.

\section{S. silvestris Aspl.}

Caméfito en taludes húmedos; bosque de Quercus; Temascaltepec.

Material de referencia: G. B. Hinton 7350 (NY). (J. T. Mickel, com. pers. en 2001).

Distribución: México (Ver., Hgo., Pue., Méx., Col., Chis., Oax.), Centro a Sudamérica.

\section{S. tarda Mickel et Beitel}

Caméfito estolonífero de tallos erectos, termófilo, higrófilo; bosque tropical subcaducifolio y cultivos asociados, entre 750 y 1200 m s.n.m.; Tejupilco.

Material de referencia: L. Abundiz-Bonilla 324 (IZTA). G. B. Hinton 2491 (NY paratipo), 8462 (CODAGEM, ENCB, NY). D. Tejero-Díez 2908 (IZTA). Distribución: México (Méx., Mich., Col., Oax., Gro.).

\section{POLYPODIOPSIDA}

\section{Aspleniaceae}

\section{*Asplenium abscissum Willd.}

Hemicriptófito terrestre o rupícola de hojas fasciculadas; bosque mesófilo de montaña a 2100 m s.n.m.; Ocuilan (cañada de Mexicapa, entre Méx. y Cuernavaca, Mor.).

Material de referencia: G. B. Hinton 17091 (ENCB, NY). 
Distribución: Sureste de E.U.A., México (S.L.P., Ver., Jal., Méx., Mor., Chis., Oax., Gro.), Centro a Sudamérica, Antillas.

\section{*A. auriculatum Sw.}

Hemicriptófito de hojas fasciculadas, mesófilo, esciófilo en taludes de tierra; bosque mesófilo de montaña a 2400 m s.n.m.; Tenancingo.

Material de referencia: S. Aguilar y alumnos 20 y s. $n$. 29/ene./1988 (IZTA). P. Granillo y alumnos s. n. 13/feb./1988 (IZTA).

Distribución: México (Ver., Jal., Pue., Hgo., Qro., Méx., Mich., Chis., Oax., Gro.), Centro a Sudamérica, Antillas.

A. blepharophorum Bertol. (=A. commutatum Mett. ex Kuhn; =A. myapteron Fée)

Hemicriptófito de hojas fasciculadas, mesófilo, crece en el sotobosque o sitios abiertos; bosque de Abies principalmente y también se halla en bosque mesófilo de montaña, de Quercus, de Pinus-Quercus, entre 2000 y 3400 m s.n.m.; Jilotepec, Aculco, Tlalmanalco, Amecameca, Atlautla, Ocuilan, Temascaltepec, Valle de Bravo, Coatepec Harinas, Zacualpan.

Material de referencia: W. R. Anderson y C. W. Laskowski 4005 (ENCB). G. Calderón 82-V (ENCB). M. Codallos 13 (IZTA). E. Matuda 30569, 30947 (CODAGEM, MEXU). G. B. Hinton 6847 (MEXU). S. Hernández 2 (IZTA). Riva Solis 1 (IZTA). J. Rzedowski 26423, 27258, 28808 (ENCB). D. TejeroDiez 2366, 2681, 2960, 2965 (IZTA). L. Zalaya y L. Pacheco 35 (ENCB).

Distribución: México (Sin., S.L.P., Ver., Nay., Jal., Pue., Méx., Mich., D.F., Col., Mor., Chis., Oax., Gro.), Centroamérica, La Española.

\section{A. castaneum Schltdl. et Cham.}

Hemicriptófito rupícola de hojas fasciculadas, mesófilo; bosque mesófilo de montaña, de Abies-Pinus, de Pinus y pastizal alpino, entre 2130 y 4000 m s.n.m.; Villa Nicolás Romero, Isidro Fabela, Texcoco, Ixtapaluca, Huixquilucan, Ocoyoacac, Zinacantepec, Tlalmanalco, Amecameca, San Felipe del Progreso, Tenancingo.

Material de referencia: M. L. Arreguín 667 (ENCB). R. Cruz 123 (ENCB). R. Flores 45 y D. Tejero-Díez (IZTA). L. Gómez 15 (ENCB). E. Matuda 28202 (MEXU). M. A. Mazón 179 (ENCB). N. M. Monroy 97 (ENCB, MEXU). C. G. Pringle 5191 (B, US). J. Rzedowski 22774, 30168, 31555, 36772, 36826, 37996 (ENCB). D. Tejero-Díez 2892 (IZTA).

Distribución: México (Dgo., Ver., Jal., Gto., Pue., Méx., Mich., D.F., Mor., Chis., Oax., Gro.), Centro a Sudamérica. 
A. cuspidatum Lam. (=A. lacerum Schltdl. et Cham.; =A. fragrans Sw.)

Epífito de hojas fasciculadas en troncos y ramas de árboles, mesófilo, esciófilo; bosque mesófilo de montaña, entre 1900 y 2400 m s.n.m.; Temascaltepec, Ocuilan, Sultepec.

Material de referencia: Covarrubias 3 (IZTA). E. Lyonnet 1326, 1841, 2104 (MEXU). S. D. Koch 7942 (ENCB, MEXU). C. G. Pringle 8955 (ENCB). J. Rzedowski 30873 (ENCB). D. Tejero-Díez 2229, 2365, 2643, 2691 (IZTA). Weller 595 (ENCB).

Distribución: México (Sin., Ver., Nay., Jal., Qro., Méx., Mich., Mor., Chis., Oax., Gro.), Centro a Sudamérica, Antillas.

\section{*A. exiguum Bedd.}

Hemicriptófito de hojas fasciculadas; bosque mesófilo de montaña en cañadas a 2300 m s.n.m.; Ocuilan.

Material de referencia: E. Lyonnet [521100001] (MEXU). (A. R. Smith, com. pers. en 2001).

Distribución: México (Méx., D.F., Gto., Qro., Gro.).

A. fibrillosum Pringle et Davenp. ex Davenp.

Hemicriptófito rupícola de hojas fasciculadas, mesófilo; bosque mesófilo de montaña, de Pinus, de Abies y de Pinus, entre 2500 y 3800 m s.n.m.; Chapa de Mota, Jocotitlán, Zinacantepec, Tlalmanalco, Ocuilan.

Material de referencia: M. L. Arreguín 622 (ENCB). D. Tejero-Diez 2631, 2707, 2994, 4178 (IZTA).

Distribución: México (S.L.P., Ags., Gto., Méx., Mich., Mor., D.F.).

\section{*A. formosum Willd.}

Hemicriptófito rupícola de hojas aproximadas; bosque de Quercus-Pinus, cerca de ríos a 1740 m s.n.m.; Tejupilco.

Material de referencia: H. Cruz y C. Rojas 5 (IZTA).

Distribución: México (Dgo., Ver., Nay., Jal., Méx., Mich., Col., Tab., Mor., Chis., Oax., Gro.), Centro a Sudamérica, Antillas.

\section{A. hallbergii Mickel et Beitel}

Hemicriptófito de hojas fasciculadas, mesófilo, esciófilo; bosque ripario tropical, mesófilo de montaña y de Pinus-Quercus, entre (1650) 1900 y 2750 m s.n.m.; 
Texcoco, Huixquilucan, Amanalco, Tlalmanalco, Atizapán, Ocuilan, Coatepec Harinas, Tenancingo.

Material de referencia: C. Enríquez 4 y L. Abundiz-Bonilla (IZTA). E. Lyonnet 1448 (MEXU). M. A. Mazón 179 (ENCB). D. Ortiz 3 (ENCB). M. T. Pulido 303 (ENCB). B. E. Rodríguez 1115 (ENCB). D. Tejero-Díez 2052, 2053, 2194, 2270, 2865 (IZTA).

Guatemala.

Distribución: México (S.L.P., Ver., Jal., Gto., Méx., Mich., Mor., Oax.),

\section{A. monanthes L.}

Hemicriptófito de hojas fasciculadas, ubicuista; bosque mixto de QuercusJuniperus con leguminosas, de Quercus, mesófilo de montaña, de Pinus, de PinusQuercus, de Abies y vegetación secundaria derivada de las anteriores, entre 1750 y 3450 m s.n.m.; Jilotepec, Temascalapa, Chapa de Mota, San Martín de las Pirámides, Tepotzotlán, Villa del Carbón, Villa Nicolás Romero, Jilotzingo, Naucalpan, Villa de Allende, Lerma, Toluca, Chalco, Ocoyoacac, Amanalco, Tlalmanalco, Amecameca, Juchitepec, Tenango del Valle, Tepetlixpa, Ocuilan, Temascaltepec, Coatepec Harinas, Sultepec, Tejupilco.

Material de referencia: Álvarez y López 258 (ENCB). R. Archundia 39 (ENCB). F. Arreguín 29 (ENCB). M. L. Arreguín 437, 458, 510a (ENCB). M. T. Alvarado 78-56 (ENCB). J. Díaz 275 (ENCB, MEXU). D. B. Dunn 17149 (ENCB). García Cruz s. n. 13/ene./1985 (IZTA). D. González Baena 1 (IZTA). M. Gutiérrez 60 (ENCB). G. B. Hinton 6838 (MEXU). A. Juárez 29 (IZTA). J. T. Mickel $651 b$ (MEXU), 662 (CODAGEM). L. Paray 2416 (ENCB). J. Rzedowski 18417, 28813 (ENCB). Sánchez-León 43 (ENCB). Serrano R. 10 (IZTA). D. Tejero-Diez y M. Castilla 428, 622, 1084 (ENCB, IZTA) D. TejeroDíez 2219, 2246, 2269, 2479, 2687 (IZTA). M. S. Xelhuantzi 5105 (ENCB).

Distribución: Suroeste de E.U.A., México (Chih., N.L., Dgo., Ver., Nay., Jal., Hgo., Qro., Gto., Pue., Méx., Mich., D.F., Col., Mor., Chis., Oax., Gro.), Centro y Sudamérica, Antillas, África, Hawai.

\section{A. munchii A. R. Sm.}

Caméfito estolonífero, mesófilo, esciófilo; bosque de Quercus húmedo y mesófilo de montaña, entre 1900 y 2700 m s.n.m.; Jilotepec, Temascaltepec, Zacualpan, Ocuilan.

Material de referencia: Flores López 5 (IZTA). G. B. Hinton 2389, 6849 (MEXU). E. J. Lott y T. Wendt 100 (ENCB, MEXU). E. Lyonnet 2876 (IZTA, MEXU). Ramos Camacho 3 (IZTA). D. Tejero-Diez 2728 (IZTA). L. Vidal 26 (IZTA). 
Distribución: México (Jal., Méx., Mich., Mor., Chis., Oax., Gro.), Guatemala.

\section{A. palmeri Maxon}

Hemicriptófito de hojas fasciculadas, estolonífero, ripícola; pastizal inducido, bosque ripario tropical, mixto de Quercus-Juniperus con leguminosas y de Pinus, entre 1750 y 2700 m s.n.m.; Tepotzotlán, Coatepec Harinas, Almoloya de Alquisiras, Ocuilan.

Material de referencia: González G. 47 (IZTA). S. Magallón 91 (ENCB). D. Tejero-Díez 2072, 3014 (IZTA).

Distribución: México (Son., Chih., Coah., Tams., N.L., Sin., Dgo., S.L.P., Ver., Jal., Hgo., Qro., Gto., Méx., Mich., D.F., Oax., Gro.), Centro a Sudamérica.

\section{*A. polyphyllum Bertol.}

Hemicriptófito de hojas fasciculadas, mesófilo, esciófilo; bosque de Abies, entre 2900 y 3450 m s.n.m.; Ocuilan, Coatepec Harinas.

Material de referencia: E. Lyonnet 1410 (ENCB, MEXU). D. Tejero-Díez 2301, 2713, 2963, 2964 (IZTA).

Distribución: México (Méx., Mich., D.F., Chis., Oax., Gro.), Centro a Sudamérica, Antillas.

\section{A. praemorsum Sw.}

Epífito de hojas fasciculadas, mesófilo; bosque de Quercus, mesófilo de montaña y de Pinus-Quercus, entre 1900 y 2500 m s.n.m.; Texcoco, Naucalpan, Donato Guerra, Tlalmanalco, Amecameca, Ocuilan, Tenancingo, Villa Guerrero, Temascaltepec, Valle de Bravo, Coatepec Harinas, Zacualpan, Sultepec, Tejupilco.

Material de referencia: M. L. Arreguín (ENCB). M. Gauzin 94 (ENCB). G. B. Hinton 1251, 4158 (MEXU). Y. Maya 6 (ENCB). J. T. Mickel 695 (CODAGEM). J. Rzedowski 28774 (ENCB). D. Tejero-Diez 2154, 2189, 2232, 2514, 2644, 2680 (IZTA). M. Zúñiga 195 (ENCB).

Distribución: México (Tams., S.L.P., Ver., Qro., Méx., Mich., D.F., Mor., Chis., Oax., Gro.), Centro a Sudamérica, Antillas.

\section{A. pumilum Sw.}

Terófito a hemicriptófito rupícola o en taludes de tierra ruderales o ripícola; bosque tropical subcaducifolio y ripario tropical, entre 1000 y 1900 m s.n.m.; Tejupilco, Tenancingo, Zumpahuacán, Malinalco. 
Material de referencia: G. B. Hinton 1835 (MEXU). D. Tejero-Diez 2656, 2864, 2902 (IZTA).

Distribución: Sureste de E.U.A., México (B.C.S., N.L., Sin., S.L.P., Q.R., Yuc., Ver., Nay., Jal., Qro., Méx., Tab., Mor., Chis., Oax., Gro.), Centro a Sudamérica.

A. sessilifolium Desv. (=A. potosinum Hieron. var. incisum Hieron.)

Hemicriptófito de hojas fasciculadas, en cárcavas, mesófílo; bosque mixto de Quercus-Juniperus con leguminosas y de Pinus, entre 1500 y 2600 m s.n.m.; Tlalmanalco, Ocuilan, Tejupilco, Amatepec.

Material de referencia: M. L. Arreguín 506a, 511 (ENCB). G. B. Hinton 7360 (ENCB). E. Matuda 30029 (MEXU). J. Rzedowski 29958 (ENCB). D. Tejero-Díez 2367, 2682 (IZTA).

Distribución: México (Sin., Dgo., S.L.P., Ver., Jal., Hgo., Qro., Pue., Méx., Chis., Oax., Gro.), Centro y Sudamérica.

*A. tenerrimum Mett. ex Kuhn (=A. fournieri Kuhn ex E. Fourn.)

Hemicriptófito a epífito en troncos, termófilo; bosque tropical caducifolio y ripario tropical, entre 800 y 1000 m s.n.m.; Sultepec, Amatepec.

Material de referencia: D. Tejero-Diez 2653, 3021 (IZTA).

Distribución: México (Sin., Jal., Méx., Mich., Chis., Oax., Gro.), Centro a Sudamérica.

Especie probable de encontrar: A. resiliens Kunze. La colecta J. Rzedowski 189 NY (J. T. Mickel, com. pers. en 2001), procede del km 33 de la carretera vieja a Cuernavaca, D.F. a $7 \mathrm{~km}$ de la frontera con el Edo. de México y $1 \mathrm{~km}$. del edo. de Morelos en la Sierra de Zempoala-Huitzilac; de amplia distribución en México.

Blechnaceae

Blechnum falciforme (Liebm.) C. Chr.

Caméfito de hojas fasciculadas; bosque de Quercus-Pinus a 2040 m s.n.m.; Temascaltepec.

Material de referencia: G. B. Hinton 3470 (NY). (J. T. Mickel, com. pers. en 2002).

Distribución: México (Tams., Ver., Hgo., Méx., Pue., Chis., Oax., Gro.), Centro a Sudamérica. 
B. glandulosum Kaulf. ex Link

Hemicriptófito de hojas fasciculadas, mesófilo, higrófilo, ripícola; bosque mesófilo de montaña, de Quercus, mixto de Quercus-Juniperus con leguminosas y tropical caducifolio, entre 1800 y 2400 m s.n.m.; Jilotepec, Valle de Bravo, Ocuilan, Coatepec Harinas, Tenancingo, Tejupilco, Ixtapan de la Sal, Temascaltepec, Sultepec, Zacualpan.

Material de referencia: G. B. Hinton 35 (MEXU). I. Hernández 183 (ENCB). E. Matuda 27442, 31939 (MEXU). Martínez Cortés 6 (IZTA). Martínez González 7 (IZTA). J. T. Mickel 705 (ENCB). K. Roe y E. Roe 1855 (ENCB). J. Rzedowski 30867 (ENCB, MEXU). H. Sánchez-Mejorada 889 (MEXU). D. Tejero-Diez 2113, 2247 (IZTA).

Distribución: Sureste de E.U.A., México (Tams., S.L.P., Ver., Nay., Jal., Hgo., Qro., Pue., Méx., Mich., Mor., Chis., Oax., Gro.), Centro a Sudamérica, Antillas.

*B. schiedeanum (Schltdl. ex C. Presl) Hieron.

Caméfito, ripícola: bosque de Quercus con leguminosas y mesófilo de montaña, entre 1650 y 1750 m s.n.m.; Tejupilco.

Material de referencia: E. Matuda 30828 (MEXU). D. Tejero-Díez 2443, $3143 b$ (IZTA).

Distribución: México (Ver., Pue., Méx., Chis., Oax., Gro.).

B. stoloniferum (Mett. ex E. Fourn.) C. Chr. (=Lomaria blechnoides Bory)

Hemicriptófito estolonífero de hojas aproximadas, rupícola (fisurícola); bosque de Pinus-Quercus, de Abies y de Pinus, entre 2600 y 2900 m s.n.m.; Villa Nicolás Romero, Temascaltepec, Ocuilan.

Material de referencia: M. L. Arreguín 606 (ENCB). G. B. Hinton 3265 (ENCB), 7222 (ENCB, NY). D. Tejero-Diez 2973 (IZTA).

Distribución: México (Chih., Dgo., Ver., Hgo., Méx., Mor., Mich., Chis., Oax., Gro.), Guatemala.

*Woodwardia semicordata Mickel et Beitel

Hemicriptófito de hojas fasciculadas, mesófilo; bosque de Pinus-Quercus, a 2400 m s.n.m.; Villa del Carbón, Tenancingo.

Material de referencia: E. Matuda 26860 (MEXU). H. Sánchez-Mejorada 794 (MEXU). D. Tejero-Díez y alumnos s. n. 26/ene./1990 (IZTA).

Distribución: México (Ver., Hgo., Pue., Méx., Chis., Oax., Gro.). 
W. spinulosa M. Martens et Galeotti

Caméfito rizomatoso de hojas aproximadas, rupícola o en taludes de tierra, mesófilo, higrófilo; bosque de Pinus, mesófilo de montaña y de Abies principalmente y esporádicamente en ambiente ripario de clima cálido, entre 700 y 2550 m s.n.m.; Jilotepec, Villa Nicolás Romero, Isidro Fabela, Villa de Allende, Tlalmanalco, Temascaltepec, Amecameca, Tenango del Aire, Ocuilan, Villa Guerrero, Tejupilco.

Material de referencia: M. L. Arreguín 613 (ENCB). G. B. Hinton 1324, 4130 (MEXU). E. Lyonnet 231 (ENCB). E. Matuda 18814 (ENCB), 30764 (ENCB, MEXU). M. Martínez 13 (IZTA). G. McPherson 1049 (ENCB). J. J. Ochoa 5 (ENCB). A. Pineda s. n. 21/abril/1968 (ENCB). C. A. Purpus 1583 (ENCB). J. Rzedowski 19845, 22820, 25985, 27133 (ENCB). D. Tejero-Diez 2160, 2224, 2599 (IZTA).

Distribución: México (Son., Tams., Sin., Dgo., Ver., Nay., Jal., Hgo., Qro., Gto., Pue., Méx., Mich., D.F., Mor., Chis., Oax., Gro.).

Cyatheaceae

Alsophila firma (Baker) D. S. Conant (=Nephelea mexicana (Schltdl. et Cham.) R. M. Tryon; =Cyathea mexicana Schltdl. et Cham.)

Caméfito estipitoso, a 1800 m s.n.m.; Tejupilco.

Material de referencia: G. B. Hinton 3629 (US). (J. T. Mickel, com. pers. en 2001).

Distribución: México (S.L.P., Ver., Hgo., Qro., Pue., Méx., Chis., Oax., Gro.).

Davalliaceae

Nephrolepis cordifolia (L.) C. Presl

Caméfito a epífito (en Phoenix canarensis), de hojas fasciculadas; cultivado y escapado de cultivo en jardines y alrededores de poblados con clima cálido al suroeste del estado de México; Malinalco.

Material de referencia: D. Tejero-Díez 2213 (IZTA).

Distribución: Sureste de E.U.A., México (Ver., Pue., Méx., Mich., Chis., Oax.), Centro a Sudamérica, Antillas y trópicos del Viejo Mundo.

N. undulata (Afzel. ex Sw.) J. Sm. (=N. occidentalis Kunze)

Terófito a hemicriptófito rizomatoso, termófilo; bosque tropical subcaducifolio, mixto de Quercus-Juniperus con leguminosas y cultivos de frutales tropicales, entre 1350 y 1900 m s.n.m.; Sto. Tomás de los Plátanos, Malinalco, Tejupilco. 
Material de referencia: D. Tejero-Díez 2215, 2430, 2459, 2611 (IZTA). Distribución: México (Tams., Sin., Ver., Nay., Jal., Méx., Mich., Mor., Chis., Oax., Gro.), Centro y Sudamérica, Antillas.

DenNSTAedtiaceae

Dennstaedtia distenta (Kunze) T. Moore

Caméfito rizomatoso de hojas aproximadas, mesófilo, esciófilo, ripícola; bosque mesófilo de montaña, entre 1900 y 2200 m s.n.m.; Ocuilan, Tejupilco, Sultepec, Zacualpan.

Material de referencia: G. B. Hinton 3748 (MEXU). E. Matuda 30864 (CODAGEM). D. Tejero-Diez 2320, 2675, 3029 (IZTA).

Distribución: México (Son., Chih., Sin., Dgo., S.L.P., Ver., Hgo., Qro., Méx., Mich., Mor., Chis., Oax., Gro.), Centroamérica y Antillas.

Especie probable de encontrar: D. globulifera (Poir.) Hieron., que se distribuye en sitios húmedos entre 1000 y 1900 m s.n.m. con bosque tropical ripario, en los estados adyacentes de Michoacán, Guerrero y Morelos (del municipio de Cuernavaca, que tiene continuidad ambiental con la región de Ocuilan, procede la colecta E. Lyonnet 2801 MEXU).

*Pteridium arachnoideum (Kaulf.) Maxon

Geófito rizomatoso, termófilo, en sitios alterados por fuego; bosque de Quercus, a 1750 m s.n.m.; Tejupilco.

Material de referencia: D. Tejero-Díez 2441 (IZTA).

Distribución: México (Ver., Hgo., Pue., Méx., Gro., Oax. Chis.).

*P. caudatum (L.) Maxon

Geófito rizomatoso de hojas distantes, mesófilo; bosque abierto de QuercusPinus con elementos mesófilos en suelos lateríticos, a 2300 m s.n.m.; Temascaltepec.

Material de referencia: D. Tejero-Díez 2927 (IZTA).

Distribución: Sureste de E.U.A., México (B.C., Tams., Sin., N.L., Yuc., Ver., Nay., Jal., Cam., Q.R., Qro., Méx., Isla Socorro, Mich., Col., Chis., Oax., Gro.), Centroamérica, norte de Sudamérica, Antillas.

P. feei (W. Schaffn. ex Fée) Faull

Geófito rizomatoso, mesófilo, en sitios alterados por tala o agricultura; bosque de Quercus, de Pinus, de Pinus-Quercus, mesófilo de montaña y de Quercus- 
Abies, entre 1800 y 2800 m s.n.m.; Tepotzotlán, Villa del Carbón, Villa Nicolás Romero, Villa de Allende, Amanalco, Temascaltepec, Valle de Bravo, Amecameca, Ocuilan, Tenancingo, Tejupilco, Sultepec.

Material de referencia: M. L. Arreguín 476, 611 (ENCB). H. R. Buelna 90 (ENCB). I. Chávez 9 y M. Castilla (IZTA). J. Díaz 155 (ENCB). A. Gaytán 92 y D. Tejero-Diez (IZTA). Herrera Arenas 10 (IZTA). H. Iltis y J. Dobley 216 (ENCB). F. Martínez 70 (ENCB). E. Matuda 27369, 30083, 30861, 30497 (CODAGEM). J. T. Mickel 673 (MEXU). J. Rzedowski 31288 (ENCB). D. Tejero-Diez 2249 (IZTA).

Distribución: México (Dgo., S.L.P., Ver., Nay., Jal., Hgo., Qro., Gto., Pue., Méx., Mich., Mor., Chis., Oax., Gro.), Centroamérica.

DRYOPTERIDACEAE

Dryopteris cinnamomea (Cav.) C. Chr.

Hemicriptófito de hojas fasciculadas, rupícola o terrestre, mesófilo, esciófilo; bosque de Quercus preferentemente y en menor medida en matorral xerófilo, bosque de Pinus, de Quercus-Pinus y mesófilo de montaña, entre 2100 y 2600 m s.n.m.; Aculco, Jilotepec, Soyaniquilpan, Acambay, Zumpango, Tepotzotlán, Villa del Carbón, Jocotitlán, Otumba, Atizapán, Villa Victoria, Amecameca, Texcalyacac, Ocuilan, Ixtapan de la Sal, Sultepec.

Material de referencia: A. Arredondo 48 (ENCB). M. L. Arreguín 676 (ENCB). R. Cruz Cisneros 1097 (ENCB). L. Cruz Palacios 1, 48, 51, 69, 110, (IZTA). G. García 25 y L. Abundiz-Bonilla (IZTA). L. V. González 124, 140, 158, 182, 206, 249, 273 (IZTA). E. Matuda 26466 (CODAGEM, MEXU). E. Matuda 27022 (MEXU). Née s. n. (MA tipo). C. Rojas y S. Romero 633 (IZTA). J. Rzedowski 28605, 29907, 37828 (ENCB). D. Tejero-Díez y M. Castilla 1453 (IZTA). D. Tejero-Diez 2197, 2777, 3002 (IZTA).

Distribución: Suroeste de E.U.A., México (Son., Chih., Dgo., Zac., S.L.P., Ver., Ags., Jal., Hgo., Qro., Gto., Pue., Méx., Mich., Tlax., D.F., Mor., Chis., Oax., Gro.).

\section{D. karwinskyana (Mett.) Kuntze}

Hemicriptófito de hojas fasciculadas, termófilo; bosque tropical caducifolio, tropical subcaducifolio y mixto de Quercus-Juniperus con leguminosas, entre 800 y 1300 m s.n.m.; Tejupilco, Sultepec.

Material de referencia: L. Cruz Palacios 131, 132 (IZTA). G. B. Hinton 1818 (MEXU). Karwinski s. n. (B, Holotipo). E. Matuda y col. 31464 (CODAGEM, MEXU). D. Tejero-Díez 2413, 3022 (IZTA). 
Distribución: México (Sin., Dgo., Nay., Jal., Méx., Mich., Chis., Oax., Gro.), Guatemala a Costa Rica.

\section{D. maxonii Underw. et C. Chr.}

Hemicriptófito de hojas fasciculadas, mesófilo, esciófilo; bosque mesófilo de montaña y mixto de Quercus-Juniperus con leguminosas principalmente y en menor medida en bosque tropical ripario y tropical subcaducifolio, entre 1000 y 2350 m s.n.m.; Temascaltepec, Zacazonapan, Ocuilan, Malinalco, Tenancingo, Tejupilco, Ixtapan de la Sal, Zacualpan, Amatepec.

Material de referencia: L. Cruz Palacios 26, 31, 91, 137, 143, (IZTA). G. B. Hinton 2571 (MEXU). E. Matuda 27026, 29541 (CODAGEM, ENCB). J. Rzedowski y K. Roe 1756 (ENCB). D. Tejero-Diez 2005, 2105, 2216, 2846, 2953, 3019 (IZTA). Zúñiga 172 (ENCB).

Distribución: México (Sin., Nay., Jal., Mich., Méx., Mor., Gro.), Guatemala a Costa Rica.

*D. nubigena Maxon et C. V. Morton.

Hemicriptófito de hojas fasciculadas, entre 2150 y 2500 m s.n.m.; Temascaltepec, Texcaltitlán.

Material de referencia: G. B. Hinton 3447 (K, NY), 3469 (BM, K, US). (J. T. Mickel y A. R. Smith, com. pers. en 2003).

Distribución: México (Méx., Chis., Oax.), Guatemala.

D. patula (Sw.) Underw.

Hemicriptófito rupícola o terrestre, epífito en base de troncos, mesófilo; bosque de Quercus y mesófilo de montaña a 2300 m s.n.m.; Ocuilan.

Material de referencia: D. Tejero-Díez 2197, 2198 (IZTA).

Distribución: México (Ver., Jal., Hgo., Gto., Pue., Méx., Mich., D.F., Col., Mor., Chis., Oax., Gro.), Centro y Sudamérica, Antillas Mayores.

D. pseudofilix-mas (Fée) Rothm.

Caméfito mesófilo, higrófilo; bosque mesófilo de montaña, de Pinus, de PinusAbies y de Abies, entre 2200 y 3000 m s.n.m.; Villa Nicolás Romero, Villa Victoria, Villa de Allende, Ocoyoacac, Zinacantepec, Tlalmanalco, Temascaltepec, Amecameca, Texcalyacac, Ocuilan.

Material de referencia: M. L. Arreguín 672 (ENCB). G. Calderón 105-V (ENCB). Cardoso 1438 (MEXU). L. Cruz Palacios 118 (IZTA). H. Gómez 114 
(ENCB). P. Huerta s. n. 13/nov./1975 (ENCB). A. Márquez 9 (ENCB). J. Rzedowski 34651 (ENCB). D. Tejero-Diez 2712, 2934, 2949, 3001, 3157 (IZTA). M. A. Ventura 155 (ENCB).

Distribución: México (N.L., Coah., Hgo., Qro., Pue., Méx., Mich., D.F., Mor., Pue., Oax.), Guatemala.

D. rosea (E. Fourn.) Mickel et Beitel

Hemicriptófito rupícola de hojas fasciculadas, mesófilo; bosque mesófilo de montaña, entre 2150 y 2200 m s.n.m.; Ocuilan.

Material de referencia: L. Cruz Palacios 123 (IZTA).

Distribución: México (Ver., Jal., Pue., Méx., Mich., Mor., Chis., Oax., Gro.).

D. rossii C. Chr.

Hemicriptófito cortamente rizomatoso de hojas aproximadas, mesófilo, esciófilo; bosque de Pinus-Quercus, mesófilo de montaña, de Quercus-Pinus principalmente y en menor medida en bosque mixto de Quercus-Juniperus con leguminosas, entre 1750 y 2400 m s.n.m.; Amanalco, Temascaltepec, Valle de Bravo, Ocuilan, Malinalco, Tenancingo, Villa Guerrero, Coatepec Harinas, Tejupilco, Zacualpan, Sultepec.

Material de referencia: L. Cruz Palacios 6, 21, 22, 86, 99, 122, 129, 133, 135, 136, 139, 145 (IZTA). E. Guizar 622 (CHAPA, ENCB). G. B. Hinton 4545 (MEXU). E. Matuda 27208 (CODAGEM), 27753 (CODAGEM, MEXU). J. T. Mickel 668 (CODAGEM, MEXU). J. Rzedowski 30788 (MEXU). H. SánchezMejorada 818 (CHAPA, ENCB, MEXU). D. Tejero-Díez 2091, 2111, 2118, 2147, 2424, 2440, 2448 (IZTA).

Distribución: México (B.C., Chih., Son., Dgo., Sin., Zac., Nay., Jal., Hgo., Qro., Gto., Méx., Mich., D.F., Mor., Pue., Oax., Gro.).

D. wallichiana (Spreng.) Hyl. (=D. paleacea (Sw.) Hand.-Mazz. $=D$. parallelogramma (Kunze) Alston)

Caméfito estipitiforme, mesófilo, higrófilo; bosque de Abies en cañada principalmente y en menor medida en bosque de Pinus, de Quercus y mesófilo de montaña, entre 1900 y 3200 m s.n.m.; Tepotzotlán, Villa Nicolás Romero, Jilotzingo, Toluca, Villa Victoria, Villa de Allende, Tlalmanalco, Amecameca, Tenango del Aire, Atlautla, Temascaltepec, Valle de Bravo, Ocuilan, Coatepec Harinas, Zacualpan. 
Material de referencia: L. Abundiz-Bonilla 3 (IZTA). M. T. Alvarado 15/ dic./78 (ENCB). M. L. Arreguín 672 (ENCB). L. Cruz Palacios 16, 109, 121, 126, 140, 153 (IZTA). J. Díaz 278 (ENCB, MEXU). M. González 8 (ENCB). Hernández Montalvo 28 (IZTA). G. B. Hinton 3555, 6846 (MEXU). E. Lyonnet 1418, 2021, 2492 (MEXU). E. Molseed 544 (MEXU). C. Pacheco y Salazar Ruiz 17 (IZTA). A. Piña 65 (ENCB). R. Ramírez 41 (ENCB). F. Ramos $3 T$ (ENCB). D. Tejero-Diez 2223, 2237, 2376 (IZTA).

Distribución: México (Chih., Tams., Ver., Jal., Hgo., Qro., Gto., Pue., Méx., Mich., Tlax., D.F., Mor., Chis., Oax., Gro.), Centro y Sudamérica, Antillas, África, Asia.

*Phanerophlebia macrosora (Baker) Underw.

Caméfito caudiciforme de hojas fasciculadas, esciófilo; bosque mesófilo de montaña, a 2100 m s.n.m.; Ocuilan.

Material de referencia: D. Tejero-Díez 2255 (IZTA).

Distribución: México (Jal., Hgo., Méx., Chis., Oax., Gro.), Centroamérica.

P. nobilis (Schltdl. et Cham.) C. Presl var. nobilis

Caméfito con rizomas, hojas fasciculadas, mesófilo; bosque de Pinus, mesófilo de montaña y de Abies, entre 2200 y 2600 m s.n.m.; Jilotepec, Aculco, Tepotzotlán, Jilotzingo, Texcoco, Villa de Allende, Tlalmanalco, Amecameca, Tenancingo, Ocuilan.

Material de referencia: M. L. Arreguín 435 (ENCB). J. Díaz 276 (MEXU). L. Doval 155 (ENCB). F. García 4 (ENCB). S. D. Koch 7670 (ENCB). E. Matuda 28263, 30948 (CODAGEM, ENCB, MEXU). J. Rzedowski 31639, 34234 (ENCB). D. Tejero-Díez 2368, 2688, 2745, 2763, 2804 (IZTA). R. Vidal 3 (IZTA).

Distribución: México (S.L.P., Ver., Jal., Hgo., Qro., Pue., Méx., Mich., Tlax., D.F., Mor., Oax., Gro.).

P. nobilis var. remotispora (E. Fourn.) Yatsk.

Caméfito de hojas fasciculadas, mesófilo; bosque de Pinus-Quercus, a 2700 m s.n.m.; Temascaltepec.

Material de referencia: G. B. Hinton 1335 y 3544 (US). Guillemin s. $n$. (NY). (J. T. Mickel, com. pers. en 2001).

Distribución: México (S.L.P., Ver., Hgo., Qro., Pue., Méx., Mich., Chis., Oax.), Guatemala. 
Plecosorus speciosissimus (A. Braun ex Kunze) T. Moore (=Polystichum speciosissimum (A. Braun ex Kunze) Copel.).

Caméfito caudiciforme, fotófilo, cerca de arroyos; pastizal inducido y bosque de Abies y de Pinus hatwegii, entre 2700 y 3700 m s.n.m.; Jilotzingo, Isidro Fabela, Texcoco, Naucalpan, Ixtapaluca, Ocoyoacac, Toluca, Chalco, Tlalmanalco, Amecameca, Tenango del Aire, Ocuilan.

Material de referencia: G. Calderón 101-V (ENCB). J. Castañeda 988 y D. Tejero-Diez (IZTA). Clausen 6024 y Cervantes (MEXU). A. G. Hernández 117 (ENCB). C. López 34 (ENCB). E. Lyonnet 3191 (IZTA), 1534 (MEXU). Monroy 38 (ENCB). Pantoja s. n. 27/ago./1975 (MEXU). J. Rzedowski 18421, 19107, 25398, 30169, 31646 (ENCB). F. Solares 201 (ENCB). D. Tejero-Diez 2028 (IZTA). T. Wendt y T. Atkinson 3433 (ENCB).

Distribución: México (S.L.P., Ver., Jal., Qro., Gto., Pue., Méx., D.F., Mich., Mor., Chis., Oax., Gro.), Centroamérica.

\section{Polystichum drepanoides E. Fourn.}

Hemicriptófito de hojas fasciculadas, en cárcavas de avenidas en laderas; bosque de Pinus-Abies, a 3000 m s.n.m.; Temascaltepec.

Material de referencia: Dunn y Dunn 18963 (NY). (J. T. Mickel, com. pers. en 2001).

Distribución: México (Méx., Mich., Chis., Gro.), Centroamérica.

\section{*P. fournieri A. R. Sm.}

Hemicriptófito de hojas fasciculadas, ripícola; bosque de Abies principalmente y en menor medida en bosque mesófilo de montaña, entre 2200 y 2900 m s.n.m.; Villa Victoria, Tlalmanalco, Amecameca, Ocuilan.

Material de referencia: S. Becerra 30 (ENCB). M. M. Cruz 28 (ENCB). D. Tejero-Diez 2227, 2941 (IZTA).

Distribución: México (S.L.P., Méx., Mor., Chis., Oax., Gro.), Centroamérica.

*P. hartwegii (Klotzsch) Hieron. (=P. distans E. Fourn.)

Caméfito a hemicriptófito de hojas fasciculadas, esciófilo, frecuente de encontrar en cárcavas y cañadas; bosque de Quercus, mesófilo de montaña, de Quercus-Pinus y de Pinus-Abies, entre 2100 y 2800 m s.n.m.; Villa Nicolás Romero, Jilotzingo, Texcoco, Tlalmanalco, Valle de Bravo, Tenango del Aire, Ocuilan, Sultepec, Zacualpan.

Material de referencia: M. L. Arreguín 526 (ENCB). R. Cruz 121 (ENCB). A. Hernández 17 (IZTA). Moral Díaz 11 (IZTA). H. R. Pelayo 44 (ENCB). A. 
Pineda 709 (ENCB). R. Ramos 2 T (ENCB). J. Rzedowski 28811, 30905 (ENCB, MEXU) 30385 (ENCB, IEB, NY). D. Tejero-Diez 2231, 2321, 2374, 2515, 2553, 2693 (IZTA). L. Zelaya y L. Pacheco 37 (ENCB).

Distribución: México (S.L.P., Ver., Jal., Hgo., Qro., Pue., Méx., Mich., Mor., Chis., Oax., Gro.), Centroamérica.

\section{P. rachichlaena Fée}

Hemicriptófito en sitios abiertos cerca de arroyos; bosque mesófilo de montaña, de Pinus y de Abies-Pinus, entre 2500 y 3200 m s.n.m.; Atlautla, Villa Victoria, Amecameca, Ocuilan.

Material de referencia: L. Cruz Palacios 149 (IZTA). E. Matuda 28079 (ENCB). J. G. Schaffner 290 (K isotipo probable fide Mickel, 1992). D. TejeroDíez 2940, 3012 (IZTA).

Distribución: México (Jal., Méx., D.F., Chis., Oax.), Centroamérica.

P. turrialbae H. Christ (=P. smithii Mickel et Beitel)

Hemicriptófito de hojas fasciculadas, esciófilo, ripícola; bosque de Abies y de Pinus-Quercus, entre 2800 y 3200 m s.n.m.; Ocoyoacac, Zinacantepec, Ocuilan. Material de referencia: R. Cisneros 59 y D. Tejero-Díez (IZTA). L. Cruz Palacios 149 (IZTA). J. G. Schaffner 86 (NY). D. Tejero-Diez 2374, 2704 (IZTA).

Distribución: México (Méx., D.F., Chis., Oax.), Centroamérica.

\section{GLeicheniaceAe}

Dicranopteris pectinata (Willd.) Underw.

Geófito rizomatoso de hojas distantes, volubles, maleza ruderal en ambiente semicálido húmedo; bosque de Quercus-Pinus, entre 1500 y 1700 m s.n.m.; Tejupilco.

Material de referencia: G. B. Hinton 7543 (MEXU). D. Tejero-Díez 3146, 3170 (IZTA).

Distribución: México (Ver., Hgo., Pue., Méx., Chis., Oax., Gro.), Centro y Sudamérica, Antillas.

*Sticherus bifidus (Willd.) Ching

Geófito rizomatoso de hojas distantes, volubles, maleza ruderal en ambiente semicálido húmedo; bosque de Quercus-Pinus a 1650 m s.n.m.; Tejupilco.

Material de referencia: D. Tejero-Díez 3171 (IZTA). 
Distribución: México (Ver., Jal., Pue., Méx., Chis., Oax., Gro.), Centro a Sudamérica, Antillas.

Especie probable de encontrar: Sticherus palmatus (J. H. Schaffn. ex Underw.) Copel.; Mickel y Beitel (1988) la citan para el D.F., Morelos y Guerrero.

GRAMMITIDACEAE

Melpomene moniliformis (Lag. ex Sw.) A. R. Sm. et R. C. Moran (=Grammitis moniliformis (Lag. ex Sw.) Proctor)

Hemicriptófito rizomatoso de hojas distantes, rupícola o sobre taludes de tierra; bosque de Abies-Pinus, a 3000 m s.n.m.; Sierra Zempoala (entre los municipios de Huitzilac, Mor. y Ocuilan, Méx.).

Material de referencia: Y. Sandoval 131 (UAMIZ).

Distribución: México (Jal., Méx., Mich., Mor., Chis., Oax., Gro.), Centro a Sudamérica, Antillas.

M. pilosissima (M. Martens et Galeotti) A. R. Sm. et R. C. Moran (=Grammitis pilosissima (M. Martens et Galeotti) C. V. Morton)

Epífito rizomatoso de hojas distantes; bosque de Abies-Pinus y pastizal alpino, entre 2800 y 4000 m s.n.m.; Texcoco, Ocoyoacac, Tlalmanalco.

Material de referencia: M. L. Arreguín 666 (ENCB). E. Lyonnet 1378 (ENCB, MEXU), 1480 (ENCB). J. Rzedowski 23487 (ENCB). T. Wendt y T. Atkinson 3948 (ENCB).

Distribución: México (Ver., Jal., Méx., D.F., Mich., Chis., Oax., Gro.), Centroamérica.

Terpsichore spathulata A. R. Sm.

Hemicriptófito rupícola de hojas aproximadas péndulas; bosque de AbiesPinus con elementos mesófilos y pastizal alpino, cerca de cañadas con arroyos, entre 2850 y 4100 m s.n.m.; Ocoyoacac, Tlalmanalco, Coatepec Harinas.

Material de referencia: J. H. Beaman 2817 (ENCB). E. Lyonnet 1479 (ENCB). J. Rzedowski 23465 (ENCB). D. Tejero-Díez 2972 (IZTA).

Distribución: México (Ver., Jal., Pue., Méx., Mich., D.F., Chis., Oax.), Guatemala. 


\section{HyMENOPHYLLACEAE}

\section{Hymenophyllum trapezoidale Liebm.}

Hemicriptófito a caméfito rizomatoso de hojas distantes, rupícola en taludes, higrófilo; bosque mesófilo de montaña y de Abies-Pinus, entre 2100 y 2850 m s.n.m.; Temascaltepec, Ocuilan, Coatepec Harinas.

Material de referencia: E. González 3 (IZTA). G. B. Hinton 3268 (MEXU, NY). E. Lyonnet 2858 (IZTA, MEXU). D. Tejero-Diez 2733, 2975 (IZTA, UAMIZ).

Distribución: México (Ver., Pue., Méx., Mor., Chis., Oax., Gro.), Centro a Sudamérica.

\section{Trichomanes capillaceum L.}

Hemicriptófito a caméfito rizomatoso de hojas distantes, rupícola en taludes, higrófilo; bosque mesófilo de montaña, a 2100 m s.n.m.; Ocuilan.

Material de referencia: E. Lyonnet 2859 (IZTA, MEXU) y 2860 (MEXU). D. Tejero-Diez 2899 (IZTA, UAMIZ).

Distribución: México (Ver., Hgo., Pue., Méx., Mor., Tab., Chis., Oax., Gro.), Centro a Sudamérica (Venezuela y Ecuador), Antillas.

\section{*T. hymenophylloides Bosch}

Hemicriptófito a caméfito rizomatoso de hojas distantes, rupícola en taludes, higrófilo; bosque mesófilo de montaña, a 2100 m s.n.m.; Ocuilan.

Material de referencia: E. Lyonnet 2862 (IZTA, MEXU). D. Tejero-Díez 2256 (IZTA, UAMIZ).

Distribución: México (Ver., Méx., Mor., Chis., Oax.), Centro a Sudamérica, Antillas.

\section{*T. radicans Sw.}

Hemicriptófito a caméfito rizomatoso de hojas distantes, rupícola en taludes y base de peñas, higrófilo; bosque mesófilo de montaña y de Abies-Pinus, entre 2100 y 2850 m s.n.m.; Ocuilan, Coatepec Harinas.

Material de referencia: D. Tejero-Díez 2741, 2966 (IZTA, UAMIZ).

Distribución: México (Chih., S.L.P., Ver., Jal., Hgo., Qro., Pue., Méx., Mich., Mor., Chis., Oax., Gro.), Centro y Sudamérica, Antillas, Viejo Mundo. 
Elaphoglossum affine (M. Martens et Galeotti) T. Moore

Caméfito a hemicriptófito rizomatoso de hojas distantes, esciófilo, rupícola; bosque de Abies cerca de cañadas, entre 2800 y 3200 m s.n.m.; Zinacantepec, Tlalmanalco, Amecameca, Ocuilan, Coatepec Harinas.

Material de referencia: M. L. Arreguín 675 (ENCB). J. Rzedowski 19187, 21600, 21862 (ENCB). D. Tejero-Díez 2710, 2962, 2974 (IZTA).

Distribución: México (Ver., Méx., Mich., D.F., Mor., Chis., Oax., Gro.), Guatemala.

\section{*E. dissitifrons Mickel}

Epífito a hemicriptófito largamente rizomatoso, de hojas moderadamente distantes, mesófilo; bosque de Pinus-Quercus, a 2500 m s.n.m.; Temascaltepec, Sultepec.

Material de referencia: G. B. Hinton 3455 (NY). E. Matuda 38095 (CODAGEM, MEXU, US).

Distribución: México (Hgo., Méx., Oax., Gro.).

E. engelii (H. Kars.) H. Christ

Hemicriptófito rizomatoso de hojas aproximadas, rupícola, mesófilo, fotófilo; bosque de Abies, entre 2800 a 3100 m s.n.m.; Tlalmanalco, Amecameca, Ocuilan, Huitzilac, Coatepec Harinas.

Material de referencia: E. Lyonnet 1313 (ENCB), 1413 (ENCB, FCME, UAMIZ), 2024 (ENCB, MEXU), 2467 (MEXU). J. Rzedowski 23279 (ENCB, NY). D. Tejero-Díez 2971, 4108 (IZTA).

Distribución: México (Méx., Mor., Chis.), Centro a Sudamérica, La Española.

E. erinaceum (Fée) T. Moore

Hemicriptófito rizomatoso en taludes y cárcavas, esciófilo; bosque de Pinus y mesófilo de montaña, entre 1900 y 2300 m s.n.m.; Ocoyoacac, Temascaltepec, Amecameca, Ocuilan, Villa Guerrero, Tenancingo, Sultepec, Zacualpan.

Material de referencia: M. Cisneros 54 y D. Tejero-Diez (IZTA). G. B. Hinton 1867 (MEXU). E. Matuda 18795 (MEXU). J. T. Mickel 706 (ENCB, NY). T. Mojica 8 (IZTA). S. Pérez Herrera 32 y D. Tejero-Díez (IZTA). D. Tejero-Díez 2157, 2512, 2737, 2877 (IZTA).

Distribución: México (Sin., Ver., Jal., Qro., Pue., Méx., Mich., Mor., Chis., Oax., Gro.), Centro y Sudamérica (hasta Bolivia y Brasil), Antillas. 


\section{E. glaucum T. Moore}

Epífito de hojas aproximadas; bosque de Pinus-Quercus y mesófilo de montaña, entre 2200 y 2650 m s.n.m.; Temascaltepec, Ocuilan, Coatepec Harinas.

Material de referencia: G. B. Hinton 8997 (ENCB). E. Lyonnet 2024 (ENCB). D. Tejero-Diez 2225, 2683, 2730, 2978 (IZTA).

Distribución: México (Ver., Nay., Jal., Qro., Méx., Mich., Mor., Chis., Oax., Gro.), Guatemala.

\section{E. gratum (Fée) T. Moore}

Hemicriptófito en taludes a caméfito rupícola, mesófilo, esciófilo; bosque mixto de Quercus-Juniperus con leguminosas, mesófilo de montaña y de Pinus, entre 1900 y 2600 m s.n.m.; Villa Nicolás Romero, Isidro Fabela, Villa de Allende, Ocoyoacac, Amanalco, Tlalmanalco, Amecameca, Temascaltepec, Atlautla, Ocuilan, Joquicingo, Texcaltitlán.

Material de referencia: M. L. Arreguín 485 (ENCB). T. Camarillo 3 (IZTA). R. M. Cisneros 53 (IZTA). A. González y M. Miranda 185 (IZTA). G. B. Hinton 1966 (US). E. Lyonnet 1425, 1449, 2467 (MEXU). J. Rzedowski 19441, 21858, 21982, 28053, 34645 (ENCB). H. Sánchez-Mejorada 827 (MEXU). J. G. Schaffner 279, $332 b$ (RB sintipo). D. Tejero-Diez 2236, 2242, 3158 (IZTA).

Distribución: México (Dgo., Ver., Jal., Hgo., Méx., Mich., D.F., Mor., Oax., Gro.), Guatemala.

\section{E. hartwegii (Fée) T. Moore}

Hemicriptófito en taludes de tierra o rocas ígneas; bosque de Quercus-Pinus, de Pinus y de Abies principalmente y en menor medida en bosque mesófilo de montaña, entre 2270 y 4100 m s.n.m.; Aculco, Villa de Allende, Ixtapaluca, Amanalco, Tlalmanalco, Amecameca, Ocuilan.

Material de referencia: J. Beaman 2023 (MEXU, US). J. García 1436 (CHAPA). S. D. Koch 76327 (CHAPA, ENCB). E. Matuda 27573, 27597 (MEXU, US). C. Purpus 175, 1586, 1588, 3819 (US). J. Rzedowski 25692 (ENCB). R. Vega 37, 587 (CHAPA, ENCB).

Distribución: México (Ver., Jal., Mich., Méx., Chis.), Centro a Sudamérica.

\section{*E. lindenii (Bory ex Fée) T. Moore}

Caméfito rupícola en peñascos, mesófilo, esciófilo, en cañadas; bosque de Pinus-Quercus y de Abies con elementos mesófilos, entre 2550 y 3100 m s.n.m.; Huixquilucan, Amecameca, Ocuilan, Zinacantepec. 
Material de referencia: M. L. Arreguín 653 (ENCB). J. Rzedowski 35592 (ENCB). D. Tejero-Díez 2243, 2706 (IZTA).

Distribución: México (Ver., Jal., Méx., Mich., Oax.), Centro a Sudamérica.

E. monicae Mickel

Hemicriptófito rizomatoso en taludes de tierra y rocas ígneas, mesófilo; bosque de Abies, entre 2600 y 3200 m s.n.m.; Villa Nicolás Romero, Tlalmanalco, Temascaltepec, Amecameca, Ocuilan, Coatepec Harinas, Texcaltitlán, Tejupilco.

Material de referencia: L. Ayala 3 y D. Tejero-Diez (IZTA). G. B. Hinton 7221, 8934 (NY, US). E. Lyonnet 1407, 2465 (MEXU, US). E. Matuda 28139 (CODAGEM, US). J. Rzedowski 26695 (ENCB isotipo!), 33760, 34628, 34687 (UAMIZ), 36626 (ENCB). D. Tejero-Diez 2304, 2961, 2976 (IZTA).

Distribución: México (Sin., Dgo., Ver., Jal., Méx., D.F., Mor., Gro.).

E. muelleri (E. Fourn.) C. Chr. (=E. araneosum (D.C. Eaton) C. Chr.; E. venustum (Fée) T. Moore)

Hemicriptófito de hojas fasciculadas en taludes ruderales húmedos o rupícolas en rocas ígneas, mesófilo; bosque ripario tropical y templado, de Quercus, de Quercus-Pinus, de Pinus-Quercus y mesófilo de montaña, entre 1100 y $3150 \mathrm{~m}$ s.n.m.; Jilotepec, Aculco, Villa del Carbón, Villa Nicolás Romero, Isidro Fabela, Texcoco, Villa de Allende, Amanalco, Jilotzingo, Naucalpan, Huixquilucan, Temascaltepec, Valle de Bravo, Amecameca, Texcalyacac, Ocuilan, Villa Guerrero, Coatepec Harinas, Tenancingo, Tejupilco, Sultepec, Zacualpan.

Material de referencia: L. Aguilar $27 a$ y D. Tejero-Diez (IZTA). Barkley et al. 7345 (MEXU). A. González y M. Miranda 38 (IZTA). F. González s. $n$. 2/oct./1985 (IZTA). G. B. Hinton 11 (ENCB), 1811, 8241 (US), 3445 (ENCB). E. Matuda 27228 (CODAGEM, MEXU), 27734 (CODAGEM). L. Mosqueda 15 y D. Tejero-Diez (IZTA). Quezada Batalla 1 (IZTA). J. Rzedowski 18732, 24065, 24310, 26741, 30253 (ENCB), 31628, 32262 (UAMIZ). H. SánchezMejorada 246, 802 (MEXU). D. Tejero-Diez 2050, 2054, 2148, 2228, 2272, $2311,2437,2511,2530,2551,2739,2896,2914,2917,2951,2992,3010$, 3110 (IZTA).

Distribución: México (N.L., Tams., Sin., Ver., Nay., Jal., Hgo., Gto., Pue., Méx., Mich., Col., Chis., Oax., Gro.), Centro a Sudamérica.

\section{E. nanchititlense Matuda}

Hemicriptófito rizomatoso de hojas aproximadas, en taludes de tierra ruderales y cárcavas; bosque mixto de Quercus-Pinus y leguminosas, de Quercus-Pinus y 
ripario con Matudaea, Alnus, Quercus y Garrya, entre 1700 y 1800 m s.n.m.; Temascaltepec, Tejupilco.

Material de referencia: E. Matuda 31589 (MEXU! tipo, CODAGEM!, US isotipos). K. Roe y E. Roe 1554 (ENCB). J. Rzedowski 20702 (ENCB). D. TejeroDiez 2442, 2916 (IZTA).

Distribución: México (Dgo., Jal., Pue., Méx.).

E. paleaceum (Hook. et Grev.) Sledge

Epífito; bosque mesófilo de montaña, a 2250 m s.n.m.; Ocuilan.

Material de referencia: D. Tejero-Díez 2701 (IZTA).

Distribución: México (Ver., Jal., Qro., Méx., Mich., Chis., Oax., Gro.), Centro a Sudamérica, Grandes Antillas, Azores, Madeira.

E. petiolatum (Sw.) Urb.

Epífito a hemicriptófito rizomatoso de hojas aproximadas, rupícola; bosque de Pinus-Quercus, a 2600 m s.n.m.; Amecameca.

Material de referencia: J. Rzedowski 26741 (NY). (J. T. Mickel, com. pers. en 2001).

Distribución: México (Sin., Dgo., S.L.P., Ver., Jal., Hgo., Qro., Gto., Pue., Méx., D.F., Mich., Col., Mor., Chis., Oax., Gro.), Centro a Sudamérica, Antillas.

E. piloselloides (C. Presl) T. Moore

Hemicriptófito de hojas aproximadas, sobre taludes de roca ígnea o tierra; bosque mesófilo de montaña, entre 2100 y 2400 m s.n.m.; Ocuilan, Villa Guerrero, Tejupilco, Sultepec, Zacualpan.

Material de referencia: G. B. Hinton 8205 (US). E. Matuda 26599 (CODAGEM, MEXU). J. M. Medina 9 (IZTA). D. Tejero-Díez 2158, 2191, 2897 (IZTA).

Distribución: México (Sin., Dgo., Ver., Nay., Jal., Hgo., Méx., Mich., Chis., Oax., Gro.), Centro a Sudamérica, Antillas.

\section{*E. pilosius Mickel}

Hemicriptófito de hojas fasciculadas, en taludes; bosque de Abies, a $3100 \mathrm{~m}$ s.n.m.; Amecameca.

Material de referencia: J. Rzedowski 21861 (ENCB). (Ejemplar no localizado recientemente en ENCB).

Distribución: México (Méx.), Costa Rica, Panamá, Sudamérica. 
E. rufescens (Liebm.) T. Moore (=E. laxipes Mickel)

Caméfito en rocas o hemicriptófito en taludes de tierra; bosque de Pinus y de Pinus-Abies con elementos mesófilos en cañadas, entre 2600 y 3150 m s.n.m.; Texcoco, Zinacantepec, Tlalmanalco, Temascaltepec, Amecameca, Ocuilan, Coatepec Harinas.

Material de referencia: R. Cruz s. n. 28/feb./1965 (ENCB). E. Lyonnet 2029 (US). G. B. Hinton 2750 (NY holotipo de E. laxipes, MO, S, US, isotipos de $E$. laxipes fide Mickel, 1992). Koch 76335 (CHAPA). E. Matuda 18794 (MEXU, US). J. Rzedowski 21599, 21855 (ENCB), 23280 (ENCB, NY), 33965a, 36041, 36089 (UAMIZ). D. Tejero-Díez 2676, 2709 (IZTA).

Distribución: México (Jal., Pue., Méx., D.F.).

E. sartorii (Liebm.) Mickel

Hemicriptófito rizomatoso en taludes de tierra, esciófilo; bosque ripario semicálido y de Pinus-Quercus, entre 1700 y 2500 m s.n.m.; Tejupilco, Sultepec.

Material de referencia: D. Tejero-Díez 2924, 3115 (IZTA).

Distribución: México (Ver., Nay., Jal., Hgo., Pue., Méx., Mor., Chis., Oax., Gro.), Centro a Sudamérica.

\section{*E. squarrosum (Klotzsch) T. Moore}

Hemicriptófito largamente rizomatoso de hojas distantes, en taludes ruderales húmedos; bosque mesófilo de montaña, 2100 m s.n.m.; Ocuilan.

Material de referencia: D. Tejero-Diez 3096 (IZTA).

Distribución: México (Méx., Chis., Oax.).

E. tenuifolium (Liebm.) T. Moore

Hemicriptófito rizomatoso sobre taludes de tierra o caméfito en rocas ígneas; bosque de Quercus, de Pinus-Quercus y de Abies-Pinus con elementos mesófilos, entre 1750 y 2800 m s.n.m.; Temascaltepec, Amecameca, Ocuilan, Coatepec Harinas.

Material de referencia: G. B. Hinton 2830 (US). E. Lyonnet 1406 (MEXU). A. Magaña y N. Pozos s. n. 16/ene./1986 (IZTA). E. Matuda 18815 (US). J. Rzedowski 34656 (CHAPA, UAMIZ). D. Tejero-Diez 2969, 3011 (IZTA).

Distribución: México (Dgo., Ver., Jal., Hgo., Méx., Mich., D.F., Mor., Chis., Oax., Gro.), Guatemala.

Especie probable de encontrar: E. pallidum Baker ex Jenman; del mpio. de Huizilac (Mor.), procede la colecta E. Lyonnet 1359 (MEXU), que tiene continuidad ambiental con la región de Ocuilan. 
MARSILEACEAE

Marsilea mollis B. L. Rob. et Fernald

Hemicriptófito rizomatoso palúdico a hidrófito estolonífero de hoja flotante; canales de riego, charcos ruderales, pozas y cuerpos de agua naturales rodeados de pastos, entre 2000 y 2650 m s.n.m.; Jilotepec, Zumpango, Huehuetoca, Tepotzotlán, Jocotitlán, Villa Victoria, Capulhuac, Almoloya del Río, Tianguistengo.

Material de referencia: M. L. Arreguín 589, 596 (ENCB). R. Cruz 609 (ENCB). J. García 987 (CHAPA, NY). L. González Quintero 1112 (ENCB). S. Romero y C. Rojas 1659 (IZTA). D. Tejero-Diez 2015, 2030, 2031, 2032, 2361, 2624 (IZTA).

Distribución: Suroeste de E.U.A., México (Son., Chih., Dgo., Ver., Ags., Jal., Méx., Mich., Mor., Chis., Oax.), Sudamérica.

OphioglossaceAe

*Botrychium decompositum M. Martens et Galeotti

Geófito rizocarnoso, humícola, esciófilo; bosque de Quercus húmedo y mesófilo de montaña, a 1650 m s.n.m; Temascaltepec, Tejupilco.

Material de referencia: G. B. Hinton 1850 (MEXU). D. Tejero-Díez 3172 (IZTA).

Distribución: México (Ver., Hgo., Qro., Méx., Mich., Chis., Oax.), Guatemala a Costa Rica.

B. schaffneri Underw.

Geófito rizocarnoso, humícola, esciófilo; bosque de Quercus húmedos y mesófilos de montaña, entre 1650 y 2200 m s.n.m.; Ocoyoacac, Tejupilco.

Material de referencia: C. G. Pringle 5192 (MEXU). D. Tejero-Díez 2447, 3142 (IZTA).

Distribución: México (Chih., Dgo., S.L.P., Jal., Ver., Hgo., Méx., Mich., Mor., Oax., Gro.), Centro a Sudamérica.

B. virginianum (L.) Sw.

Geófito rizocarnoso muy frecuente, humícola esciófilo; bosque de Quercus, mesófilo de montaña, de Pinus-Quercus y de Pinus-Abies, entre 1800 y $2850 \mathrm{~m}$ s.n.m.; El Oro, Tepotzotlán, Texcoco, Naucalpan, Villa Victoria, Ocoyoacac, Tlalmanalco, Temascaltepec, Valle de Bravo, Amecameca, Ocuilan, Villa Guerrero, Coatepec Harinas, Tenancingo, Tejupilco, Sultepec, Zacualpan. 
Material de referencia: M. L. Arreguín 504 (ENCB). E. Estrada 307 (ENCB). A. Flores 15 (ENCB). E. Matuda 27279 (MEXU). J. Rzedowski 30909 (ENCB, MEXU), 34551, 36270 (ENCB). D. Tejero-Díez 2098, 2121, 2135, 2155, 2506, 2788, 2879, 2929, 2936, 2945 (IZTA). M. Vargas 12a (IZTA).

Distribución: Norteamérica (Alaska a E.U.A.), México (Chih., S.L.P., Nay., Jal., Ver., Hgo., Gto., Qro., Pue., Méx., Mich., D.F., Mor., Chis., Oax., Gro.), Centro a Sudamérica, Antillas, Europa y Asia.

\section{Ophioglossum californicum Prantl}

Geófito; presumiblemente arriba de los 3000 m s.n.m.; Zinacantepec (Nevado de Toluca).

Material de referencia: J. N. Rose y J. H. Painter 7875 (G, M) (fide Clausen, 1938).

Distribución: Suroeste de E.U.A., México (B.C., Méx., D.F.).

\section{O. crotalophoroides Walter}

Geófito caudiciforme, en taludes de tierra ruderal, fotófilo; pastizales secundarios de bosque mesófilo de montaña y de Abies, entre 2100 y 3000 m s.n.m.; Zinacantepec, Donato Guerra.

Material de referencia: C. G. Pringle 4244 (MEXU, NY). D. Tejero-Díez 2546 (IZTA).

Distribución: Sureste de E.U.A., México (Dgo, Nay., Jal., Qro., Méx., Mich., Chis., Gro.), Centro a Sudamérica, Antillas.

\section{O. engelmannii Prantl.}

Geófito, en taludes de tierra ruderales; pastizales y matorrales secundarios derivados del bosque de Quercus, entre 2200 y 2400 m s.n.m.; Aculco, Huehuetoca, Tepotzotlán, Atizapán, Valle de Bravo.

Material de referencia: M. L. Arreguín 626 (ENCB). C. G. Pringle 8538 (ENCB). H. Sánchez-Mejorada 27 (MEXU). S. Romero y C. Rojas 467a, 1553 (IZTA). D. Tejero-Diez 2534a (IZTA).

Distribución: Sur de E.U.A., México (B.C., Chih., Coah., Jal., Hgo., Méx., Mich., D.F., Chis., Oax., Gro.).

\section{O. nudicaule L. f.}

Geófito a hemicriptófito en hendiduras de rocas de sitios abiertos; bosque de Quercus y de Pinus-Quercus, entre 2400 y 2800 m s.n.m.; Aculco, Zinacantepec.

Material de referencia: C. G. Pringle 5227 (ENCB, MEXU). D. TejeroDíez 2534b (IZTA). 
Distribución: Sureste de E.U.A., México (Sin., Dgo., S.L.P., Nay., Jal., Ags., Ver., Méx., Mich., D.F.), Centro a Sudamérica, Antillas, África.

\section{O. reticulatum $\mathrm{L}$.}

Geófito, en hendiduras de roca ígnea o taludes de tierra; matorral secundario derivado del bosque tropical subcaducifolio y de Quercus, entre 1600 y 2800 m s.n.m.; Tenango de Arista, Ixtapan del Oro, Valle de Bravo, Tejupilco.

Material de referencia: D. Tejero-Díez 2023, 2560, 2580, 2618, s. n. sep./ 1998 (IZTA).

Distribución: México (Sin., S.L.P., Nay., Jal., Ver., Qro., Méx., Chis., Oax., Gro.), Centro a Sudamérica (hasta norte Argentina), Antillas, Asia, África tropical.

OSMUNDACEAE

Osmunda regalis L. var. spectabilis (Willd.) A. Gray

Caméfito estipitiforme, palúdico o ripícola; bosque de Quercus con elementos mesófilos, a 1640 m s.n.m.; Tejupilco.

Material de referencia: G. B. Hinton 7706 (MEXU). E. Matuda 30825 (CODAGEM). D. Tejero-Díez 3169 (IZTA).

Distribución: Norteamérica (Canadá a E.U.A.), México (Ver., Nay., Jal., Hgo., Qro., Pue., Méx., Mich., Tab., Chis., Oax., Gro.), Centro a Sudamérica, Antillas.

Plagiogyriaceae

Plagiogyria pectinata (Liebm.) Lellinger

Caméfito estipitiforme, palúdico o ripícola (incluso rupícola), higrófilo; bosque de Abies con elementos mesófilos y de Abies-Pinus, entre 2800 y 3000 m s.n.m.; Isidro Fabela, Zinacantepec, Coatepec Harinas, Ocuilan.

Material de referencia: D. Tejero-Díez 2705, 2300, 2970 (IZTA). J. Rzedowski 30167 (ENCB).

Distribución: México (Chih., Dgo., Ver., Jal., Hgo., Méx., Mich., Mor., Chis., Oax., Gro.), Centro a Sudamérica, Antillas.

Polypodiaceae

*Campyloneurum amphostenon (Kunze ex Klotzsch) Fée

Epífito a hemicriptófito rizomatoso de hojas aproximadas, mesófilo, esciófilo; bosque templado ripario, de Quercus-Pinus y mesófilo de montaña, entre 2200 y 2600 m s.n.m.; Aculco, Tenancingo, Temascaltepec, Amecameca. 
Material de referencia: G. B. Hinton 6833 (MEXU). E. Matuda 30946 (CODAGEM, MEXU). J. Rzedowski 28809 (ENCB). D. Tejero-Diez 2743, 2878 (IZTA).

Distribución: México (S.L.P., Ver., Hgo., Pue., Méx., Chis., Oax., Gro.), Guatemala a Costa Rica, Sudamérica, Antillas.

Pecluma alfredii (Rosenst.) M. G. Price (=P. cupreolepis (A. M. Evans) M. G. Price)

Epífito a hemicriptófito rupícola cortamente rizomatoso de hojas aproximadas; bosque tropical ripario, mixto de Quercus con leguminosas, mesófilo de montaña y de Pinus-Quercus, entre 1650 y 2500 m s.n.m.; Villa de Allende, Ixtapan del Oro, Temascaltepec, Valle de Bravo, Ocuilan, Tenancingo.

Material de referencia: J. Díaz 273 (ENCB, MEXU). D. Tejero-Díez 2591, 2690b, 2794, 2798, 2869, 2880, 3180 (IZTA). S. G. Weller 596 (ENCB).

Distribución: México (Tams., Sin., Dgo., S.L.P., Ver., Jal., Hgo., Pue., Méx., Mich., D.F., Mor., Chis., Oax., Gro.), Centroamérica.

\section{P. ferruginea (M. Martens et Galeotti) M. G. Price}

Hemicriptófito rupestre-fisurícola (y en ocasiones sobre taludes de tierra), cortamente rizomatoso con hojas fasciculadas; huertos de árboles frutales tropicales, bosque ripario tropical y mixto de Juniperus-Quercus con leguminosas, entre 1650 y 1850 m s.n.m.; Amanalco, Ixtapan del Oro, Temascaltepec, Malinalco, Tenancingo, Tejupilco, Ixtapan de la Sal.

Material de referencia: G. B. Hinton 4161 (MEXU). D. Tejero-Diez 2084, 2214, 2455, 2567, 2591, 2754, 2869 (IZTA).

Distribución: México (Sin., Nay., Jal., Hgo., Méx., Mich., Mor., Col., Chis., Oax., Gro.).

Phlebodium areolatum (Humb. et Bonpl. ex Willd.) J. Sm.

Hemicriptófito rupestre-fisurícola y en taludes de tierra, excepcionalmente epífito, rizomatoso de hojas laxamente separadas; bosque mixto de QuercusJuniperus con leguminosas, de Quercus-Pinus, de Pinus, de Abies-Pinus y de Pinus de altura, entre 1700 y 2800 m s.n.m.; Huehuetoca, Atizapán, Ixtapan del Oro, Valle de Bravo, Amecameca, Otzoloapan, Tepetlixpa, Temascaltepec, Ocuilan, Tejupilco, Almoloya de Alquisiras, Sultepec.

Material de referencia: Barkley et al. 7397 (MEXU). L. A. Bojórquez 9 (ENCB). G. Córdoba 102 (ENCB). E. Matuda 27367, 31839 (MEXU). G. B. Hinton 1529 (MEXU), G. Pérez 149 (ENCB). K. Ramírez 58 (IZTA). K. Roe y E. Roe 1550 (ENCB). J. Rzedowski 20721 (ENCB). D. Tejero-Diez 2092, 
2380, 2434, 2475, 2508, 2603, 2610 (IZTA). R. M. Tryon y A. F. Tryon 5136 (MEXU).

Distribución: Sureste de E.U.A., México (Chih., N.L., Sin., S.L.P., Ver., Nay., Jal., Hgo., Qro., Gto., Pue., Méx., Mich., D.F., Col., Mor., Chis., Oax., Gro.), Centro a Sudamérica, Antillas.

*Pleopeltis angusta Humb. et Bonpl. ex Willd. var. angusta

Epífito en troncos, largamente rizomatoso de hojas distantes; bosque mixto de Quercus con leguminosas y de Quercus con elementos mesófilos, entre 1700 y 2100 m s.n.m.; Donato Guerra, Ixtapan del Oro.

Material de referencia: D. Tejero-Díez 2547, 2589 (IZTA).

Distribución: México (Dgo., Jal., Méx., Mich., Col., Chis., Oax., Gro.), Guatemala a Nicaragua.

P. mexicana (Fée) Mickel et Beitel (=Polypodium lanceolatum L. var. trichophorum Weath.)

Epífito a hemicriptófito rupestre-fisurícola, largamente rizomatoso de hojas distantes, mesófilo; bosque tropical ripario, mixto de Quercus-Juniperus con leguminosas, mesófilo de montaña y de Pinus-Quercus, entre 1750 y 2300 m s.n.m.; Donato Guerra, Tlalmanalco, Temascaltepec, Valle de Bravo, Amecameca, Coatepec Harinas, Ocuilan, Joquicingo, Tenancingo, Sultepec, Zacualpan.

Material de referencia: S. García 37 (ENCB). J. T. Mickel 676 (ENCB). J. Rzedowski 30880 (ENCB). D. Tejero-Diez 2112, 2190, 2476, 2692, 2789, 2814, 2876, 2904, 2944, 3113, s. n. 31/ago./1986 (IZTA). R. M. Vega 102 (ENCB). J. Zavala 16 (ENCB).

Distribución: México (Sin., S.L.P., Ver., Nay., Jal., Qro., Méx., Mich., D.F., Mor., Chis., Oax., Gro.), Centroamérica.

P. polylepis (Roem. ex Kunze) T. Moore var. interjecta (Weath.) E. A. Hooper (=P. interjecta (Weath.) Mickel et Beitel (=Polypodium peltatum Cav. var. interjectum Weath.)

Epífito rizomatoso de hojas distantes, mesófilo; bosque de Abies-Pinus, a 3000 m s.n.m.; Zinacantepec.

Material de referencia: D. Tejero Díez 2711 (IZTA).

Distribución: México (Ver., Pue., Méx., Mich., Chis., Oax.) a El Salvador.

P. polylepis (Roem. ex Kunze) T. Moore var. polylepis

Epífito a hemicriptófito rupícola largamente rizomatoso de hojas distantes, mesófilo; pastizales y matorrales secundarios, bosque de Quercus, mesófilo de 
montaña, de Pinus y de Abies-Pinus con elementos mesófilos, entre 2450 y 3200 m s.n.m.; Temascalapa, Huehuetoca, Timilpan, San Martín de las Pirámides, Villa del Carbón, San Felipe del Progreso, Otumba, Coacalco, Villa Nicolás Romero, Atizapán, Jilotzingo, Texcoco, Naucalpan, Villa Victoria, Ixtapaluca, Chalco, Tlalmanalco, Amecameca, Tepetlixpa, Ocuilan.

Material de referencia: B. L. Cruz 398 (ENCB). R. Cruz 246 (ENCB). J. Espinosa 516 (ENCB). M. G. Gómez 176 (ENCB). L. González Gutiérrez 103 (IZTA). L. González Quintero 862 (ENCB). S. D. Koch 75-163 (ENCB). Y. Maya IV-4 (ENCB). J. Medina 154 (IZTA). S. Morelos 8 (ENCB). J. A. Moreno 77/13/50 (ENCB). M. E. Ordorica 112 (ENCB). J. Rzedowski 18812, 20066, 20853, 30006, 30753, 34012, 34240 (ENCB). D. Tejero-Diez 2340, 2347, 2891, 2935, 3009 (IZTA). D. Tejero-Diez y M. Castilla 488 (ENCB), 534 (IZTA).

Distribución: México (N.L., Tams., Dgo., Zac., S.L.P., Ver., Ags., Hgo., Qro., Gto., Pue., Méx., Mich., D.F., Mor., Oax., Gro.).

\section{*Polypodium californicum Kaulf.}

Hemicriptófito rizomatoso en rocas de cárcavas, mesófilo de altura, higrófilo; bosque de Abies, entre 2900 y 3400 m s.n.m.; Texcoco, Lerma/Ocoyoacac.

Material de referencia: S. D. Koch 789, 7810 (CHAPA, MO). E. Lyonnet 85 (BM, MEXU, US). A. Sánchez-González s. n. 10/mar./2001 (IZTA).

Distribución: Oeste de E.U.A., México (B.C., Qro., Gto., Méx., Oax.).

P. colpodes Kunze (=P. fuscopetiolatum A. R. Sm.)

Epífito a hemicriptófito rupestre-fisurícola largamente rizomatoso de hojas distantes; bosque tropical ripario, tropical caducifolio, mixto de Quercus-Juniperus con leguminosas, mesófilo de montaña y de Pinus-Quercus, entre 1000 y 2100 y m s.n.m.; Temascaltepec, Valle de Bravo, Sto. Tomás de los Plátanos, Coatepec Harinas, Tejupilco, Ixtapan de la Sal, Sultepec, Zacualpan.

Material de referencia: G. B. Hinton 1737 (K, NY). H. Sánchez-Mejorada 822 (MEXU). D. Tejero-Díez 2074, 2107, 2139, 2175, 2433, 2471, 2474, 2480, $2520,2569,2593,2594,2621,2659,2660,2663,2820,2823,2867,2947$, 3194, 4104 (IZTA).

Distribución: México (Sin., Nay., Jal., Méx., Mich., Col., Mor., Chis., Oax., Gro.), Centro a Sudamérica (Colombia y Venezuela), República Dominicana.

P. fraternum Schltdl. et Cham.

Epífito largamente rizomatoso de hojas distantes; bosque de Quercus-Pinus, entre 1100 y 1800 m s.n.m.; Sto. Tomás de los Plátanos, Tejupilco. 
Material de referencia: D. Tejero-Díez 2915, $3193 b$ (IZTA).

Distribución: México (S.L.P., Ver., Nay., Jal., Hgo., Qro., Pue., Méx., Mich., Mor., Chis., Oax.), Guatemala a Honduras.

P. furfuraceum Schltdl. et Cham.

Epífito a hemicriptófito rupestre-fisurícola largamente rizomatoso de hojas separadas; bosque ripario tropical, mixto de Quercus-Juniperus con leguminosas y mesófilo de montaña, entre 1100 y 1900 m s.n.m.; Ixtapan del Oro, Temascaltepec, Valle de Bravo, Sto. Tomás de los Plátanos, Malinalco, Tejupilco, Almoloya de Alquisiras, Sultepec.

Material de referencia: G. B. Hinton 1254 (ENCB, MEXU). E. Matuda 30682 (CODAGEM, MEXU). H. Sánchez-Mejorada 281, 822 (MEXU). D. Tejero-Diez 1982, 2070, 2436, 2437, 2473, 2517, 2524, 2577, 2587, 2657, 2760, 2813, 2911, 2926, 3193a (IZTA).

Distribución: México (Sin., Dgo., S.L.P., Ver., Jal., Hgo., Méx., Mich., Col., Mor., Chis., Oax., Gro.), Centroamérica.

\section{*P. guttatum Maxon}

Epífito largamente rizomatoso y hojas distantes, mesófilo; bosque de encino, entre 2600 y 2900 m s.n.m.; Temascalapa, San Martín de las Pirámides, Texcoco.

Material de referencia: J. Rzedowski 20070, 24040 (ENCB). D. TejeroDiez y M. Castilla 623 (ENCB). E. Ventura 1860 (MEXU).

Distribución: México (B.C., Chih., Coah., N.L., Tams., Ags., Qro., Gto., Pue., Méx., Mor.).

\section{P. hartwegianum Hook.}

Epífito a hemicriptófito rupestre-fisurícola rizomatoso de hojas aproximadas; bosque de Quercus, mesófilo de montaña, de Quercus-Pinus y de Abies-Pinus, entre 2100 y 2500 m s.n.m.; Acambay, Texcalyacac, Temascaltepec, Amecameca, Ocuilan.

Material de referencia: G. B. Hinton 1316 (MEXU). R. Rodríguez 38 (ENCB). D. Tejero-Diez 2188, 2363, 2481, 2799, 2997, 3109 (IZTA).

Distribución: México (Chih., Dgo., Ver., Jal., Hgo., Qro., Pue., Méx., Mich., Mor., Chis., Oax., Gro.), Centroamérica.

P. madrense J. Sm. (=P. oulolepis Fée)

Epífito rizomatoso de hojas aproximadas; bosque subtropical ripario, mesófilo de montaña, de Pinus-Quercus y de Abies-Pinus, entre 1850 y 3500 m s.n.m.; 
Temascalapa, Huehuetoca, Tepotzotlán, San Felipe del Progreso, Villa Nicolás Romero, Atizapán, Jilotzingo, Texcoco, Naucalpan, Villa de Allende, Ixtapaluca, Huixquilucan, Zinacantepec, Amanalco, Tlalmanalco, Temascaltepec, Valle de Bravo, Amecameca, Tepetlixpa, Ocuilan, Villa Guerrero, Coatepec Harinas, Malinalco, Tenancingo, Sultepec, Zacualpan.

Material de referencia: M. L. Arreguín 487, 608 (ENCB). A. M. Calvo 126 (ENCB). J. L. Carrillo 7 y L. Abundiz-Bonilla (IZTA). R. Cruz Cisneros 1702, 2663 (ENCB). M. J. Díaz 220 (ENCB). C. García 58 (ENCB). F. García 67 (ENCB). S. D. Koch 7661, 75707 (ENCB). A. López 250 (ENCB). E. Matuda 26807 (CODAGEM, MEXU). J. T. Mickel 671 (ENCB). A. Pineda 595, 965 (ENCB). K. Roe y E. Roe 1777, 1828 (ENCB). M. Roldán 82 (ENCB). J. Rzedowski 18708, 20070, 20761, $31636 a$ (ENCB). D. Tejero-Diez 2109, 2119, 2120, 2369, 2469, 2509, 2555, 2708, 2790, 2833, 2881, 2928, 2980 (IZTA). D. Tejero-Diez y M. Castilla 623b (ENCB), 1120 (IZTA). R. Vega 430 (ENCB).

Distribución: México (Dgo., S.L.P., Ver., Ags., Jal., Hgo., Qro., Gto., Pue., Méx., Mich., D.F., Col., Mor., Oax., Gro.).

\section{P. martensii Mett.}

Epífito a caméfito rupícola largamente rizomatoso con hojas distantes, mesófilo, esciófilo; bosque mesófilo de montaña, de Quercus y de Abies-Pinus, entre 2550 y 3000 m s.n.m.; Acambay, Villa Victoria, Villa de Allende, Ixtapaluca, Zinacantepec, Tlalmanalco, Temascaltepec, Amecameca, Ocuilan.

Material de referencia: M. J. Díaz 171 (ENCB). X. González 63 (ENCB). L. V. González Gutiérrez 133 (IZTA). E. Lyonnet 2477 (MEXU). J. Rzedowski 21711, 26449 (ENCB). D. Tejero-Díez 2379, 2382, 2482, 2702, 2933 (IZTA).

Distribución: México (S.L.P., Ver., Jal., Hgo., Qro., Gto., Pue., Méx., Mich., D.F., Mor.).

\section{P. platylepis Mett. ex Kuhn}

Epífito a hemicriptófito rupestre-fisurícola largamente rizomatoso con hojas distantes; bosque mesófilo de montaña y de Pinus-Quercus con elementos mesófilos, entre 2200 y 2700 m s.n.m.; Tlalmanalco, Valle de Bravo, Amecameca, Ocuilan.

Material de referencia: J. Flores 14 y D. Tejero-Diez (IZTA). S. Heilmeister s. n. 2/oct./1977 (ENCB). D. S. Koch 813 (ENCB). V. López 1009 (ENCB). E. Lyonnet (541200028, 481200005) (MEXU). J. Rzedowski 19884 (ENCB, LP). D. Tejero-Díez 2370, 2556, 2678 (IZTA).

Distribución: México (Jal., Qro., Méx., Mich., Chis., Oax., Gro.), Centroamérica. 
*P. plebeium Schltdl. et Cham.

Epífito rizomatoso de hojas distantes péndulas; bosque mesófilo de montaña y de Quercus, a 2600 m s.n.m.; Lerma/Huixquilucan.

Material de referencia: J. Rzedowski 18708, 24040 (ENCB).

Distribución: México (S.L.P., Ver., Hgo., Qro., Pue., Méx., Chis., Oax.), Centroamérica.

\section{P. plesiosorum Kunze}

Hemicriptófito largamente rizomatoso de hojas distantes, rupestre-fisurícola a humícola; bosque mesófilo de montaña, entre 1300 y 2200 m s.n.m.; Tenancingo, Amatepec.

Material de referencia: E. Matuda 29540 (MEXU). D. Tejero-Díez 2747, 4066 (IZTA).

Distribución: México (N.L., Tams., S.L.P., Ver., Nay., Hgo., Qro., Pue., Méx., Mich., Col., Mor., Chis., Oax., Gro.), Centroamérica.

P. polypodioides (L.) Watt var. aciculare Weath.

Hemicriptófito rupestre-fisurícola a epífito largamente rizomatoso de hojas distantes; matorral xerófilo y bosque mixto de Quercus-Juniperus con leguminosas, huertos familiares de frutales tropicales, mesófilo de montaña y de Pinus-Quercus, entre 1700 y 2400 m s.n.m.; Huehuetoca, Villa del Carbón, Ixtapan del Oro, Temascaltepec, Coatepec Harinas, Tenancingo, Tejupilco, Sultepec.

Material de referencia: S. García 82 (ENCB). E. Guizar 1032 (CHAPA, ENCB). G. B. Hinton 1253 (MEXU). K. Roe y E. Roe 1718 (ENCB). J. Rzedowski 20764, 30879 (ENCB). D. Tejero-Diez 1994, 2128, 2750, 2787 (IZTA). D. Tejero-Díez y R. Moreno 2470, 2592 (IZTA). D. Tejero-Diez y M. Castilla 2871 (IZTA).

Distribución: México (Dgo., Zac., S.L.P., Ver., Nay., Jal., Hgo., Qro., Gto., Méx., Mich., D.F., Col., Mor., Chis., Oax., Gro.), Centroamérica.

\section{P. rosei Maxon}

Epífito rizomatoso de hojas distantes; bosque mixto de Quercus-Juniperus con leguminosas, mesófilo de montaña y de Pinus-Quercus, entre 1600 y 2300 m s.n.m.; Ixtapan del Oro, Temascaltepec, Valle de Bravo, Otzoloapan, Ocuilan, Coatepec Harinas, Malinalco, Tenancingo, Sultepec, Zacualpan.

Material de referencia: A. Gómez Pompa s. n. 15/oct./1960 (MEXU). G. B. Hinton 4159 (K). Kimnach 319 (MICH). E. Lyonnet 1997 (MEXU). E. Matuda 
31838 (MEXU). J. Rzedowski 20760 (ENCB). D. Tejero-Diez 1982, 2100, 2507, 2576, 2588, 2673, 2800, 2834, 2986, 3076 (IZTA).

Distribución: México (Sin., Zac., Jal., Qro., Méx., Mich., D.F., Mor., Gro.).

*P. sanctae-rosae (Maxon) C. Chr.

Caméfito rizomatoso, rupícola en bardas limitantes de huertos, esciófilo; cultivo de frutales tropicales, entre 1700 y 1800 m s.n.m.; Malinalco, Tejupilco.

Material de referencia: D. Tejero-Díez 2435, 2751 (IZTA).

Distribución: México (Nay., Jal., Méx., Chis., Oax.), Centroamérica.

P. subpetiolatum Hook. (=P. adelphum Maxon)

Hemicriptófito humícola o rupestre-fisurícola y en ocasiones epífito, largamente rizomatoso con hojas distantes, mesófilo; bosque templado ripario, mixto de QuercusPinus con leguminosas, mesófilo de montaña, de Pinus-Quercus y de Abies-Pinus, entre 1750 y 2850 m s.n.m.; Jilotepec, Soyaniquilpan, Tepotzotlán, Villa del Carbón, Jocotitlán, Atizapán, Huixquilucan, Chalco, Tlalmanalco, Temascaltepec, Valle de Bravo, Amecameca, Ocuilan, Villa Guerrero, Coatepec Harinas, Tenancingo, Tejupilco, Sultepec, Zacualpan.

Material de referencia: L. A. Abundiz-Bonilla 829 (IZTA). E. Díaz y A. Orozco 251 (ENCB). A. Gómez Pompa 1959 (MEXU). G. León 227 (ENCB). E. Matuda 27227 (CODAGEM, MEXU). F. Méndez 5-A (ENCB). J. T. Mickel 701 (CODAGEM). J. Medina 5, 50 (IZTA). L. Paray 2415 (ENCB). J. Rzedowski 18705 (ENCB, LP), 26448, 28238 (ENCB), 30912 (MEXU), 30784 (NY). D. Tejero-Diez 2131, 2146, 2192, 2193, 2220, 2378, 2450, 2451, 2472, 2499, 2557, 2764, 2786, 2797, 2882, 2988, 3003, 3183 (IZTA).

Distribución: México (Chih., N.L., Sin., Ver., Ags., Jal., Hgo., Qro., Pue., Méx., Mich., D.F., Mor., Chis., Oax., Gro.), Centroamérica.

\section{P. thyssanolepis A. Braun ex Klotzsch}

Hemicriptófito humícola o caméfito rupícola largamente rizomatoso con hojas aproximadas, esciófilo; huerto de frutales tropicales, matorral xerófilo, bosque tropical caducifolio, tropical ripario, mixto de Quercus-Juniperus con leguminosas, mesófilo de montaña, de Quercus, de Quercus-Pinus y de Abies-Pinus, entre 1600 y 2800 m s.n.m.; Temascalapa, Zumpango, Huehuetoca, Villa del Carbón, Jocotitlán, Otumba, Coacalco, Ecatepec, Atizapán, Naucalpan, Ixtapaluca, Huixquilucan, Tlalmanalco, Temascaltepec, Amecameca, Tenango del Aire, Texcalyacac, Malinalco, Tenancingo, Ixtapan de la Sal, Sultepec, Zacualpan. 
Material de referencia: P. Aguilar 199 (ENCB). D. Aldona 57 (ENCB). M. L. Arreguín 70 (ENCB). A. M. Calvo 126 (ENCB). G. B. Hinton 62 (ENCB). J. Medina 51 (IZTA). D. Montesinos 112 (ENCB). S. Romero y C. Rojas 495, 815, 1116, 1560 (IZTA). J. Rzedowski 18720, 24310, 27451, 30772 (ENCB). D. Tejero-Díez 2088, 2179, 2210, 2258, 2523, 2785, 2870, 2901, 2996 (IZTA). D. Tejero-Díez y M. Castilla 486, 572, 925 (IZTA). A. Velázquez 165 (ENCB). Zúñiga y Martínez 194 (ENCB).

Distribución: Suroeste de E.U.A., México (Chih., N.L., Sin., Dgo., Zac., S.L.P., Ver., Ags., Nay., Jal., Hgo., Qro., Gto., Pue., Méx., Mich., D.F., Col., Mor., Chis., Oax., Gro.), Centro a Sudamérica, Antillas.

PTERIDACEAE

Adiantum andicola Liebm.

Hemicriptófito largamente rizomatoso con hojas aproximadas a fasciculadas, mesófilo, esciófilo; bosque de Abies y en menor medida bosque mesófilo de montaña y de Pinus-Quercus, entre 1900 y 3500 m s.n.m.; Jilotepec, Chapa de Mota, Atlacomulco, El Oro, Villa Nicolás Romero, Atizapán, Jilotzingo, Villa Victoria, Ixtapaluca, Toluca, Amanalco, Ixtapan del Oro, Tlalmanalco, Temascaltepec, Valle de Bravo, Amecameca, Juchitepec, Tenango del Valle, Ocuilan, Villa Guerrero, Coatepec Harinas, Tejupilco, Sultepec, Zacualpan.

Material de referencia: M. L. Arreguín 457, 486, 604, 4592 (ENCB). Barkley et al. 2845 (MEXU). Castro 10 (IZTA). Copeland s. n. 31/dic./1937 (MEXU). A. González y M. Miranda 176 (IZTA). L. González Gutiérrez 44 (IZTA). G. B. Hinton 6832 (ENCB). E. Lyonnet 3127, 3194 (MEXU). E. Matuda 27270 (CODAGEM, MEXU). J. T. Mickel 659 (ENCB). Ch. H. Perino 3124 (ENCB). A. Ramírez 17 (ENCB). R. Riba s. n. dic./1961 (MEXU). Ramírez Padilla 1 (IZTA). J. Rzedowski 20863, 26733 (ENCB), 30871 (MEXU), 32443 32449, 32583, 35583 (ENCB). H. Sánchez-Mejorada 363 (MEXU). Schwabe 7742 (MEXU). C. Soto 11 (IZTA). Serrano Reyes 11 (IZTA). D. Tejero-Díez $2025,2062,2123,2195,2312,2313,2371,2510,2938,3210$ (IZTA). L. Villasana 143 y D. Tejero-Díez (IZTA). R. Weber 124 (ENCB).

Distribución: México (N.L., Sin., Dgo., S.L.P., Ver., Jal., Hgo., Qro., Gto., Pue., Méx., Mich., D.F., Mor., Chis., Oax., Gro.), Centroamérica.

\section{A. braunii Mett. ex Kuhn}

Hemicriptófito rizomatoso de hojas aproximadas, mesófilo de partes bajas, ripícola; bosque tropical caducifolio, tropical ripario, mixto de Quercus-Juniperus con leguminosas y mesófilo de montaña, entre 1300 y 2350 m s.n.m.; Ixtapan del 
Oro, Temascaltepec, Valle de Bravo, Sto. Tomás de los Plátanos, Ocuilan, Coatepec Harinas, Tejupilco, Ixtapan de la Sal, Zacualpan.

Material de referencia: A. González y M. Miranda 559 (IZTA). G. B. Hinton 7317 (CODAGEM, ENCB). J. T. Mickel 683 (ENCB, NY). Rodríguez 1 (IZTA). H. Sánchez-Mejorada 249, 817 (MEXU). D. Tejero-Díez 2097, $2179 b, 2196,2283,2438,2462,2563,2582,2612,2664,2907,2943,3212$ (IZTA).

Distribución: México (Son., Sin., Dgo., Ver., Nay., Jal., Hgo., Qro., Pue., Méx., Mich., Col., Mor., Chis., Oax., Gro.), Centro a Sudamérica.

\section{A. capillus-veneris L.}

Hemicriptófito terrestre a caméfito rupícola en taludes, rizomatoso de hojas aproximadas, péndulas, ripícola, fotófilo; vegetación secundaria (pastizales o matorrales), bosque tropical subcaducifolio, tropical ripario, mixto de QuercusJuniperus con leguminosas, mesófilo de montaña y de Quercus-Pinus, entre 1300 y 2400 m s.n.m.; Tepotzotlán, Villa del Carbón, Texcoco, Ixtapan del Oro, Temascaltepec, Tenango del Valle, Ocuilan, Malinalco, Ixtapan de la Sal, Tonatico.

Material de referencia: García Hernández 3 (IZTA). C. Juárez 123 (ENCB). E. Matuda 26859 (CODAGEM, MEXU). M. T. Pulido 351 (ENCB), K. Roe y E. Roe 1869 (ENCB). H. Sánchez-Mejorada 807, 815 (MEXU). D. Tejero-Diez 2002, 2721, 2821, 3067, 3073, 3211 (IZTA).

Distribución: Sureste de E.U.A., México (B.C., Son., Chih., Coah., N.L., Tams., Dgo., Zac., S.L.P., Ver., Jal., Qro., Gto., Méx., Mich., Tlax., Mor., Chis., Oax., Gro.), Centro a Sudamérica, Antillas y regiones templadas del Viejo Mundo.

A. concinnum Humb. et Bonpl. ex Willd.

Hemicriptófito en taludes de tierra o roca, de tallo muy corto, con hojas aproximadas, péndulas, termófilo; bosque tropical caducifolio, tropical ripario, tropical subcaducifolio, mixto de Quercus-Juniperus con leguminosas, mesófilo de montaña, pastizales y matorrales secundarios, entre 1400 y 2500 m s.n.m.; Ixtapan del Oro, Temascaltepec, Valle de Bravo, Sto. Tomás de los Plátanos, Ocuilan, Coatepec Harinas, Ixtapan de la Sal, Tejupilco, Sultepec, Zacualpan.

Material de referencia: Clausen s. n. 27/jul./1935 (MEXU). G. B. Hinton 1881 (MEXU). E. Lyonnet 2874 (MEXU). E. Matuda y col. 27027, 27188 (CODAGEM, MEXU). J. T. Mickel 684 (CODAGEM, MEXU). J. Rzedowski 34407 (ENCB). D. Tejero-Díez 2077, 2140c, 2414, 2586, 2666, 3201 (IZTA).

Distribución: México (B.C., Son., Sin., Dgo., S.L.P., Ver., Nay., Jal., Qro., Gto., Pue., Méx., Mich., Col., Mor., Chis., Oax., Gro.), Centro a Sudamérica, Antillas. 
*A. lunulatum Burm. f.

Hemicriptófito de tallo corto con hojas aproximadas y estoloníferas, termófilo, fotófilo; bosque tropical caducifolio y tropical ripario, entre 800 y 1000 m s.n.m.; Tejupilco, Sultepec, Tlatlaya.

Material de referencia: D. Tejero-Díez 2651, 2665, 2910, 3025 (IZTA).

Distribución: México (N.L., Sin., Nay., Jal., Méx., Mich., Col., Chis., Oax., Gro.), Centro a Sudamérica, Antillas, regiones cálidas del Viejo Mundo.

\section{A. patens Willd.}

Hemicriptófito de tallo corto con hojas aproximadas, termófilo, en sitios abiertos húmedos; bosque tropical caducifolio, tropical subcaducifolio, tropical ripario, mixto de Quercus-Juniperus con leguminosas, mesófilo de montaña, de PinusQuercus, ente 1000 y 2400 m s.n.m.; Ixtapan del Oro, Valle de Bravo, Zacazonapan, Tejupilco, Sultepec, Amatepec.

Material de referencia: S. Bustamante 3 (IZTA). G. B. Hinton 1683 (MEXU). E. Matuda 30032, 31428 (CODAGEM, ENCB, MEXU). J. Rzedowski 20668 (ENCB). D. Tejero-Díez 2424, 2446, 2590, 2661, 2832 (IZTA).

Distribución: México (Son., Sin., Dgo., Nay., Jal., Méx., Mich., Mor., Chis., Oax., Gro.), Centro a Sudamérica.

\section{A. poiretii Wikstr.}

Hemicriptófito rizomatoso con hojas aproximadas, mesófilo, esciófilo; bosque mixto de Quercus-Juniperus con leguminosas, mesófilo de montaña, de QuercusPinus, de Pinus y pastizal secundario, entre 1700 y 2750 m s.n.m.; Jilotepec, Temascalapa, Huehuetoca, Chapa de Mota, El Oro, Tepotzotlán, Atizapán, Jilotzingo, Texcoco, Villa de Allende, Ixtapaluca, Ixtapan del Oro, Tlalmanalco, Temascaltepec, Valle de Bravo, Tenango del Valle, Ocuilan, Malinalco, Zacualpan.

Material de referencia: R. Cruz Cisneros 438, 937 (ENCB). Cruz Cruz 2 (IZTA). Espinosa Araujo 11 (IZTA). A. González y M. Miranda 17 (IZTA). Gutiérrez Ramírez 47 (IZTA). Hernández González 14 (IZTA). G. B. Hinton 86, 1674 (MEXU). S. D. Koch 768 (ENCB). E. Matuda 26806 (CODAGEM, ENCB, MEXU). A. Ramírez 17 (IZTA). J. Rzedowski 29903 (ENCB). D. Salazar 4 (IZTA). D. Tejero-Diez 2076, 2731, 2738, 2956, 3209 (IZTA). D. TejeroDíez y M. Castilla 614 (IZTA). G. Trejo 9 (IZTA). Vázquez Ventura 6 (IZTA). J. Zarco 72 (ENCB).

Distribución: México (B.C., Son., Chih., N.L., Tams., Sin., Dgo., S.L.P., Ver., Nay., Jal., Hgo., Qro., Gto., Pue., Méx., Mich., D.F., Mor., Chis., Oax., Gro.), Centro a Sudamérica, Antillas, Europa, Asia, África. 


\section{A. shepherdii Hook.}

Hemicriptófito de tallo corto con hojas fasciculadas, termófilo, fotófilo; pastizal secundario derivado del bosque tropical caducifolio y del mixto de Pinus-Quercus con leguminosas, entre 800 y 1750 m s.n.m.; Tejupilco, Tlatlaya.

Material de referencia: Bates s. n. 1834 (K holotipo). G. B. Hinton 1602 (MEXU). E. Matuda 31053 (CODAGEM, MEXU). D. Tejero-Diez 2453 (IZTA).

Distribución: México (Méx., Mich., Gro.).

\section{A. trapeziforme L.}

Hemicriptófito de rizoma corto con hojas aproximadas, termófilo; bosque tropical ripario, $1500 \mathrm{~m}$ s.n.m.; Tejupilco/Sultepec.

Material de referencia: G. B. Hinton 7644 (MEXU, NY).

Distribución: México (Tams., S.L.P., Ver., Nay., Jal., Hgo., Qro., Méx., Chis., Oax., Gro.), Centro a Sudamérica, Antillas.

\section{A. tricholepis Fée}

Hemicriptófito de tallo corto con hojas fasciculadas, termófilo, esciófilo; huertos de árboles tropicales, bosque tropical caducifolio, subcaducifolio, tropical ripario y mixto de Quercus-Juniperus con leguminosas, entre 800 y 1100 m s.n.m.; Sto. Tomás de los Plátanos, Zacazonapan, Tejupilco, Sultepec.

Material de referencia: E. Matuda 29799 (CODAGEM, MEXU). D. TejeroDíez 2638, 2828, 3024, 3185 (IZTA).

Distribución: Sur de E.U.A., México (Son., Chih., Coah., N.L., Tams., Sin., Dgo., S.L.P., Yuc., Ver., Jal., Cam., Hgo., Qro., Pue., Méx., Mich., D.F., Col., Mor., Chis., Oax., Gro.), Centroamérica.

Especies probables de encontrar: A. princeps T. Moore, A. tenerum Sw. y A. raddianum C. Presl; las cuales han sido colectadas en los estados aledaños al área de estudio en comunidades vegetales que se comparten.

Aleuritopteris aurantiaca (Cav.) Ching (=Cheilanthes aurantiaca (Cav.) T. Moore)

Hemicriptófito de hojas aproximadas, termófilo, rupícola o en taludes de tierra, fotófilo; bosque mixto de Quercus-Juniperus con leguminosas, mesófilo de montaña y de Quercus-Pinus, entre 1600 y 1900 m s.n.m.; Ocuilan, Villa Guerrero, Tenancingo, Tejupilco.

Material de referencia: Clausen s. n. 27/jul./1955 (MEXU). G. B. Hinton 4350 (MEXU). D. Tejero-Diez 2205, 2432, 2445, 2922, 3075 (IZTA). 
Distribución: México (Nay., Jal., Méx., Mich., Mor., Gro.). A. aurea (Baker) Ching var. aurea (=Cheilanthes aurea Baker)

Hemicriptófito de hojas fasciculadas, termófilo, rupícola, fotófilo; bosque tropical subcaducifolio, entre 1300 y 1600 m s.n.m.; Temascaltepec, Malinalco, Amatepec.

Material de referencia: G. B. Hinton 6137 (US). E. Matuda 32549 (MEXU). D. Tejero-Díez 3065 (IZTA).

Distribución: México (Méx., Mor., Oax., Gro.).

\section{A. farinosa (Forssk.) Fée (=Cheilanthes farinosa (Forssk.) Kaulf.)}

Hemicriptófito de hojas fasciculadas, rupícola o en taludes de tierra, expuesto o en sotobosque; matorral xerófilo, pastizal con matorral inducido, bosque de Quercus, de Quercus-Pinus, templado ripario, mesófilo de montaña, de Pinus y de Abies-Pinus, entre 2080 y 2750 m s.n.m.; Jilotepec, Zumpango, Tepotzotlán, Villa Nicolás Romero, Naucalpan, Huixquilucan, Tlalmanalco, Temascaltepec, Valle de Bravo, Amecameca, Ocuilan, Coatepec Harinas, Tenancingo, Sultepec, Zacualpan.

Material de referencia: F. Arce 88 (ENCB). A. Gómez Pompa s. n. 15/oct./ 1960 (MEXU). G. León 228 (ENCB). E. Lott y T. Wendt P-97 (MEXU, NY). L. Luna 12 (ENCB). E. Lyonnet 1999 (MEXU). E. Matuda y col. 26459 (CODAGEM, MEXU), 29176, 30715 (CODAGEM). R. Olvera 109 (ENCB). Pérez Fragoso 8 (IZTA). J. Rzedowski 20116, 25140, 26428, 27936 (ENCB), 30790 (MEXU), 30926, 34630 (ENCB). P. Sánchez 10 (ENCB). H. SánchezMejorada s. n. 5/mar./1952 (MEXU). D. Tejero-Díez 2102, 2110, 2201, 2498, 2552 (IZTA).

Distribución: México (Chih., Sin., Dgo., Zac., S.L.P., Ver., Jal., Hgo., Qro., Pue., Méx., Mich., D.F., Mor., Chis., Oax., Gro.), Centro a Sudamérica, Antillas, montañas del Viejo Mundo e islas del Pacífico.

\section{Anogramma chaerophylla (Desv.) Link}

Terófito de hojas fasciculadas, ripícola; bosque ripario, a 1600 m s.n.m.; Tejupilco (entre Platanal y Pantoja).

Material de referencia: G. B. Hinton 7335 (NY). (J. T. Mickel, com. pers. en 2002).

Distribución: México (Ver., Méx., Mich., Mor., Chis., Oax.).

\section{A. leptophylla (L.) Link}

Terófito de hojas fasciculadas, rupícola y ripícola en taludes de tierra, higrófilo; bosque templado ripario y mesófilo de montaña, entre 1640 y 2630 m s.n.m.; Tlalmanalco, Valle de Bravo, Amecameca, Villa Guerrero, Tenancingo, Tejupilco. 
Material de referencia: M. L. Arreguín 712 (ENCB). J. Gómez 31 y D. Tejero-Diez (IZTA). I. López Pérez 22 y M. Castilla (IZTA). B. Mendoza 6 y M. Castilla (IZTA). J. Rzedowski 27945 (ENCB). D. Tejero-Diez 2875, 2905, 2946, 3173 (IZTA).

Distribución: México (Chih., Tams., Sin., Ver., Nay., Jal., Gto., Méx., Mich., Mor., Chis., Oax., Gro.), Centro y Sudamérica, regiones cálidas del Viejo Mundo.

*Argyrochosma formosa (Liebm.) Windham

Hemicriptófito de rizoma corto con hojas fasciculadas, en taludes ruderales de lutitas calcáreas; bosque tropical caducifolio, a 1400 m s.n.m.; Ixtapan de la Sal, Tonatico.

Material de referencia: H. Bravo 78 (MEXU). D. Tejero-Díez 3069 (IZTA).

Distribución: México (N.L., Tams., S.L.P., Ver., Ags., Hgo., Qro., Gto., Méx., Chis., Oax., Gro.), Guatemala.

A. incana (C. Presl) Windham (=Cheilanthes incana (C. Presl) Mickel et Beitel)

Hemicriptófito de hojas fasciculadas, rupícola o en taludes de tierra, mesófilo; bosque mixto de Quercus-Juniperus con leguminosas, de Quercus-Arbutus, de Quercus-Pinus, mesófilo de montaña, de Pinus-Quercus y pastizal inducido, entre 1900 y 2640 m s.n.m.; Acambay, Tepotzotlán, Coacalco, Ixtapaluca, Amecameca, Texcalyacac, Ocuilan, Malinalco, Ixtapan de la Sal.

Material de referencia: F. García 15 (ENCB). K. Roe y E. Roe 1867 (ENCB). J. Rzedowski 29694, 30757 (ENCB). D. Tejero-Díez 2483, 2837, 2895, 2995 (IZTA). Yatskievych 83-131a (ENCB, MEXU).

Distribución: México (B.C., Son., Chih., N.L., Dgo., Zac., S.L.P., Ver., Ags., Nay., Jal., Hgo., Qro., Gto., Pue., Méx., Mich., D.F., Mor., Chis., Oax., Gro.), Guatemala, La Española.

Especie probable de encontrar: A. pallens (Weath.) Windham, dado que se distribuye a través de la porción seca del Altiplano Mexicano, de Chihuahua a Puebla.

*Astrolepis beitelii (Mickel) D. M. Benham et Windham (=Cheilanthes beitelii Mickel)

Hemicriptófito de hojas fasciculadas, termófilo, rupestre-fisurícola o terrestre sobre taludes, fotófilo; bosque mixto de Quercus-Juniperus con leguminosas, 1750 m s.n.m.; Malinalco.

Material de referencia: D. Tejero-Diez 2841 (IZTA).

Distribución: México (Ver., Ags., Jal., Hgo., Qro., Méx., Mich., Gro.), Guatemala. 
A. crassifolia (Houlston et T. Moore) D. M. Benham et Windham (=Cheilanthes crassifolia (Houlston et T. Moore) Mickel et Beitel)

Hemicriptófito terrestre a caméfito rupícola cortamente rizomatoso de hojas aproximadas, fotófilo; bosque tropical caducifolio, mixto de Quercus-Juniperus con leguminosas, mesófilo de montaña, pastizal inducido y matorral xerófilo, entre 900 y 2500 m s.n.m.; Tepotzotlán, Otumba, Ixtapan del Oro, Coatepec Harinas, Ixtapan de la Sal.

Material de referencia: H. Bravo 82 (MEXU). L. Pérez 1017 (ENCB). D. Tejero-Díez 2129, 2583 (IZTA). D. Tejero-Diez y M. Castilla 487, 515 (ENCB).

Distribución: México (Tams., S.L.P., Ver., Hgo., Pue., Qro., Gto., Méx., Mor., Oax., Gro.) a Honduras.

*A. integerrima (Hook.) D. M. Benham et Windham (=Cheilanthes integerrima (Hook.) Mickel)

Hemicriptófito a caméfito rupícola de hojas fasciculadas, xerófilo; pastizal inducido, matorral xerófilo y bosque tropical caducifolio, entre 1500 y 2550 m s.n.m.; Teotihuacan, Texcoco, Ixtapaluca, Ixtapan de la Sal.

Material de referencia: F. H. Gómez 4 (ENCB). P. Piña V-76 (ENCB). $M$. T. Pulido 37 (ENCB). D. Tejero-Diez 2171 (IZTA).

Distribución: Suroeste de E.U.A., México (Son., Chih., Coah., N.L., Dgo., S.L.P., Ver., Ags., Hgo., Qro., Gto., Méx., Chis., Oax.), La Española.

A. sinuata (Lag. ex Sw.) D. M. Benham et Windham (=Cheilanthes sinuata (Lag. ex Sw.) Domin; =Notholaena sinuata (Lag. ex Sw.) Kaulf.)

Hemicriptófito en taludes de tierra o rupestre-fisurícola rizomatoso de hojas aproximadas, xerófilo, fotófilo; bosque tropical ripario, matorral xerófilo y pastizal inducido, entre 1450 y 2600 m s.n.m.; Temascalapa, Huehuetoca, Tepotzotlán, Villa del Carbón, Otumba, Coacalco, Ecatepec, Texcoco, Ixtapaluca, Valle de Bravo, Tenancingo, Tejupilco.

Material de referencia: A. M. Calvo 125 (ENCB). B. L. Cruz 382 (ENCB). R. Cruz Cisneros 365 a (ENCB). C. Fuentes A II-15 (ENCB). G. B. Hinton 1966 (MEXU). M. E. Ordorica 72 (ENCB). D. Ramírez 30 (ENCB). S. Romero y C. Rojas 1570 (IZTA, ENCB). J. Rzedowski 30734 (ENCB). D. Tejero-Diez 2780b, 2866 (IZTA). R. M. Tryon y A. F. Tryon 5135 (MEXU). D. Tejero-Diez y M. Castilla 466a, 839 (IZTA).

Distribución: Suroeste de E.U.A., México (B.C., Son., Chih., Coah., N.L., Tams., Sin., Dgo., Zac., S.L.P., Ver., Nay., Jal., Hgo., Qro., Gto., Pue., Méx., Mich., D.F., Mor., Chis., Oax., Gro.), Centro a Sudamérica, La Española. 


\section{Bommeria ehrenbergiana (Klotzsch) Underw.}

Hemicriptófito de hojas aproximadas, en taludes de tierra de sitios abiertos; bosque tropical caducifolio y mesófilo de montaña, entre 1320 y 2080 m s.n.m.; Sto. Tomás de los Plátanos, Coatepec Harinas, Ixtapan de la Sal.

Material de referencia: E. Matuda 28799 (CODAGEM, US). H. SánchezMejorada 820 (MEXU). D. Tejero-Diez 2133 (IZTA).

Distribución: México (N.L., S.L.P., Ver., Hgo., Pue., Méx., Oax., Gro.).

*B. elegans (Davenp.) Ranquer et Haufler (=Hemionitis elegans Davenp.)

Hemicriptófito de hojas fasciculadas, termófilo, en taludes riparios y en canales de agua; bosque tropical subcaducifolio, tropical ripario y huerta de frutales, entre 900 y 1300 m s.n.m.; Sto. Tomás de los Plátanos, Ocuilan, Zacualpan.

Material de referencia: E. Matuda 32603 (MEXU). F. Medellín y F. Takaki s. n. 4/oct./1957 (ENCB). H. Sánchez-Mejorada 801 (MEXU). D. Tejero-Diez 2609, 3023, 3190 (IZTA).

Distribución: México (Zac., Nay., Jal., Méx., Mor., Oax.).

B. hispida (Mett. ex Kuhn) Underw.

Hemicriptófito largamente rizomatoso de hojas distantes, rupícola y terrestre, fotófilo, bosque semicálido, 1720 m s.n.m.; Temascaltepec.

Material de referencia: G. B. Hinton 1431 (GH) (fide Haufler, 1979; ejemplar no localizado por J. T. Mickel en visita reciente a GH).

Distribución: Suroeste de E.U.A., México (Son., Chih., Coah., Dgo., S.L.P., Ags., Jal., Hgo., Méx.?, Mich.), Nicaragua.

B. pedata (Sw.) E. Fourn.

Hemicriptófito de hojas fasciculadas, termófilo, en taludes de tierra o rupícola en hendiduras, fotófilo; matorral xerófilo, bosque tropical caducifolio, tropical subcaducifolio, mixto de Quercus-Juniperus con leguminosas, tropical ripario, de Quercus, de Pinus-Quercus y áreas reforestadas con Eucalyptus, entre 1300 y 2400 m s.n.m.; Huehuetoca, Tepotzotlán, Villa del Carbón, Atizapán, Naucalpan, Ixtapan del Oro, Temascaltepec, Valle de Bravo, Sto. Tomás de los Plátanos, Tepetlixpa, Malinalco, Tejupilco, Zacualpan.

Material de referencia: S. Acosta 275 (ENCB). A. Arizmendi 28 (ENCB). M. L. Arreguín 625 (ENCB). F. Castañeda y H. Sánchez-Mejorada 18 (CODAGEM). E. Matuda 27186 (CODAGEM, MEXU). N. Naranjo 74 (ENCB). A. Ortiz s. n. 2/nov./1977 (ENCB). J. Rzedowski 20716 (ENCB, LP). F. Solares 
102 (ENCB). D. Tejero-Díez 2089, 2411, 2454, 2619, 2773, 2816, 3060, 3140, 3188 (IZTA). T. Velázquez 2 y L. Abundiz-Bonilla (IZTA).

Distribución: México (B.C., Son., Chih., Sin., Dgo., Zac., S.L.P., Ver., Nay., Jal., Gto., Pue., Méx., Mich., D.F., Mor., Chis., Oax., Gro.), Centroamérica.

Especie probable de encontrar: B. subpalacea Maxon; los ejemplares $J$. G. Schaffner 7 (NY fide Haufler, 1979) y E. Matuda 32509 (MEXU) se colectaron en la sierra de las Cruces, D.F. y en el municipio de Cuernavaca, Mor. respectivamente; ambos en la frontera con el estado de México.

Cheilanthes allosuroides Mett. (=Pellaea allosuroides (Mett.) Hieron.)

Hemicriptófito rupestre-fisurícola a terrestre de hojas aproximadas, xerófilo, esciófilo; matorral xerófilo, bosque mixto de Quercus-Juniperus con leguminosas y tropical ripario, entre 1650 y 2400 m s.n.m.; Polotitlán, Huehuetoca, Tepotzotlán, Villa del Carbón, Otumba, Atizapán, Amecameca, Tenango del Aire, Tenancingo, Sultepec, Zacualpan.

Material de referencia: M. L. Arreguín 627 (ENCB). R. González 47 (ENCB). G. B. Hinton Aculco-47 (ENCB). E. Matuda 26800 (CODAGEM), 29190 (MEXU). L. Mazadiego 9 y L. Abundiz-Bonilla (IZTA). S. Romero y C. Rojas 769, 1559 (ENCB). D. Tejero-Díez 2081, 2774, 2878 (IZTA). D. TejeroDiez y M. Castilla 548 (ENCB, IZTA).

Distribución: México (B.C., Son., Chih., Sin., Dgo., Zac., S.L.P., Ver., Nay., Jal., Qro., Gto., Pue., Méx., Mich., D.F., Mor., Oax., Gro.).

\section{*C. angustifolia Kunth}

Hemicriptófito de hojas fasciculadas, termófilo, fotófilo; pastizal inducido y bosque de Quercus abierto, entre 1230 y 1700 m s.n.m.; Temascaltepec, Tejupilco.

Material de referencia: G. B. Hinton 83 (MEXU). J. Rzedowski 20774 (ENCB). D. Tejero-Díez 2457, 3116 (IZTA).

Distribución: México (Nay., Jal., Qro., Gto., Méx., Mich., Mor., Oax., Gro.).

*C. arizonica (Maxon) Mickel (=C. lerstenii Mickel et Beitel)

Hemicriptófito terrestre o rupestre-fisurícola en basaltos, de hojas fasciculadas, esciófilo; bosque de Quercus-Pinus y de Juniperus-Quercus, entre 2300 y 2700 m s.n.m.; Ocuilan, Malinalco.

Material de referencia: D. Tejero-Diez 2839 (IZTA), 2993 (IZTA, NY).

Distribución: Sur de E.U.A., México (Ver., Jal., Méx., Chis., Oax., Gro.) a Honduras. 
*C. bolborrhiza Mickel et Beitel

Hemicriptófito cortamente rizomatoso de hojas aproximadas, termófilo; bosque tropical caducifolio, a 2050 m s.n.m.; Malinalco.

Material de referencia: D. Tejero-Díez 2952 (IZTA).

Distribución: México (Méx., Mor., Oax.), El Salvador.

\section{C. bonariensis (Willd.) Proctor (=Notholaena aurea (Poir.) Desv.)}

Hemicriptófito cortamente rizomatoso de hojas aproximadas, xerófilo, rupícola o terrestre en taludes, fotófilo; matorral xerófilo, pastizal inducido, bosque tropical caducifolio, mixto de Quercus-Juniperus con leguminosas, de Quercus, de Quercus-Pinus, mesófilo de montaña, de Pinus, de QuercusAbies, entre 1650 y 2800 m s.n.m.; Polotitlán, Tequixquiac, Zumpango, Huehuetoca, Tepotzotlán, Villa del Carbón, Otumba, Tultitlán, Villa Nicolás Romero, Atizapán, Villa de Allende, Ixtapaluca, Metepec, Chapultepec, Temascaltepec, Valle de Bravo, Amecameca, Tenango del Aire, Sultepec, Zacualpan.

Material de referencia: A. Ascencio 65 (ENCB). E. B. Copeland 99 (MEXU). Estévez 97 (ENCB). G. B. Hinton 63 (ENCB), 3309 (MEXU). J. Martinez N. J. 100 (ENCB). E. Matuda 26381 (CODAGEM, MEXU), 26810, 27199 (CODAGEM, MEXU). J. Medina 52 (IZTA). Reeder y Reeder 2239 (MEXU). S. Romero y C. Rojas 41, 93, 161, 426, 684, 758, 783, 1046, 1255 (IZTA). M. Roldán 119 (ENCB). J. Rzedowski 18837, 20033 (ENCB). M. Salgado 61 (ENCB). M. E. Sánchez 466 (ENCB). D. Tejero-Diez y M. Castilla 439 (IZTA). D. Tejero-Díez 2090, 2518, 2780a, 3017 (IZTA).

Distribución: Suroeste de E.U.A., México (B.C., Son., Chih., Coah., N.L., Tams., Sin., Dgo., Zac., S.L.P., Ver., Jal., Hgo., Qro., Gto., Pue., Méx., Mich., Tlax., D.F., Mor., Chis., Oax., Gro.), Centro a Sudamérica, Antillas.

*C. brachypus (Kunze) Kunze (=Cheilanthes squamosa Hook. et Grev. var. brachypus Kunze; =Notholaena brachypus (Kunze) J. Sm.)

Caméfito con hojas arrosetadas, rupícola o en taludes de tierra, termófilo, fotófilo; bosque tropical caducifolio, tropical subcaducifolio, mixto de QuercusJuniperus con leguminosas, entre 1100 y 1700 m s.n.m.; Ixtapan del Oro, Sto. Tomás de los Plátanos, Tejupilco, Ixtapan de la Sal.

Material de referencia: D. Tejero-Díez 2172, 2410, 2597, 3192 (IZTA).

Distribución: México (Sin., S.L.P., Ver., Nay., Jal., Qro., Méx., Mich., Col., Chis., Oax., Gro.), Centroamérica. 


\section{C. chaerophylla (M. Martens et Galeotti) Kunze}

Hemicriptófito cortamente rizomatoso de hojas aproximadas, termófilo, en taludes de tierra o rupícola, expuesto o en semisombra; bosque tropical caducifolio y mixto de Quercus-Juniperus con leguminosas, entre 1300 y 1850 m s.n.m.; Temascaltepec, Sto. Tomás de los Plátanos, Tejupilco, Zacualpan.

Material de referencia: D. Tejero-Díez 2085, 2417, 2608, 2819 (IZTA).

Distribución: México (Jal., Méx., Mich., Col., Chis., Oax., Gro.), Costa Rica.

\section{C. cucullans Fée}

Hemicriptófito rupestre-fisurícola rizomatoso de hojas distantes, xerófilo; matorral xerófilo y bosques de Juniperus con leguminosas, entre 1850 y $2350 \mathrm{~m}$ s.n.m.; Tequixquiac, Villa del Carbón, Coacalco, Atizapán, Valle de México, Huixquilucan, Amecameca, Zumpahuacán, Zacualpan.

Material de referencia: M. Ortega 6 y L. Abundiz-Bonilla (IZTA). R. Reyes 209 (ENCB). S. Romero y C. Rojas 827 (ENCB). J. Rzedowski 18719 (ENCB, NY) 29602, 30735 (ENCB). J. G. Schaffner 82 (K holotipo; fide Mickel, 1992). D. Tejero-Díez 2073, 2775, 2861 (IZTA).

Distribución: México (Chih., Ags., Jal., Qro., Pue., Méx., Mich., D.F., Mor., Chis., Oax., Gro.).

\section{C. cuneata Kaulf. ex Link}

Hemicriptófito de hojas aproximadas en talud de tierra o rupestre-fisurícola, expuesto o en semisombra; bosque mixto de Quercus-Juniperus con leguminosas, de Pinus-Quercus, mesófilo de montaña y de Pinus, entre 1700 y 2300 m s.n.m.; Temascaltepec, Valle de Bravo, Ocuilan, Villa Guerrero, Tejupilco, Sultepec, Zacualpan.

Material de referencia: G. B. Hinton 1684 (MEXU). E. Matuda y col. 29190 (CODAGEM). J. T. Mickel 680 (ENCB). D. Tejero-Díez 2093, 2149, 2206, 2423, 2457b, 2674, 2792, 2810 (IZTA).

Distribución: México (Sin., Nay., Jal., Méx., Mich., Mor., Oax., Gro.).

*C. decomposita (M. Martens et Galeotti) Fée

Hemicriptófito de hojas fasciculadas; bosque mixto de Quercus-Pinus con leguminosas, 1850 m s.n.m.; Valle de Bravo.

Material de referencia: D. Tejero-Díez 2578 (IZTA).

Distribución: México (Sin., Ver., Nay., Jal., Col., Méx., Oax., Gro.). 


\section{C. kaulfussii Kunze}

Hemicriptófito de hojas fasciculadas, terrestre a rupícola, esciófilo; bosque tropical caducifolio, mixto de Quercus-Juniperus con leguminosas, de QuercusPinus y mesófilo de montaña, entre 1050 y 2350 m s.n.m.; Tepotzotlán, Villa Nicolás Romero, Tlalnepantla, Villa de Allende, Huixquilucan, Ixtapan del Oro, Temascaltepec, Amecameca, Ocuilan, Villa Guerrero, Malinalco, Tejupilco, Zacualpan.

Material de referencia: M. Cervantes 30 (ENCB). B. E. Gutiérrez 330 (ENCB). L. Luna s. n. 18/sep./1977 (ENCB). W. E. Manning y M. S. Manning 5311 (MEXU). E. Matuda 30332 (MEXU). R. Ramírez 101 (ENCB). R. Riba s. n. dic./1961 (MEXU). V. Rivera 1 (IZTA). J. Rzedowski 29635 (ENCB). D. Tejero-Díez 2166, 2208, 2230, 2422, 2458, 2623, 2809 (IZTA).

Distribución: Sur de E.U.A., México (Son., Chih., N.L., Sin., Dgo., Zac., S.L.P., Ver., Ags., Nay., Jal., Qro., Pue., Méx., Mich., D.F., Mor., Chis., Oax., Gro.), Centro a Sudamérica.

\section{Iendigera (Cav.) Sw. (=C. frigida Linden ex T. Moore)}

Hemicriptófito rupestre-fisurícola, sobre tierra o geófito rizomatoso de hojas distantes, esciófilo; bosque mixto de Quercus-Juniperus con leguminosas, de Quercus, matorral xerófilo, pastizal con matorral de Quercus, bosque mesófilo de montaña, de Pinus-Quercus, de Abies-Quercus, entre 1750 y 3000 m s.n.m.; Jilotepec, Temascalapa, Huehuetoca, San Martín de las Pirámides, Tepotzotlán, Coacalco, Texcoco, Zinacantepec, Valle de Bravo, Amecameca, Texcalyacac, Ocuilan, Malinalco.

Material de referencia: M. L. Arreguín 518 (ENCB). A. Arizmendi 26 (ENCB). D. Ascencio 75 (ENCB). S. Gaona 845 (ENCB). M. Martínez 2 (IZTA). H. Sánchez-Mejorada 779 (MEXU). J. Rzedowski 18813, 34557 (ENCB). D. Tejero-Díez y M. Castilla 410, 1122, 2955 (IZTA). D. Tejero-Díez 2211, 2703, 2836, 2898, 2982, 2992 (IZTA). N. Valentín 160 (ENCB).

Distribución: Sur de E.U.A., México (Son., Chih., Sin., Dgo., Zac., S.L.P., Ver., Jal., Hgo., Qro., Gto., Pue., Méx., Mich., Tlax., D.F., Mor., Chis., Oax., Gro.), Centro a Sudamérica, Antillas.

\section{*C. longipila Baker var. longipila}

Hemicriptófito de hojas fasciculadas, rupícola en roca sedimentaria cálcica; bosque mixto de Juniperus con leguminosas, $1850 \mathrm{~m}$ s.n.m.; Zumpahuacán.

Material de referencia: H. Sánchez-Mejorada 812 (MEXU). D. TejeroDíez 2857, 3030 (IZTA).

Distribución: México (S.L.P., Jal., Méx., Oax., Gro.). 
C. lozanii (Maxon) R. M. Tryon et A. F. Tryon var. lozanii (=Pellaea lozanii Maxon)

Hemicriptófito de hojas fasciculadas, termófilo, en taludes de tierra riparios o ruderales; bosque tropical caducifolio, tropical ripario y tropical subcaducifolio, entre 450 y 1400 m s.n.m.; Valle de Bravo, Sto. Tomás de los Plátanos, Zacazonapan, Tejupilco, Tlatlaya.

Material de referencia: E. Matuda 27189, 31053, 31452, 31144, 31452, 31543 (CODAGEM, MEXU). D. Tejero-Díez, 2408, 2637, 2649 (intermedio entre las dos variedades), 2825, 3189 (IZTA).

Distribución: México (Mich., Méx., D.F., Col., Chis., Oax., Gro.).

*C. lozanii var. seemannii (Hook.) Mickel et Beitel (=Pellaea seemannii Hook.)

Hemicriptófito de hojas fasciculadas, rupícola y en taludes de tierra; bosque tropical subcaducifolio, a 1300 m s.n.m.; Malinalco.

Material de referencia: D. Tejero-Díez 3061 (IZTA).

Distribución: México (B.C., Son., Chih., Sin., Dgo., S.L.P., Nay., Jal., Qro., Gto., Méx., Mich., Mor., Chis., Oax., Gro.).

C. marginata Kunth

Hemicriptófito de hojas fasciculadas, rupestre-fisurícola, fotófilo; bosque de Quercus con elementos mesófilos y de Pinus-Abies, entre 2600 y 3000 m s.n.m.; Naucalpan, Ocoyoacac, Tlalmanalco.

Material de referencia: Fisher 35408 (NY). A. M. Hernández 17 (ENCB). J. T. Mickel 650 (ENCB). E. Román 204 (ENCB). J. Rzedowski 29257 (ENCB).

Distribución: México (N.L., Ags., Qro., Gto., Pue., Méx., Mich., D.F., Mor., Chis., Oax., Gro.), Centro a Sudamérica.

*C. marsupiantes (Fée) T. Reeves ex Mickel et A. R. Sm.

Caméfito rizomatoso en peñascos expuestos; bosque de Quercus y de Pinus-Abies, entre 2600 y 3000 m s.n.m.; Zinacantepec, San Martín de las Pirámides.

Material de referencia: E. Matuda 31197 (UC, US). J. Rzedowski 18813 (MICH). (J. T. Mickel, com. pers. en 2001). D. Tejero-Díez 2703 (IZTA). E. Ventura 1446 (MEXU).

Distribución: México (Ver., Pue., Méx., Tlax.). 
*C. mexicana Davenp.

Hemicriptófito rizomatoso de hojas distantes, rupícola en cantiles subexpuestos; matorral xerófilo, bosques de Quercus, entre 2250 y 2400 m s.n.m.; Teotihuacan, Huixquilucan.

Material de referencia: J. Rzedowski 37147 (IEB). J. G. Schaffner 42 (NY). (J. T. Mickel, com. pers. en 2001).

Distribución: México (Chih., S.L.P., Méx.), Guatemala.

C. microphylla (Sw.) Sw.

Hemicriptófito rizomatoso de hojas aproximadas; bosque de Pinus-Quercus, ca. 2700 m s.n.m.; Tlalmanalco.

Material de referencia: J. G. Schaffner 50 (P, colectado en 1877).

Distribución: Sur-sureste de E.U.A., México (Son., Chih., Coah., N.L., Tams., Dgo., Zac., S.L.P., Ver., Jal., Hgo., Qro., Gto., Méx., Mich., D.F., Mor., Chis., Oax., Gro.), Centro a Sudamérica, Antillas.

\section{C. myriophylla Desv.}

Hemicriptófito de hojas fasciculadas, xerófilo, en taludes de tierra y piso, fotófilo; matorral xerófilo o matorrales secundarios, pastizal, bosque tropical caducifolio, mixto de Quercus-Juniperus con leguminosas y de Quercus-Pinus, entre 1500 y 2700 m s.n.m.; Polotitlán, Jilotepec, Tequixquiac, Zumpango, Huehuetoca, Tepotzotlán, Villa del Carbón, Otumba, Atizapán, Metepec, Temascaltepec, Texcoco, Tenango del Aire, Tenango del Valle, Ocuilan, Malinalco, Ixtapan de la Sal, Sultepec, Zacualpan.

Material de referencia: M. L. Arreguín 651 (ENCB). C. Bautista 14 (ENCB). Delgado Ramírez 1 (IZTA). L. Estévez s. n. 18/oct./1980 (ENCB). Gómez Ramírez s. n. 25/ene./1981 (IZTA). J. Hinton A-46 (ENCB). G. B. Hinton 4165 (MEXU). E. Matuda 26768 (CODAGEM). J. Medina 53 (IZTA). Moctezuma López 42 (IZTA). L. Pérez 1013 (ENCB). S. Romero y C. Rojas 527, 758a, 785, 1118, 1692 (IZTA). J. Rzedowski 20032, 30952 (ENCB). D. Tejero-Díez y M. Castilla 465 (IZTA). D. Tejero-Diez 2087, 2170b, 2669b, 2759, 2776, 2835 (IZTA). E. Ventura 1666 (ENCB). Webster y Breckon 16243, 16247 (MEXU).

Distribución: México (B.C., Chih., Dgo., Zac., S.L.P., Ver., Ags., Jal., Hgo., Qro., Gto., Pue., Méx., Mich., Tlax., D.F., Mor., Oax., Gro.), Centro a Sudamérica.

C. notholaenoides (Desv.) Maxon ex Weath.

Hemicriptófito rizomatoso de hojas aproximadas, rupícola o en taludes de tierra, esciófilo; bosque mixto de Quercus-Juniperus con leguminosas y mesófilo 
de montaña, entre 1700 y 2100 m s.n.m.; Ixtapan del Oro, Coatepec Harinas, Zacualpan.

Material de referencia: E. Matuda 30553 (MEXU), 30718 (CODAGEM). D. Tejero-Díez 2083, 2130, 2584 (IZTA).

Distribución: Sur de E.U.A., México (Chih., Coah., N.L., Tams., Zac., S.L.P., Q.R., Ver., Jal., Hgo., Qro., Pue., Méx., Mich., D.F., Mor., Chis., Oax., Gro.), Centro a Sudamérica, Antillas.

\section{C. pyramidalis Fée}

Hemicriptófito de hojas fasciculadas, mesófilo, fotófilo; matorral xerófilo, pastizal inducido y matorral secundario, bosque mesófilo de montaña, de Quercus, de Pinus-Quercus y de Pinus-Abies, entre 2050 y 2950 m s.n.m.; Huehuetoca, San Martín de las Pirámides, Tepotzotlán, Otumba, Villa Nicolás Romero, Atizapán, Texcoco, Naucalpan, Jilotzingo, Ixtapaluca, Huixquilucan, Tlalmanalco, Valle de Bravo, Amecameca, Juchitepec, Ocuilan, Villa Guerrero, Coatepec Harinas, Tejupilco.

Material de referencia: A. Amador 80 (ENCB). M. L. Arreguín 460 (ENCB). R. Cruz 1286 (ENCB). A. Huerta 16 (ENCB). J. Ochoa 38 (ENCB). L. Paray 2433 (ENCB). C. Pérez del Valle 3 y L. Abundiz-Bonilla (IZTA). M. E. Rodríguez s. n. 12/oct./1975 (ENCB). J. Rzedowski 18710, 18768, 20115, 29669 (ENCB). D. Tejero-Díez 2115, 2144, 2559, 2925, 3107 (IZTA). D. Tejero-Díez y M. Castilla 563, 1248, (ENCB). G. Vázquez 13 (ENCB).

Distribución: México (B.C., Son., Chih., Sin., Dgo., Zac., S.L.P., Ver., Ags., Nay., Col., Jal., Hgo., Qro., Gto., Pue., Méx., Mich., Tlax., D.F., Mor., Chis., Oax., Gro.), Centroamérica.

*C. skinneri (Hook.) T. Moore (=Pellaea skinneri Hook.)

Hemicriptófito en taludes de tierra ruderales y riparios, termófilo, esciófilo; bosque tropical caducifolio, tropical ripario, tropical subcaducifolio y mixto de Quercus-Juniperus con leguminosas, entre 450 y 1500 m s.n.m.; Sto. Tomás de los Plátanos, Zacazonapan, Tejupilco, Ixtapan de la Sal, Tlatlaya.

Material de referencia: J. Rzedowski 20736 (ENCB). D. Tejero-Díez 2185, 2409, 2415, 2419, 2607, 2648, 2829 (IZTA).

Distribución: México (B.C., Chih., Sin., Dgo., Ver., Nay., Jal., Méx., Mich., Col., Mor., Chis., Oax., Gro.), Centroamérica.

Cheiloplecton rigidum (Sw.) Fée var. rigidum

Hemicriptófito de hojas fasciculadas, termófilo, fotófilo; bosque tropical caducifolio y bosque mixto de Quercus-Juniperus con leguminosas, entre 600 
y 2100 m s.n.m.; Temascaltepec, Valle de Bravo, Sto. Tomás de los Plátanos, Zacazonapan, Ocuilan, Malinalco, Tejupilco, Ixtapan de la Sal, Almoloya de Alquisiras, Tlatlaya.

Material de referencia: E. Matuda 30002 (CODAGEM). J. T. Mickel 686 (ENCB, NY). Née s. n. (MA tipo; fide Mickel, 1992). Sepúlveda 12 (ENCB). D. Tejero-Díez 2067, 2168, 2561, 2613, 2636, 2787, 2827, 2842 (IZTA).

Distribución: México (Chih., Zac., S.L.P., Ver., Nay., Jal., Hgo., Qro., Pue., Méx., Mich., Mor., Chis., Oax., Gro.), Centroamérica.

*Hemionanthes gryphus (Mickel) Mickel

Hemicriptófito terrestre de hojas fasciculadas; ecotonía del bosque tropical caducifolio y el bosque mixto de Quercus con leguminosas, a $1400 \mathrm{~m}$ s.n.m.; Tejupilco.

Material de referencia: E. Velázquez Montes 1149 (MEXU).

Distribución: México (Nay., Méx., Mich., Col.).

Hemionitis subcordata (D. C. Eaton ex Davenp.) Mickel (=Gymnogramma subcordata D.C. Eaton ex Davenp.; =Coniogramme americana Maxon)

Hemicriptófito de hojas fasciculadas, termófilo, en taludes de tierra ruderales; bosque tropical caducifolio y tropical ripario, entre 600 y 1000 m s.n.m.; Tejupilco, Tlatlaya.

Material de referencia: G. B. Hinton 8062 (ENCB, MEXU). E. Matuda 31059 (CODAGEM).

Distribución: México (Sin., Nay., Jal., Méx., Mich., Chis., Oax., Gro.), Centroamérica.

Mildella fallax (M. Martens et Galeotti) Nesom (=M. intramarginalis (Kaulf. ex Link) Trevis. var. serratifolia (Hook. et Baker) C. C. Hall et Lellinger)

Hemicriptófito con hojas fasciculadas, saxícola; bosque de Quercus, mesófilo de montaña, de Pinus-Quercus, de Pinus y de Abies-Pinus, entre 2000 y 2900 m s.n.m.; Villa del Carbón, Villa Nicolás Romero, Naucalpan, Huixquilucan, Amanalco de Becerra, Tlalmanalco, Amecameca, Ocuilan, Tenancingo.

Material de referencia: M. L. Arreguín 570, 654 (ENCB). R. Hernández 163 (ENCB). J. L. López 86 (ENCB). I. Martínez 72 (ENCB). Y. Maya IV-7 (ENCB). L. Quiroz 5111 (ENCB, MEXU). J. Rzedowski 31638 (ENCB). D. TejeroDíez 2051, 2202, 2690a (IZTA). L. Villasana 149 y D. Tejero-Díez (IZTA).

Distribución: México (N.L., Tams., Ver., Jal., Hgo., Qro., Gto., Pue., Méx., Mich., Tlax., D.F., Mor., Chis., Oax., Gro.), Centroamérica. 
Especie probable de encontrar: M. intramarginalis (Kaulf. ex Link) Trevis., que se distribuye en los estados de Querétaro, Michoacán y Morelos en ambientes compartidos con el área de estudio.

Notholaena candida (M. Martens et Galeotti) Hook. (=Cheilanthes candida M. Martens et Galeotti)

Hemicriptófito de hojas fasciculadas, termófilo; bosque tropical caducifolio, tropical subcaducifolio y mixto de Quercus-Juniperus con leguminosas, entre 900 y 1740 m s.n.m.; Sto. Tomás de los Plátanos, Malinalco, Sultepec, Tonatico.

Material de referencia: D. Tejero-Díez 2840, 3026, 3068, 3071, 3186 (IZTA).

Distribución: Sur de E.U.A., México (B.C., Son., Chih., Coah., N.L., Tams., Sin., Dgo., S.L.P., Ver., Nay., Jal., Hgo., Qro., Gto., Pue., Méx., Mich., Col., Mor., Chis., Oax., Gro.), Centroamérica.

\section{N. galeottii Fée (=Cheilanthes galeottii (Fée) Mickel et Beitel)}

Hemicriptófito de hojas fasciculadas en taludes de tierra ruderales y riparios, termófilo; bosque tropical caducifolio, tropical subcaducifolio y mixto de QuercusJuniperus con leguminosas, entre 1100 y 1850 m s.n.m.; Sto. Tomás de los Plátanos, Zumpahuacán, Ixtapan de la Sal, Sultepec.

Material de referencia: D. Tejero-Díez 2170a, 2669a, 2856, 3187 (IZTA).

Distribución: México (B.C., Chih., N.L., Sin., Dgo., S.L.P., Ver., Jal., Hgo., Qro., Gto., Méx., Mich., Tlax., D.F., Mor., Oax., Gro.), Guatemala.

*N. lemmonii D.C. Eaton var. australis R. M. Tryon

Hemicriptófito rupícola de hojas fasciculadas, fotófilo; bosque tropical subcaducifolio, a 1300 m s.n.m.; Malinalco.

Material de referencia: D. Tejero-Díez 3064 (IZTA).

Distribución: México (Jal., Pue., Méx., Mich., Oax.).

*N. schaffneri (E. Fourn.) Underw. ex Davenp.

Hemicriptófito rupestre-fisurícola de hojas fasciculadas, esciófilo; bosque tropical subcaducifolio, a 1150 m s.n.m.; Ocuilan.

Material de referencia: D. Tejero-Díez 3058 (IZTA).

Distribución: Sur de E.U.A., México (N.L., S.L.P., Zac., Ver., Gto. Pue., Méx., D.F., Mich., Mor., Oax., Gro.), Jamaica.

Especie probable de encontrar: Notholaena aschenborniana Klotzsch (=Cheilanthes aschenborniana (Klotzsch) Mett.); Mickel (1992) la citó erróneamente 
para el área de estudio al confundir el estado de donde procede el ejemplar tipo Aschenborn 593 (B) (colectado en Chapultepec, Mor.). Sin embargo, es posible que se pueda localizar en el área de estudio.

Pellaea cordifolia (Sessé et Moc.) A. R. Sm.

Hemicriptófito de hojas fasciculadas, rupícola o terrestre, xerófilo, sitios subexpuestos; matorral xerófilo, pastizal inducido, bosque mixto de QuercusJuniperus con leguminosas, de Quercus y de Pinus-Quercus, entre 1700 y 2750 m s.n.m.; Polotitlán, Aculco, Tequixquiac, Zumpango, Huehuetoca, El Oro, Tepotzotlán, Villa del Carbón, Jocotitlán, Otumba, Coacalco, Atizapán, Texcoco, Villa Victoria, Ixtapaluca, Ixtapan del Oro, Valle de Bravo, Amecameca.

Material de referencia: F. Arreguín 90 (ENCB). M. L. Arreguín 519, 632 (ENCB). L. V. González 195, 232 (IZTA). E. Matuda 27687 (MEXU). J. Rzedowski 18311, 30756 (ENCB, MEXU). S. Romero y C. Rojas 189b, 496, 759, 836, 1255a, 1390, 1569 (IZTA). R. M. Suárez y J. L. Ortíz 348 (ENCB). D. Tejero-Díez 2137, 2252, 2257, 2533, 2596, 2779, 2948 (IZTA). D. TejeroDíez y M. Castilla 521, 569 (IZTA). T. Velázquez 4 y L. Abundiz-Bonilla (IZTA). Distribución: Suroeste de E.U.A., México (Chih., Coah., N.L., Dgo., S.L.P., Ags., Jal., Hgo., Qro., Gto., Pue., Méx., Mich., D.F., Mor., Chis., Oax., Gro.), Centroamérica.

\section{*P. oaxacana Mickel et Beitel}

Hemicriptófito rizomatoso de hojas aproximadas, rupícola en taludes, termófilo; bosque tropical caducifolio, a 1300 m s.n.m.; Sto. Tomás de los Plátanos.

Material de referencia: D. Tejero-Díez 2606 (IZTA).

Distribución: México (Jal., Nay., Méx., Mor., Oax., Gro.).

\section{P. ovata (Desv.) Weath.}

Hemicriptófito rizomatoso de hojas aproximadas, rupícola o terrestre en taludes, mesófilo; bosque tropical caducifolio, subcaducifolio, ripario tropical, mixto de Quercus-Juniperus con leguminosas, mesófilo de montaña, de Pinus-Quercus, matorral secundario y huertos familiares, entre 1650 y 2550 m s.n.m.; Teotihuacan, Texcoco, Ixtapan del Oro, Temascaltepec, Valle de Bravo, Texcalyacac, Tepetlixpa, Coatepec Harinas, Zacualpan.

Material de referencia: F. H. Gómez 002 (ENCB). A. L. Herrera 61 (ENCB). H. Sánchez-Mejorada 784 (MEXU). D. Tejero-Díez 2086, 2137, 2466, 2617, 2998 (IZTA). R. M. Tryon y A. F. Tryon 5134 (MEXU). A. Ventura 4319 (ENCB). 
Distribución: Sur de E.U.A., México (B.C., Son., Chih., Coah., N.L., Tams., Dgo., Zac., S.L.P., Ver., Ags., Nay., Jal., Hgo., Qro., Gto., Pue., Méx., Mich., D.F., Mor., Chis., Oax., Gro.), Centro a Sudamérica.

\section{P. pringlei Davenp.}

Hemicriptófito de hojas fasciculadas, rupícola o terrestre, fotófilo; pastizal inducido y sitios abiertos, bosque tropical caducifolio y mesófilo de montaña, entre 1800 y 2150 m s.n.m.; Temascaltepec, Ocuilan.

Material de referencia: G. B. Hinton 1537 (MEXU). D. Tejero-Díez 2793, 2815 (IZTA).

Distribución: México (Sin., Nay., Jal., Méx., Col., Mor., Gro.).

\section{P. sagittata (Cav.) Link}

Hemicriptófito a geófito, corta a largamente rizomatoso, de hojas aproximadas, rupícola o terrestre en taludes; bosque tropical caducifolio, tropical ripario, mixto de Quercus-Juniperus con leguminosas, mesófilo de montaña, de Quercus-Pinus, de Pinus-Quercus, matorral xerófilo secundario, pastizal secundario y como maleza en bordos de cultivos, entre 1650 y 2500 m s.n.m.; Aculco, Jilotepec, Tepotzotlán, Villa de Allende, Ixtapan del Oro, Valle de Bravo, Amecameca, Tenango del Aire, Ocuilan, Joquicingo, Coatepec Harinas, Tejupilco, Sultepec, Zacualpan.

Material de referencia: R. J. Barr 62-790 y R. H. Helvy 2799 (MEXU). R. Cruz 1098 (ENCB). A. Flores 38 (ENCB). A. García 107-A (ENCB). G. B. Hinton 1539 (MEXU). E. Matuda 26719, 27204 (CODAGEM, MEXU). $A$. Pineda 458 (ENCB). D. Tejero-Díez s. n. 7/ago./1990, 2103, 2137, 2286, 2528, 2616, 2843, 2989, 3006 (IZTA). R. M. Tryon y A. F. Tryon 5138 (MEXU).

Distribución: Sur de E.U.A., México (Chih., Zac., S.L.P., Jal., Hgo., Qro., Gto., Pue., Méx., Mich., D.F., Tlax., Mor., Chis., Oax., Gro.), Centro a Sudamérica.

*P. ternifolia (Cav.) Link subsp. arizonica Windham

Hemicriptófito de hojas fasciculadas, saxícola o terrestre, mesófilo, fotófilo; bosque de Quercus y de Quercus-Pinus, entre 1950 y 2500 m s.n.m.; Chapa de Mota, Temascaltepec.

Material de referencia: D. Tejero-Díez 2811, 4177 (IZTA).

Distribución: Sureste de E.U.A., México (Chih., Son., Méx.).

\section{P. ternifolia (Cav.) Link subsp. ternifolia}

Hemicriptófito de hojas fasciculadas, saxícola o terrestre, mesófilo, fotófilo; bosque de Quercus, de Quercus-Pinus, de Abies-Quercus y matorrales 
secundarios asociados, entre 2300 y 2800 m s.n.m.; Polotitlán, Jilotepec, Acambay, Zumpango, Huehuetoca, Tepotzotlán, Otumba, Atizapán, Texcoco, Villa de Allende, Lerma, Metepec, Temascaltepec, Valle de Bravo, Amecameca, Tenango del Aire, Ocuilan.

Material de referencia: M. L. Arreguín 521 (ENCB). R. Cruz 1839 (ENCB). I. R. Estévez 109 (ENCB). J. García 301 (ENCB). J. Hinton, Aculco-86 (ENCB). J. M. Macias 67 (ENCB). E. Matuda 26823, 26520 (MEXU). L. Mazadiego 19 y L. Abundiz-Bonilla (IZTA). G. Pérez 135 (ENCB). C. G. Pringle s. n. 21/ ago./1890 (MEXU). Reeder y Reeder 2237 (MEXU). S. Romero y C. Rojas 1122 (IZTA). H. Sánchez-Mejorada 365 (MEXU). D. Tejero-Díez 2990 (IZTA). D. Tejero-Díez y M. Castilla 568 (IZTA).

Distribución: México (B.C., Son., Chih., Coah., N.L., Sin., Dgo., S.L.P., Ver., Jal., Hgo., Qro., Gto., Pue., Méx., Mich., Tlax., D.F., Mor., Chis., Oax., Gro.), Centro a Sudamérica, Antillas y Hawai.

*P. ternifolia (Cav.) Link subsp. villosa Windham

Hemicriptófito de hojas fasciculadas, saxícola o terrestre, fotófilo; bosque de Quercus a 2650 m s.n.m.; Acambay.

Material de referencia: J. Rzedowski 22894 (ENCB). D. Tejero-Díez 2492 (IZTA).

Distribución: México (Chih., Coah., Dgo., S.L.P., Pue., Méx.).

Especie probable de encontrar: $P$ atropurpurea (L.) Link, la cual crece a lo largo del Altiplano Mexicano y el sureste de México.

Pityrogramma calomelanos (L.) Link

Caméfito a hemicriptófito de hojas fasciculadas, termófilo, fotófilo, en taludes ruderales de lutitas y arenas; bosque tropical caducifolio y subcaducifolio, entre 850 y 1300 m s.n.m.; Malinalco, Tejupilco, Tlatlaya.

Material de referencia: G. B. Hinton 2585 (MEXU). D. Tejero-Díez 2650, 3059 (IZTA).

Distribución: Sureste de E.U.A., México (Sin., S.L.P., Ver., Nay., Jal., Hgo., Qro., Méx., Col., Tab., Mich., Chis., Oax., Gro.), Centro a Sudamérica, Antillas.

P. ebenea (L.) Proctor (=P. tartarea (Cav.) Maxon)

Hemicriptófito a caméfito de hojas fasciculadas, ripícola; bosque de QuercusPinus, templado ripario, mesófilo de montaña, entre 1750 y 2350 m s.n.m.; Temascaltepec, Valle de Bravo, Ocuilan, Tejupilco, Sultepec, Zacualpan. 
Material de referencia: Dunn y Dunn 18920 (ENCB). G. B. Hinton 7434 (MEXU). E. Matuda 27370, 30710, 30746 (MEXU). D. Tejero-Diez 1978a, 2226, 2250, 2309, 2807, 2689 (IZTA).

Distribución: México (Ver., Nay., Jal., Hgo., Qro., Gto., Pue., Méx., Mich., Mor., Chis., Oax., Gro.), Centro a Sudamérica, Antillas.

\section{Pteris cretica L.}

Hemicriptófito rizomatoso de hojas aproximadas, ripícola, esciófilo; bosque templado ripario, de Quercus y mesófilo de montaña, entre 1800 y 2550 m s.n.m.; Villa Nicolás Romero, Villa de Allende, Temascaltepec, Amecameca, Ocuilan, Tejupilco, Ixtapan de la Sal, Sultepec, Zacualpan.

Material de referencia: J. Díaz s. n. 27/agosto/1982 (ENCB). G. B. Hinton 7424 (ENCB, MEXU), 2804 (MEXU), 7424 (ENCB, MEXU). E. Matuda 26814, 27441, 30337 (CODAGEM, MEXU), 26458 (CODAGEM, MEXU). J. Rzedowski 26737, 27123, 30329 (ENCB). D. Tejero-Díez 2099, 2248, 2602 (IZTA).

Distribución: Sureste de E.U.A., México (Chih., N.L., S.L.P., Ver., Jal., Hgo., Qro., Gto., Pue., Méx., Mich., D.F., Mor., Chis., Oax., Gro.), Centro a Sudamérica, Antillas, regiones tropicales del Viejo Mundo.

P. erosa Mickel et Beitel

Caméfito a hemicriptófito de hojas fasciculadas; bosque mesófilo de montaña, entre 2000 y 2300 m s.n.m.; Ocuilan, Tejupilco, Zacualpan.

Material de referencia: G. B. Hinton 6049 (NY paratipo; fide Mickel et Beitel, 1988). D. Tejero-Díez 3028, 3167 (IZTA).

Distribución: México (Ver., Nay., Jal., Méx., Oax.).

\section{P. longifolia L.}

Hemicriptófito a caméfito de hojas fasciculadas, en taludes ruderales, termófilo; bosque tropical caducifolio, entre 600 y 950 m s.n.m.; Sto. Tomás de los Plátanos, Zacazonapan, Tejupilco.

Material de referencia: G. B. Hinton 3961, 4496 (MEXU). H. SánchezMejorada s. n. 15/mayo/1952 (MEXU). D. Tejero-Diez 2640, 2826 (IZTA).

Distribución: Sureste de E.U.A., México (S.L.P., Ver., Hgo., Qro., Méx., Mich., Col., Tab., Mor., Chis., Oax., Gro.), Centroamérica, Antillas. 
P. orizabae M. Martens et Galeotti

Geófito a hemicriptófito rizomatoso de hojas distantes, esciófilo; bosque mesófilo de montaña y templado ripario, entre 2200 y 2700 m s.n.m.; Tlalmanalco, Temascaltepec, Ocuilan, Zacualpan.

Material de referencia: M. L. Arreguín 503 (ENCB). A. Martínez 155 (ENCB). E. Matuda 30564 (CODAGEM, MEXU). A. Moreno 161 (ENCB). J. Rzedowski 27256 (ENCB). D. Tejero-Díez 2364, 2684 (IZTA).

Distribución: México (Ver., Jal., Hgo., Qro., Méx., Mich., Mor., Chis., Oax., Gro.), Centroamérica.

\section{P. quadriaurita Retz.}

Hemicriptófito de hojas fasciculadas en taludes ruderales húmedos; bosque tropical caducifolio, entre 1000 y 1500 m s.n.m.; Zacazonapan, Tejupilco.

Material de referencia: E. Matuda 30501 (CODAGEM, MEXU). D. TejeroDíez 2830 (IZTA).

Distribución: México (Ver., Nay., Jal., Qro., Méx., Mich., Mor., Chis., Oax., Gro.), Centro a Sudamérica, Antillas.

Trismeria trifoliata (L.) Diels (=Pityrogramma trifoliata (L.) R. M. Tryon)

Hemicriptófito rizomatoso de hojas aproximadas, ripícola, fotófilo; bosque tropical subcaducifolio, a 1400 m s.n.m.; Sto. Tomás de los Plátanos.

Material de referencia: H. Sánchez-Mejorada 789 (ENCB, MEXU).

Distribución: México (B.C., S.L.P., Ver., Hgo., Méx., Mich., Chis., Oax., Gro.), Centro a Sudamérica, Antillas.

SALVINIACEAE

*Azolla filiculoides Lam. (=A. caroliniana Mett.)

Hidrófito libre flotante en charcas y lagunetas ruderales; al lado de matorral y pastizal inducidos, a 2250 m s.n.m.; Jilotepec, Zumpango, Tepotzotlán.

Material de referencia: L. González Gutiérrez 246 y D. Tejero-Diez (IZTA). J. Rzedowski 20325, 31984, 33730 (ENCB).

Distribución: México (Chih., Pue., Méx., Mor.), Guatemala y Sudamérica.

\section{A. microphylla Kaulf. (=A. mexicana C. Presl)}

Hidrófito libre flotante en lagunas naturales, charcas ruderales y represas antropógenas; al lado de pastizal inducido, matorral xerófilo secundario, bosque 
mesófilo de montaña y de Pinus-Abies, entre 2100 y 2850 m s.n.m.; Jilotepec, Atlacomulco, Villa Victoria, Villa de Allende, Toluca, Capulhuac, Almoloya del Río.

Material de referencia: R. Cruz 1815 (ENCB). L. González Gutiérrez 193a

y D. Tejero-Díez (IZTA). D. Tejero-Diez 2029, 2542, 2625, 2932, 3077, 3200 (IZTA).

Distribución: E.U.A., México (Sin., Ver., Ags., Nay., Jal., Pue., Méx., Mich., D.F., Gro.).

SCHIZAEACEAE

*Anemia adiantifolia (L.) Sw.

Hemicriptófito rizomatoso de hojas aproximadas, termófilo, esciófilo; bosque tropical caducifolio y mixto de Quercus-Juniperus con leguminosas, entre 950 y 1850 m s.n.m.; Zacazonapan, Zumpahuacán.

Material de referencia: D. Tejero-Díez 2824, 2863 (IZTA).

Distribución: Sureste de E.U.A., México (Chih., N.L., Tams., S.L.P., Q.R., Yuc., Ver., Hgo., Qro., Méx., Tab., Mor., Chis., Oax., Gro.), Centro a Sudamérica, Antillas.

\section{A. hirsuta (L.) Sw.}

Hemicriptófito de hojas fasciculadas, termófilo, fotófilo, en taludes ruderales; pastizal inducido al lado del bosque tropical caducifolio, entre 1400 y 1600 m s.n.m.; Temascaltepec, Valle de Bravo, Ixtapan de la Sal, Tejupilco.

Material de referencia: G. B. Hinton 1640 (MEXU, NY). J. T. Mickel 1335 (NY). H. Sánchez-Mejorada 785 (ENCB, MEXU). D. Tejero-Díez 2173, 2407 (IZTA).

Distribución: México (Sin., Ver., Jal., Méx., Mich., Col., Mor., Chis., Oax., Gro.), Centro a Sudamérica.

\section{A. jaliscana Maxon}

Hemicriptófito de hojas fasciculadas, termófilo, en sotobosque o sitios abiertos; bosque mixto de Quercus-Juniperus con leguminosas, entre 1100 y 1800 m s.n.m.; Malinalco, Zacualpan, Amatepec.

Material de referencia: J. T. Mickel 1337 (NY). E. Matuda y col. 31340 (CODAGEM, ENCB, MEXU). D. Tejero-Diez 2758, 3015 (IZTA).

Distribución: México (B.C., Son., Sin., Nay., Jal., Méx., Mich., Gro.).

\section{A. karwinskyana (C. Presl) Prantl}

Hemicriptófito cortamente rizomatoso de hojas aproximadas, mesófilo, esciófilo, rupícola en hendiduras o en taludes de tierra ruderales; bosque tropical 
caducifolio, mixto de Quercus-Juniperus con leguminosas, de Quercus y de PinusQuercus, entre 1000 y 2100 m s.n.m.; Temascaltepec, Valle de Bravo, Tejupilco, Ixtapan de la Sal, Sultepec, Zacualpan, Amatepec.

Material de referencia: Anderson y Laskowski 3972 (ENCB). E. Guízar 326 (CHAPA, ENCB, MEXU). G. B. Hinton 1653 (MEXU), 2141 (ENCB). F. W. Karwinski "exs. n. 8" (B holotipo, NY, US isotipos; fide Mickel, 1992). E. Matuda y col. 29856 (CODAGEM, ENCB, MEXU, US), 31340 (CODAGEM, ENCB, MEXU), 31340 (CODAGEM, MEXU), 31346 (MEXU), 31466 (CODAGEM). J. Rzedowski 20706 (ENCB, NY). D. Tejero-Diez s. n. 1/sep./ 1991, 2094, 2178, 2460, 2522, 2918, 2923, 3016 (IZTA).

Distribución: México (Nay., Jal., Méx., Mich., Mor., Oax., Gro.).

\section{*A. mexicana Klotzsch var. mexicana}

Hemicriptófito cortamente rizomatoso de hojas aproximadas, en taludes, termófilo; bosque tropical caducifolio, entre 600 y 1900 m s.n.m.; Tejupilco, Amatepec.

Material de referencia: E. Matuda 37304 (CODAGEM, MEXU). D. TejeroDíez 2639, 2635 (IZTA).

Distribución: Sur de E.U.A., México (Coah., N.L., Tams., S.L.P., Hgo., Qro., Gto., Méx., Mor., Gro.).

*A. oblongifolia (Cav.) Sw.

Hemicriptófito cortamente rizomatoso de hojas aproximadas, rupestrefisurícola, termófilo, fotófilo; bosque mixto de Quercus-Juniperus con leguminosas, 1250 m s.n.m.; Tejupilco.

Material de referencia: G. B. Hinton 2166 (MEXU).

Distribución: México (Sin., Nay., Jal., Méx., Chis., Oax., Gro.), Centro a Sudamérica.

*A. phyllitidis (L.) Sw.

Hemicriptófito cortamente rizomatoso de hojas aproximadas, rupestrefisurícola o terrestre, termófilo, esciófilo; bosques tropical caducifolio y de QuercusPinus, entre 950 y 1700 m s.n.m.; Tejupilco.

Material de referencia: D. Tejero-Diez 2658, 3118 (IZTA).

Distribución: México (S.L.P., Ver., Nay., Jal., Hgo., Qro., Méx., Mich., Col., Chis., Oax., Gro.), Centro a Sudamérica, Antillas.

\section{A. xrecondita Mickel}

Hemicriptófito cortamente rizomatoso con hojas fasciculadas; matorral inducido a partir del bosque de Quercus, a 2200 m s.n.m.; Ixtapan de la Sal. 
Material de referencia: J. T. Mickel $712 b$ (ENCB), 1336 (NY).

Distribución: México (Nay., Jal., Méx., Mor., Mich., Oax., Gro.).

Especies probables de encontrar: A. pastinacaria Moritz ex Prantl y $A$. tomentosa (Sav.) Sw. var. mexicana (C. Presl) Mickel, dado que se distribuyen en los estados vecinos en la cuenca del río Balsas, en alturas y vegetación que se extienden al área de estudio.

\section{Lygodium venustum Sw.}

Hemicriptófito de hojas fasciculadas trepadoras (hasta $5 \mathrm{~m}$ ), termófilo; bosque tropical ripario y como maleza en cultivos cercanos, entre 500 y 1000 m s.n.m.; Tejupilco.

Material de referencia: G. B. Hinton 7392 (MEXU, NY). E. Matuda 31920 (MEXU). D. Tejero-Diez 2662 (IZTA).

Distribución: México (Tams., S.L.P., Ver., Nay., Jal., Hgo., Qro., Méx., Mich., Tab., Chis., Oax., Gro.), Centro a Sudamérica y Antillas.

\section{TeCtariaceae}

\section{Ctenitis equestris (Kunze) Ching var. equestris}

Caméfito de hojas fasciculadas, mesófilo, esciófilo; bosque tropical ripario y mesófilo de montaña, entre 1600 y 2100 m s.n.m.; Valle de Bravo, Ocuilan, Tejupilco.

Material de referencia: G. B. Hinton 7361 (MEXU). D. Tejero-Díez 2729, 2931 (IZTA).

Distribución: México (Tams., Nay., Jal., Ver., Méx., Mich., Mor., Chis., Oax., Gro.), Centroamérica.

Tectaria heracleifolia (Willd.) Underw.

Caméfito de hojas fasciculadas en taludes de tierra, termófilo, esciófilo; cultivos de café y plátano y bosque tropical subcaducifolio, entre 1100 y 1800 m s.n.m.; Valle de Bravo, Sto. Tomás de los Plátanos, Ocuilan.

Material de referencia: E. Matuda 27185 (MEXU). D. Tejero-Diez 3057, 3195 (IZTA).

Distribución: Sureste de E.U.A., México (N.L., Tams., S.L.P., Q.R., Yuc., Ver., Nay., Jal., Hgo., Qro., Pue., Méx., Mich., Col., Tab., Mor., Chis, Oax., Gro.), Centroamérica y Antillas. 
THELYPTERIDACEAE

*Macrothelypteris torresiana (Gaudich.) Ching

Hemicriptófito de hojas fasciculadas, humícola, mesófilo, esciófilo; bosque mesófilo de montaña en cañada, 2100 m s.n.m.; Coatepec Harinas.

Material de referencia: D. Tejero-Díez 4103 y A. Rojas (IZTA).

Distribución: Sureste de E.U.A., México (Ver., Qro., Méx., Mor., Chis., Oax.), Centro y Sudamérica, Antillas, Viejo Mundo.

Thelypteris albicaulis (Fée) A. R. Sm.

Geófito rizomatoso de hojas aproximadas, ripícola en taludes y canales de riego; cafetales, bosque semicálido ripario y bosque mesófilo de montaña, entre 1750 y 2200 m s.n.m.; Valle de México, Ixtapan del Oro, Ocuilan, Tenancingo.

Material de referencia: A. González y D. Tejero-Díez 46 (IZTA). E. Lyonnet 2865 (MEXU, IZTA). J. G. Schaffner 245 (P holotipo; fide Mickel 1992). D. Tejero-Díez 2595, 2748, 2889, $3166 b$ (IZTA). M. Valenzuela 82 y D. TejeroDiez (IZTA).

Distribución: México (Ver., Jal., Pue., Méx., Mich., Chis., Oax., Gro.).

\section{T. cheilanthoides (Kunze) Proctor var. cheilanthoides}

Caméfito y hemicriptófito de hojas fasciculadas, ripícola; bosque mesófilo de montaña y de Pinus, entre 2000 y 2400 m s.n.m.; Malinalco, Sultepec, Zacualpan.

Material de referencia: Moreno 54 (MEXU). J. Rzedowski 30904 (ENCB, MEXU). D. Tejero-Diez 2096, 2954 (IZTA).

Distribución: México (Ver., Jal., Pue., Méx., Mich., Chis., Oax., Gro.), Centro a Sudamérica, Antillas.

T. mortonii A. R. Sm.

Hemicriptófito rizomatoso (rastrero o erecto) de hojas aproximadas, en suelos de aluvión cerca de ríos, mesófilo, esciófilo; bosque mixto de Quercus-Juniperus con leguminosas y de Abies-Pinus, entre 1500 y 2800 m s.n.m.; Lagunas Zempoala (entre los municipios de Huitzilac, Mor. y Ocuilan, Méx.), Villa Allende, Zacualpan.

Material de referencia: E. Lyonnet y Chávez 3390 (US), Sánchez 38 (US tipo), 65 (US), fide Smith (1973). D. Tejero-Díez 2096 (IZTA).

Distribución: México (Méx., Mor.). 
T. pilosa (M. Martens et Galeotti) Crawford var. pilosa (=Dryopteris pilosa (M. Martens et Galeotti) C. Chr.)

Hemicriptófito a geófito largamente rizomatoso de hojas distantes, rupícola o terrestre, mesófilo, esciófilo; bosque de Quercus, mesófilo de montaña y de Quercus-Pinus, entre 2050 y 2700 m s.n.m.; Villa del Carbón, Villa Nicolás Romero, Jilotzingo, Texcoco, Lerma, Tlalmanalco, Amecameca, Ocuilan, Villa Guerrero, Coatepec Harinas, Zacualpan.

Material de referencia: M. L. Arreguín 520, 602 (ENCB). R. Fernández 511 (ENCB). I. López 1105 (ENCB). E. Lyonnet 240 (ENCB), 1415 (MEXU). E. Matuda 26869 (CODAGEM, MEXU), 30335 (MEXU). J. T. Mickel 703 (CODAGEM, ENCB, NY). R. Pacheco y C. Navarro 114 (ENCB). J. Rzedowski 26710, 32224 (ENCB). D. Tejero-Díez 2153, 2218, 2271, 2373 (IZTA). M. E. Vargas s. n. 16/oct./1975 (ENCB).

Distribución: E.U.A., México (Son., Chih., Ver., Nay., Jal., Hgo., Qro., Gto., Pue., Méx., Mich., D.F., Mor., Chis., Oax., Gro.), Centroamérica.

*T. pilosula (Klotzsch et H. Karst. ex Mett.) R. M. Tryon

Caméfito de hojas fasciculadas, ripícola, mesófilo, esciófilo; bosque mesófilo de montaña y de Pinus-Quercus, entre 2300 y 2600 m s.n.m.; Villa de Allende, Ocuilan, Tenancingo, Sultepec.

Material de referencia: B. Argueta 12 y D. Tejero-Díez (IZTA). M. Gaytán 84 (IZTA). A. González 45 y D. Tejero-Díez (IZTA). E. Luján 11 y D. TejeroDiez (IZTA). D. Tejero-Díez 2375, 2950 (IZTA).

Distribución: México (Ver., Jal., Qro., Gto., Pue., Méx., Mich., Chis., Oax., Gro.), Centro a Sudamérica, Antillas.

+T. puberula (Baker) C. V. Morton var. puberula (=Dryopteris feei C. Chr.)

Geófito a hemicriptófito rizomatoso de hojas distantes, ripícola en tierra o rocas, fotófilo; cultivos de frutales tropicales, bosque tropical caducifolio, tropical subcaducifolio, ripario tropical, mixto de Quercus-Juniperus con leguminosas, mesófilo de montaña, templado ripario, de Quercus, de Quercus-Pinus y de PinusAbies, entre 1100 y 3250 m s.n.m.; Villa del Carbón, Temascaltepec, Valle de Bravo, Sto. Tomás de los Plátanos, Amecameca, Zacazonapan, Ocuilan, Villa Guerrero, Malinalco, Tenancingo, Tejupilco, Sultepec, Tonatico.

Material de referencia: R. Aguilar s. n. abr./1979 (ENCB). J. Alonso s. $n$. 9/feb./1985 (IZTA). E. Ayala 11 (IZTA). García Rivera 37 (ENCB). G. Gómez 100 (ENCB). A. González 20 y D. Tejero-Díez (IZTA). G. B. Hinton 3766 (MEXU). E. Luján 5 y D. Tejero-Díez (IZTA). E. Matuda 27540 (CODAGEM, 
MEXU). S. Pérez 44 y D. Tejero-Diez (IZTA). D. Tejero-Diez 2162, 2183, 2570, 2670, 2725, 2753, 2755, 2822, 2831, 2845, 3166a, 3184 (IZTA).

Distribución: México (Tams., Sin., Ver., Nay., Jal., Qro., Gto., Pue., Méx., Mich., Mor., Chis., Oax., Gro.), Centroamérica.

T. resinifera (Desv.) Proctor (=Dryopteris resinifera (Desv.) Weath.)

Caméfito de hojas fasciculadas en suelos húmedos cerca de ríos; bosque mesófilo de montaña, entre 1850 y 2150 m s.n.m.; Tenancingo, Tejupilco.

Material de referencia: Z. Evangelista 18 y D. Tejero-Díez (IZTA). E. Matuda 30044 (MEXU, CODAGEM). C. Plasencia 106 y D. Tejero-Diez (IZTA). D. Tejero-Diez 2444 (IZTA).

Distribución: Sureste de E.U.A., México (Chih., Sin., Ver., Nay., Jal., Pue., Méx., Mich., Tab., Mor., Chis., Oax., Gro.), Centro a Sudamérica, Antillas.

T. rudis (Kunze) Proctor (=Dryopteris rudis (Kunze) C. Chr.)

Hemicriptófito a geófito rizomatoso de hojas aproximadas, ripícola en taludes, mesófilo, esciófilo; bosque de Quercus-Pinus, mesófilo de montaña, de Pinus y de Abies-Pinus, entre 1900 y 2800 m s.n.m.; Valle de Bravo, Ocuilan, Coatepec Harinas, Tenancingo, Sultepec, Zacualpan.

Material de referencia: R. Aranda 13 y D. Tejero-Díez (IZTA). S. Gallegos 10 y D. Tejero-Diez (IZTA). E. Lyonnet 1998 (MEXU). E. Matuda 30640 (CODAGEM, MEXU). J. T. Mickel 708 (ENCB). T. Mojica 10 y D. TejeroDiez (IZTA). J. Rzedowski 30901 (ENCB, MEXU). D. Tejero-Diez 2222, 2686, 3182 (IZTA).

Distribución: México (B.C., Sin., Dgo., Ver., Nay., Jal., Hgo., Pue., Méx., Mich., Mor., Chis., Oax., Gro.), Centro a Sudamérica, Antillas.

Especies probables de encontrar: T. hispidula (Decne.) C. F. Reed, T. ovata R. P. St. John var. lindheimeri (C. Chr.) A. R. Sm. y T. oligocarpa (Humb. et Bonpl. ex Willd.) Ching., que se distribuyen en los estados de la vertiente del Pacífico y la cuenca del río Balsas en alturas de 500 a 1700 m s.n.m.; con vegetación tropical y ambientes perturbados que también existen en el área de estudio.

\section{VitTARIACEAE}

Vittaria graminifolia Kaulf. (=V. filifolia Fée)

Epífito cortamente rizomatoso de hojas muy aproximadas, en troncos y ramas bajas de árboles; bosque de Quercus, mesófilo de montaña y de Pinus-Abies con 
Quercus, entre 1700 y 2650 m s.n.m.; Ocuilan, Coatepec Harinas, Tejupilco, Zacualpan.

Material de referencia: P. Arellano 9 (ENCB). G. B. Hinton 6162 (ENCB, NY). E. Matuda 30568 (MEXU). D. Tejero-Díez 2699, 2985, 2977, 3117 (IZTA).

Distribución: México (Sin., Nay., Qro., Hgo., Jal., Mich., Méx., Ver., Mor., Pue., Gro., Oax., Chis.), Centro a Sudamérica, Antillas.

WoOdsiaceae

Athyrium arcuatum Liebm. (=A. barnebyanum Mickel et Beitel)

Caméfito de hojas fasciculadas, ripícola, mesófilo, fotófilo; bosque de Quercus, de Pinus-Quercus, mesófilo de montaña y de Abies, entre 1900 y 2850 m s.n.m.; Texcoco, Ocoyoacac, San Felipe del Progreso, Villa Victoria, Amanalco, Tlalmanalco, Tenancingo, Ocuilan.

Material de referencia: A. Hernández García 83 (ENCB). S. Lemus 153 (ENCB). E. Lyonnet 244 (ENCB, MEXU). J. T. Mickel 656 (ISC), 657 (NY tipo de A. barnebyanum). A. Rojas s. n. 22/abr./2000 (UAMIZ). J. Rzedowski 24175 (ENCB, LP) 29961, 34238 (ENCB). D. Tejero-Díez 2221, 2302, 2894, 2942 (IZTA).

Distribución: México (Ver., Jal., Gto., Pue., Méx., Mich., Mor., Chis., Oax.), Guatemala.

\section{A. bourgaei E. Fourn.}

Caméfito de hojas fasciculadas, ripícola, mesófilo; bosque de Quercus, de Pinus, mesófilo de montaña, de Abies, vegetación secundaria con Juniperus y pastizal de altura, entre 2400 y 3100 m s.n.m.; Villa Nicolás Romero, Ocuilan, Tenancingo.

Material de referencia: M. L. Arreguín 610 (ENCB). A. Rojas s. n. 22/abr./ 2000 (UAMIZ). J. Rzedowski 30903 (ENCB, MEXU, NY). D. Tejero-Diez 2679 (IZTA). A. Torres 402 (ENCB).

Distribución: México (Chih., Dgo., Ver., Jal., Hgo., Gto., Méx., Mich., Mor., Chis., Oax., Gro.) a El Salvador.

\section{A. palmense (H. Christ) Lellinger}

Hemicriptófito rizomatoso de hojas distantes, termófilo; huertos de frutales tropicales, bosque tropical ripario, entre 1700 y 1800 m s.n.m.; Malinalco, Tenancingo.

Material de referencia: D. Tejero-Díez 2756, 2868 (IZTA).

Distribución: México (Dgo., Nay., Jal., Qro., Méx., Mich., Mor., Oax., Gro.)

a Costa Rica. 


\section{A. skinneri (Baker) C. Chr.}

Hemicriptófito rizomatoso de hojas aproximadas, ripícola, termófilo; bosque tropical caducifolio, a 850 m s.n.m.; Tejupilco, Tlatlaya.

Material de referencia: G. B. Hinton 2649 (MEXU, NY). D. Tejero-Díez 2652, 3197 (IZTA).

Distribución: México (Sin., Jal., Méx., Mich., Col., Chis., Oax., Gro.) a Costa Rica.

\section{+ A. tejeroi Mickel}

Hemicriptófito rizomatoso terrestre a rupícola; bosque de Quercus con elementos mesófilos, a 1650 m s.n.m.; Tejupilco.

Material de referencia: D. Tejero-Díez 2919 (IZTA holotipo, NY isotipo).

Distribución: México (Méx.).

Cystopteris fragilis (L.) Bernh.

Hemicriptófito terrestre a rupestre-fisurícola de hojas fasciculadas, mesófilo; bosque mixto de Quercus-Juniperus con leguminosas, de Quercus, de Pinus, de Quercus-Pinus, mesófilo de montaña, de Abies y pastizal alpino, entre 1700 y 4100 m s.n.m.; Jilotepec, El Oro, Teotihuacan, Villa Nicolás Romero, Atizapán, Jilotzingo, Texcoco, Villa de Allende, Ixtapaluca, Huixquilucan, Ocoyoacac, Tlalmanalco, Amecameca, Tenango del Valle, Ocuilan, Coatepec Harinas, Sultepec, Zacualpan.

Material de referencia: Álvarez Quijada 8 (IZTA). M. L. Arreguín 607 (ENCB). A. Bahena 28 (IZTA). C. Conzatti 2391 (ENCB). R. Cruz 439 (ENCB). J. Díaz 274 (ENCB). G. González 40, 68 (IZTA). E. Lyonnet 1411 (ENCB, MEXU). E. Lyonnet 2875 (IZTA, MEXU). J. T. Mickel 649 (ENCB). C. Navarro $y$ R. Pacheco 115 (ENCB). M. Ortega 4 y L. Abundiz-Bonilla (IZTA). J. Rzedowski 18709, 23488, 26458, 29670 (ENCB). D. Tejero-Díez 2122, 2279, 2372, 2513, 2585 (IZTA). L. Valencia 7 (IZTA).

Distribución: Norteamérica (Groenlandia a E.U.A.), México (B.C., Chih., Coah., N.L., Sin., Dgo., Zac., S.L.P., Ver., Nay., Jal., Hgo., Qro., Gto., Pue., Méx., Mich., D.F., Mor., Chis., Oax., Gro.), Centro a Sudamérica (hasta Chile), Antillas, Europa, Asia, África.

\section{+C. millefolia Mickel et Tejero}

Hemicriptófito rizomatoso con hojas aproximadas, ripícola, mesófilo; bosque de Pinus-Abies y de Abies, entre 2500 y 3300 m s.n.m.; Villa Victoria, Ocuilan.

Material de referencia: López Guerrero 15 (IZTA). D. Tejero-Diez 2234 (IZTA holotipo, IEB, NY, UAMIZ isotipos), 2937, 2959, 4111 (IZTA). 
Distribución: México (Méx., Mor., Mich.).

*Diplazium drepanolobium A. R. Sm.

Hemicriptófito a caméfito de hojas fasciculadas, ripícola, mesófilo; bosque de Pinus, entre 1900 y 2400 m s.n.m.; Zacualpan.

Material de referencia: D. Tejero-Díez 1986 (IZTA).

Distribución: México (Méx., Tab., Chis., Oax.), Guatemala.

\section{D. franconis Liebm.}

Caméfito de hojas fasciculadas, ripícola, mesófilo; bosque mesófilo de montaña en cañadas, a 2000 m s.n.m.; Ocuilan.

Material de referencia: D. Tejero-Díez 3168 (IZTA).

Distribución: México (S.L.P., Ver., Hgo., Qro., Méx., Mich., Chis., Oax., Gro.), Centroamérica.

\section{D. lonchophyllum Kunze}

Hemicriptófito a caméfito de hojas fasciculadas, ripícola, mesófilo; bosque de Pinus, de Quercus y mesófilo de montaña, entre 1750 y 2100 m s.n.m.; Tenancingo, Villa Guerrero, Valle de Bravo, Zacualpan, Tejupilco.

Material de referencia: Díaz Moreno 214 (ENCB, NY). Rangel Ríos 4 (IZTA). D. Tejero-Diez 2159, 2285, 2456 (IZTA).

Distribución: México (N.L., S.L.P., Ver., Nay., Jal., Hgo, Qro., Méx., Mich., Mor., Chis., Oax., Gro.), Centroamérica.

Onocleopsis hintonii F. Ballard

Caméfito, esciófilo, ripícola y palúdico; bosque mesófilo de montaña, entre 1900 y 2550 m s.n.m.; Temascaltepec, Valle de Bravo, Ocuilan, Tejupilco.

Material de referencia: G. B. Hinton 3297 (K tipo), 7228 (K, US). C. G. Pringle s. n. (US) fide Lloyd (1971). D. Tejero-Díez 2742, 3165 (IZTA).

Distribución: México (Jal., Méx., Mor., Chis., Oax., Gro.), Guatemala.

Woodsia canescens (Kunze) Mett.

Hemicriptófito de hojas fasciculadas, rupestre-fisurícola; bosque de Quercus, a 2650 m s.n.m.; Jilotepec.

Material de referencia: E. Lott y T. Wendt P-95 (MEXU).

Distribución: México (S.L.P., Hgo., Pue., Méx., D.F., Oax.). 
W. mexicana R. Br.

Hemicriptófito rupestre-fisurícola de hojas fasciculadas; bosque de AbiesQuercus abierto, 2800 m s.n.m.; El Oro.

Material de referencia: C. G. Pringle 5273 (MEXU).

Distribución: Oeste de E.U.A., México (Son., Chih., Coah., Dgo. Zac., S.L.P., Ver., Jal., Méx., D.F.).

W. mollis (Kaulf.) J. Sm.

Hemicriptófito rupestre-fisurícola o sobre tierra, de hojas fasciculadas péndulas, mesófilo; matorral xerófilo y pastizal secundario, en bosque tropical caducifolio y tropical subcaducifolio, de Quercus-Pinus, mixto de Juniperus-Quercus y leguminosas, mesófilo de montaña y de Pinus, entre 1400 y 2800 m s.n.m.; Polotitlán, Jilotepec, Huehuetoca, Tepotzotlán, Villa del Carbón, Coacalco, Villa Nicolás Romero, Atizapán, Ixtapaluca, Huixquilucan, Amanalco, Ixtapan del Oro, Tlalmanalco, Amecameca, Ozumba, Ocuilan, Coatepec Harinas, Tejupilco, Almoloya de Alquisiras, Sultepec.

Material de referencia: V. Benhumea 208 (ENCB). H. Ern 138 (ENCB). I. García 134 (ENCB). J. E. López Vidal 83 (ENCB). E. Matuda 20178, 25586, (MEXU), 26508, 26753 (CODAGEM). J. Medina 54 (IZTA). E. Mendoza 101 (ENCB). J. T. Mickel 675 (CODAGEM). C. G. Pringle 1274, 3387 (MEXU). S. Romero y C. Rojas 1734 (IZTA). J. Rzedowski 18704, 18722, 30773 (ENCB). D. Tejero-Diez 2080, 2108, 2132, 2418, 2581, 2778 (IZTA).

Distribución: México (B.C., Chih., N.L., Sin., Zac., S.L.P., Ver., Nay., Jal., Hgo., Qro., Gto., Pue., Méx., Mich., Tlax., D.F., Mor., Chis., Oax., Gro.), Centroamérica.

*W. phillipsii Windham

Hemicriptófito rupestre-fisurícola de hojas fasciculadas; bosque de Quercus abierto, entre 2300 y 2650 m s.n.m.; Acambay, Teotihuacan.

Material de referencia: D. Tejero-Diez 2484, s. n. 20/jul./1991 (IZTA).

Distribución: Sur de E.U.A., México (Son., Chih., Méx.).

Especies excluidas

El siguiente conjunto de especies, consideradas en el área de estudio por diferentes autores, han sido relegadas, dado que sus citas son producto de determinaciones erróneas, o bien porque no se han visto ejemplares en los herbarios revisados: Asplenium cristatum Lamarck, Asplenium lamprocaulon Fée, Campyloneurum angustifolium (Sw.) Fée; Dryopteris futura A. R. Sm.; Llavea cordifolia Lag., Lophosoria quadripinnata (J. F. Gmel.) C. Chr. (la cual se 
encontró cultivada en El Salto, mpio. Donato Guerra), Melpomene leptostoma (Fée) A. R. Sm. et R. C. Moran, Pleopletis crassinervata (Fée) T. Moore, Polypodium puberulum Schltdl. et Cham. (=P. glaberulum Mickel et Beitel).

Especies de procedencia dudosa

Las siguientes especies son conocidas para el área de estudio (D.F. o México) exclusivamente de ejemplares colectados por J. G. Schaffner: Antrophyum ensiforme Hook., 71 (NY); Elaphoglossum potosianum $\mathrm{H}$. Christ $(=E$. trichomidiatum Mickel), 93 (NY); Huperzia dichotoma (Jacq.) Trevis., 3 (NY); H. pithyoides (Schldtl. et Cham.) Holub, 1 (NY); Selaginella martensii Spring, 6 (NY); Thelypteris palustris Schott var. pubescens (G. Lawson) Fernald, s. $n$. (MEXU). Sin embargo, existe la sospecha, debido a las preferencias climáticas conocidas de estas plantas, de que el lugar de colecta podría ubicarse en Veracruz (véase Rzedowski, 1959).

\section{DISCUSIÓN Y CONCLUSIONES}

En total se reconocieron 248 taxa (especies, taxa subespecíficos e híbridos); 251 si se consideran 3 especies presentes en el Distrito Federal que no fueron halladas en el estado de México. Otras 13 se colectaron en las inmediaciones al área de estudio, por lo que se esperaría que exploraciones futuras las pudiesen documentar. De estos taxa, dos especies se consideran nuevas para la ciencia (Mickel y Tejero-Díez, 2004) y al menos otras 60 no se habían mencionado anteriormente para la región en la literatura pertinente. Con tales cifras, el área de estudio se perfila a ser uno de los 10 estados con mayor riqueza de pteridófitos de México.

El conjunto estudiado está agrupado en 64 géneros. Los que están representados por 10 o más especies son: Cheilanthes (23 ó 9.3\%), Elaphoglossum (19 ó 7.7\%), Asplenium (17 ó 6.8\%), Polypodium (16 ó 6.4\%), Selaginella (15 ó $6.0 \%$ ) y Adiantum (10 ó $4.0 \%$ ), que suman $40 \%$ del total. Por otra parte, $67.1 \%$ de los géneros está representado por una a tres especies, $18.6 \%$ por cuatro a seis especies y $6.2 \%$ por siete a nueve especies. Comparativamente con otras pteridofloras (Knobloch y Correll, 1962; Lorea-Hernández y Velázquez-Montes, 1998; Mickel y Beitel, 1988; Mickel, 1992; Palacios-Rios, 1992 y Smith, 1981), tanto

el número de géneros con más de diez especies como la cantidad de especies en cada género es reducido (excepto el encontrado en Chihuahua que es menor). Tal hecho puede ser función del carácter marcadamente estacional y poco diverso del clima en el estado de México, que se pone de manifiesto por el papel primario de 
Cheilanthes. Sin embargo, llama la atención la posición en segundo lugar de Elaphoglossum con respecto al que ocupa en otros estados; lo anterior posiblemente se debe a la preferencia de las especies de este género por los climas más frescos y húmedos, mismos que prevalecen en el estado de México en la vertiente $\mathrm{S}$ y SW de las altas montañas. La predominancia del clima templado en un ambiente montañoso está indicada por la posición relativa que guardan entre sí los otros géneros con 10 o más especies, la cual es más o menos semejante a la que se registra en otros estados, en cuyo territorio existen montañas relativamente altas (al menos entre 2000 y 3000 m) pertenecientes al Eje Volcánico Transversal o en la vertiente del Océano Pacífico (cf. con Guanajuato y Michoacán en Díaz-Barriga y Palacios-Rios, 1992). Evidentemente falta en el área de estudio la representación de géneros de afinidad cálido húmeda que se distribuyen a altitudes más bajas, tal es el caso de: Acrostichum, Adiantopsis, Antrophyum, Cyathea, Danaea, Lastreopsis, Marattia, Microgramma, Odontosoria, etc.

Por las características físicas ya indicadas, dentro del territorio estudiado predominan los pteridófitos con forma de vida hemicriptófito (57\%) sobre las especies epífitas $(10.7 \%)$ y otras formas como el caméfito caudiciforme y fanerófito estipitiforme, que en los helechos y plantas afines se favorecen con el aumento de la humedad (Page, 1979). Tal proporción contrasta con la de estados como Veracruz, donde la estación seca es menos marcada y los pteridófitos epífitos constituyen 19.5\% (Palacios-Rios., com. pers.) (hasta 50\% en la sierra Sta. Marta, según Lira y Riba (1984)) del total de las especies, y las familias de plantas estipitiformes y caudiciformes como Cyatheaceae y algunas especies de Blechnum y Diplazium están bien representadas.

Los municipios del estado de México con mayor riqueza de especies, son aquellos que en su territorio tienen sierras o montañas con cotas altitudinales entre 2100 y 2700 m s.n.m.; influenciadas por los eventos de humedad provenientes del Océano Pacífico (Jáuregui Oslo y Vidal Bello, 1981). Estas condiciones favorecen la presencia del bosque mesófilo de montaña y del bosque de Quercus o coníferas con elementos higrófilos (en cañadas y ríos), tales como: Tlalmanalco, Amecameca, Ocuilan, Coatepec Harinas, Temascaltepec-Valle de Bravo, Sultepec-Zacualpan y Tejupilco.

La pteridoflora del estado de México comparte $27 \%$ de las especies con Chihuahua $(30.8 \%$ si consideramos además las que están presentes en el sur o sureste de E.U.A.), 66\% con Veracruz, 69.7\% con Jalisco, 67\% con Chiapas, 83\% con Oaxaca, $75 \%$ con Guerrero y $50.7 \%$ con Costa Rica. Los datos anteriores muestran el carácter eminentemente neotropical de la pteridoflora del estado de México. Además, se manifiesta una relación estrecha con Oaxaca en primer lugar y en segundo término con Guerrero y Jalisco, estados vinculados a la Sierra Madre del Sur y Sierra Madre Occidental. Sin embargo, no es mucha la diferencia con respecto a Veracruz, lo que indica la importancia del Eje Volcánico Transversal, junto 
con la región montañosa del Nudo Mixteco, como puente de paso entre las sierras de ambas vertientes oceánicas para la pteridoflora mexicana. El estado de México no es, a pesar de su ubicación geográfica, un sitio relevante en cuanto al número de elementos endémicos, pues sólo cinco especies (2.0\%) son propias del estado y las regiones adyacentes con similitud biológica.

\section{AGRADECIMIENTOS}

Se agradece a J. T. Mickel la revisión del material de referencia y la disposición para este estudio de la valiosa información de sus apuntes y el herbario NY. El primer autor reconoce la invaluable ayuda en campo de L. Abundiz-Bonilla, R. Moreno, I. Aguirre y M. Castilla. El trabajo de tesis de maestría del primer autor, llevado a cabo entre 1984 y 1988, del cual se desprende este estudio, fue evaluado en su fase final por M. L. Arreguín y Fernando Chiang; el jurado correspondiente fue constituido por Rafael Lira, Mónica Palacios Rios y Ernesto Velázquez (quien incluso aportó ejemplares y datos). Se agradece la buena disposición de los encargados de herbarios mexicanos mencionados durante el tiempo en que se consultaron. Los siguientes investigadores revisaron las identificaciones del material de herbario de su especialidad A. R. Smith (Thelypteris, Polystichum y Asplenium en parte); Leticia Pacheco (Diplazium), Blanca Pérez García (Marsileaceae y Plagiogyriaceae) y Alexander Rojas (Elaphoglossum); esta última persona cedió observaciones que hizo en los herbarios mexicanos y extranjeros. Un reconocimiento especial se debe al Dr. Ramón Riba (q.p.d.), quien logró inculcar en el primer autor un aprecio por los pteridófitos durante sus clases en la Facultad de Ciencias de la Universidad Nacional Autónoma de México y revisó los licopodios. Finalmente, se agradece profundamente a los editores de la revista Acta Botanica Mexicana, J. Rzedowski y Rosa Ma.Murillo, por su esfuerzo en la revisión del manuscrito.

\section{LITERATURA CITADA}

Abundiz-Bonilla, L. y D. Tejero-Díez. 1990. El género Selaginella Pal.-Beauv. (Selaginellaceae, Lycopodiophyta) en el oeste del estado de México, México. Acta Bot. Mex. 11: 2347.

Aguirre, R. y M. L. Arreguín. 1988. Claves de familias, géneros, especies y variedades de pteridófitas del estado de Nuevo León, México. Anales Esc. Nac. Cienc. Biól. México 29: $29-41$.

Anónimo. 1981a. Síntesis geográfica del Estado de México. Coordinación General de los Servicios Nacionales de Estadística, Geografía e Informática, Secretaría de Programación y Presupuesto. México D.F. 174 pp. 
Anónimo. 1981b. Nomenclátor del Estado de México. Coordinación General de los Servicios Nacionales de Estadística, Geografía e Informática. Secretaría de Programación y Presupuesto. México D.F. 122 pp.

Arreguín-Sánchez, M. L. 1983. Morfología de las esporas de helechos cheilanthoides del Valle de México. Anales Esc. Nac. Cienc. Biól. México 27: 9-28.

Arreguín-Sánchez, M. L. 1985a. Morfología de las esporas de la subfamilia Dryopteridoideae del Valle de México. Anales Esc. Nac. Cienc. Biól. México 32: 9-61.

Arreguín-Sánchez, M. L. 1985b. Morfología de las esporas de la subfamilia Asplenioideae del Valle de México. Estudios Palinológicos y Paleobotánicos, Serie Científica del Instituto Nacional de Antropología e Historia 147: 7-22.

Arreguín-Sánchez, M. L. 1986. Nuevos registros y taxa interesantes de pteridófitas del Valle de México (Isoetaceae, Psilotaceae y Selaginellaceae). Phytologia 59(7): 451-453.

Arreguín-Sánchez, M. L. 1991. Claves para la separación de los taxa de pteridófitas del Valle de México por medio de sus esporas. Palynol. et Palaeobot. 3(1): 5-54.

Brumitt, R. K. y C. E. Powell. 1992. Authors of plant names. Royal Botanical Gardens. Kew. $732 \mathrm{pp}$.

Clausen, R. T. 1938. A monograph of the Ophioglossaceae. Mem. Torrey Bot. Club 19(2): 1-177.

Cruz Palacios, I. L. 1992. Revisión del género Dryopteris Adanson (Dryopterideae, Polypodiaceae) en el occidente del estado de México, México. Tesis licenciatura. Escuela Nacional de Estudios Profesionales Iztacala, Universidad Nacional Autónoma de México. Tlalnepantla, México. 85 pp.

Davis, H. B. 1936. Life and work of Cyrus Guernsey Pringle. University of Vermont. Burlington, Vermont. 756 pp.

Díaz-Barriga, H. y M. Palacios-Rios. 1992. Listado preliminar de especies de pteridófitas de los estados de Guanajuato, Michoacán y Querétaro. In: Rzedowski, J. y G. Calderón (eds.). Flora del Bajío y de Regiones Adyacentes, fascículo complementario III. Instituto de Ecología, A. C. Pátzcuaro, Mich. 57 pp.

Font-Quer, P. 1982. Diccionario de botánica. Ed. Labor, S. A. Barcelona. 1244 pp.

Gallegos, S. 1997. Revisión taxonómica del género Adiantum (Polypodiaceae, Pteridophyta) en el occidente del estado de México, México. Tesis licenciatura. Escuela Nacional de Estudios Profesionales Iztacala, Universidad Nacional Autónoma de México. Tlalnepantla, México. 60 pp.

Haufler, C. H. 1979. A biosystematic revision of Bommeria. J. Arnold Arbor. 60: 445-476.

Hinton, J. y J. Rzedowski. 1975. G. B. Hinton: Explorador botánico en el sudoeste de México. Anales Esc. Nac. Cienc. Biól. México 21(1-4): 3-114.

Holmgren, P. K. y N. H. Holmgren. 2003. Index Herbariorum. International Association for Plant Taxonomy y New York Botanical Garden. Bronx. (http://www.nybg.org/bsci/ih).

Jáuregui Oslo, E. y J. Vidal Bello. 1981. Aspectos de la climatología del estado de México. Bol. Inst. Geografía. Univ. Nac. México 11: 21-54.

Jones, G. N. 1966. An annotated bibliography of Mexican ferns. University of Illinois Press. Urbana y Londres. $297 \mathrm{pp}$.

Knobloch, I. W. y D. S. Correll. 1962. Ferns and fern allies of Chihuahua, Mexico. Texas Research Foundation. Renner, Texas. 198 pp. 
Köppen, W. 1948. Climatología. Fondo de Cultura Económica. México, D.F. 478 pp.

Lira, R. y R. Riba. 1984. Aspectos fitogeográficos y ecológicos de la flora pteridófita de la sierra de Sta. Marta, Veracruz, Méx. Biotica 9(4): 451-467.

Lorea-Hernández, F. y E. Velázquez-Montes. 1998. Pteridófitas; Lista de los taxa y su distribución geográfica en la entidad. In: Diego-Pérez, N. y R. Ma. Fonseca (eds.). Estudios florísticos en Guerrero No. 9. Facultad de Ciencias, Universidad Nacional Autónoma de México. México, D.F. 83 pp.

Lorea, F. y R. Riba. 1990. Guía para la recolección y preparación de ejemplares para herbario de pteridófitas. Consejo Nacional de la Flora de México, A. C. México, D.F. 12 pp.

Lloyd, R. 1971. Systematics of the onocleoid ferns. Univ. Calif. Publ. Bot. 61: 1-86.

Matuda, E. 1956a. Los helechos del Valle de México y alrededores. Anales Inst. Biol. Univ. Nac. Autón. México. 27: 49-168.

Matuda, E. 1956b. Los helechos del estado de México. Dirección de Agricultura y Ganadería, Gobierno del Estado México. Toluca, México. 70 pp.

Mickel, J. T. y J. M. Beitel. 1988. Pteridophyte flora of Oaxaca, Mexico. Mem. New York Bot. Gard. 46: 1-568.

Mickel, J. T. 1992. Pteridophytes. In: McVaugh, R. Flora Novo-Galiciana. (W. R. Anderson, ed.). 17: 120-467.

Mickel, J. T. 2001. A new species in the Elaphoglossum petiolatum complex (Elaphoglossaceae) from Mexico. Brittonia 53(4): 487-489.

Mickel, J. T. y D. Tejero-Díez. 2004. Three new species of ferns (Woodsiaceae and Polypodiaceae) from Mexico. Brittonia 56(2): 115-120.

Miranda, F. 1947. Estudios sobre la vegetación de México: V. Rasgos de la vegetación en la cuenca del Río Balsas. Revista Soc. Mex. Hist. Nat. 8(1-4): 95-114.

Moran, R. C. y R. Riba (eds.). 1995. Psilotaceae a Salviniaceae. In: Davidse G., M. Sousa y S. Knapp (eds. grales.). Flora Mesoamericana I. Universidad Nacional Autónoma de México, Missouri Botanical Garden y The Natural History Museum. México, D.F. $470 \mathrm{pp}$.

Mueller-Dombois, D. y H. Ellenberg. 1974. Aims and methods of vegetation ecology. John Wiley \& Sons. Nueva York. 176 pp.

Page, C. N. 1979. The diversity of ferns. An ecological perspective. In: Dyer, A. F. (ed.). The experimental biology of ferns. Academic Press. Londres. pp. 1-56.

Palacios-Rios, M. 1992. Pteridófitas del estado de Veracruz, México. Tesis de maestría en ciencias. Facultad de Ciencias, Universidad Nacional Autónoma de México. México D.F. 362 pp.

Riba, R. y A. Butanda. 1987. Bibliografía comentada sobre pteridófitas de México. Consejo Nacional de la Flora de México, A. C. México, D.F. 87 pp.

Riba, R., L. Pacheco, A. Valdés y Y. Sandoval. 1996. Pteridoflora del estado de Morelos. Lista de familias, géneros y especies. Acta Bot. Mex. 37: 45-65.

Rzedowski, J. 1959. Las colecciones botánicas de Wilhelm (José Guillermo) Schaffner en San Luis Potosí. Acta Científica Potosina 3(1): 99-121.

Rzedowski, J. 1978. Vegetación de México. Ed. Limusa. México, D.F. 432 pp.

Rzedowski, J. y G. Calderón (eds.). 1979. Flora fanerogámica del Valle de México. Vol. I. Compañía Editorial Continental, S. A. México, D.F. 403 pp. 
Smith, A. R. 1973. The Mexican species of Thelypteris subgenus Amauropelta. Amer. Fern J. 63: 116-127.

Smith, A. R. 1981. Pteridophytes. In: Breedlove, D. E. (ed.). Flora of Chiapas, parte 2. California Academy of Sciences. San Francisco. 370 pp.

Tejero-Díez, D. 1987. Conocimiento actual de la pteridoflora en la mitad oeste del estado de México. In: Memorias del X Congreso Mexicano de Botánica. Soc. Bot. Méx. Trabajo 623. s/pp.

Tejero-Díez, D. 1998. Pteridoflora del occidente del estado de México, México. Tesis de maestría en ciencias. Facultad de Ciencias, Universidad Nacional Autónoma de México. México, D.F. 142 pp. y apéndice.

Tejero-Díez, D., S. Aguilar Rodríguez y S. Flores Maya. 1998. El género Equisetum L. en el occidente del estado de México, México. Acta Bot. Mex. 44: 7-23.

Recibido en mayo de 2001. Aceptado en septiembre de 2004. 